\title{
Atmospheric Test Models and Numerical \\ Experiments for the Simulation of the Global \\ Distributions of Weather Data Transponders \\ III. Horizontal Distributions
}

C.R. Molenkamp, A.S. Grossman

\section{December 20, 1999}

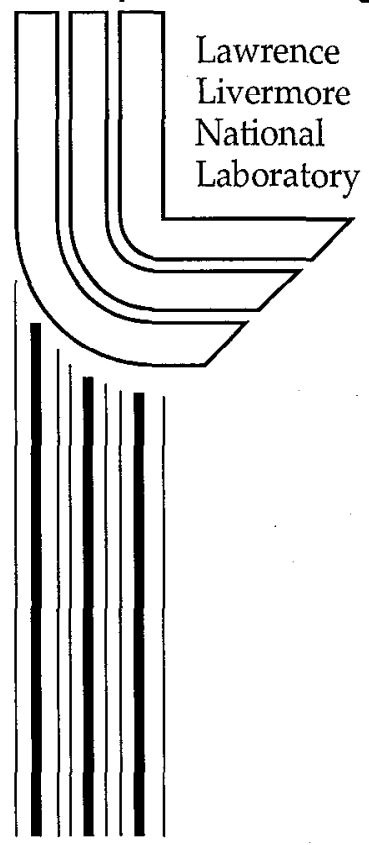




\section{DISCLAIMER}

This document was prepared as an account of work sponsored by an agency of the United States Government. Neither the United States Government nor the University of California nor any of their employees, makes any warranty, express or implied, or assumes any legal liability or responsibility for the accuracy, completeness, or usefulness of any information, apparatus, product, or process disclosed, or represents that its use would not infringe privately owned rights. Reference herein to any specific commercial product, process, or service by trade name, trademark, manufacturer, or otherwise, does not necessarily constitute or imply its endorsement, recommendation, or favoring by the United States Government or the University of California. The views and opinions of authors expressed herein do not necessarily state or reflect those of the United States Government or the University of California, and shall not be used for advertising or product endorsement purposes.

Work performed under the auspices of the U. S. Department of Energy by the University of California Lawrence Livermore National Laboratory under Contract W-7405-Eng-48.

This report has been reproduced

directly from the best available copy.

Available to DOE and DOE contractors from the

Office of Scientific and Technical Information

P.O. Box 62, Oak Ridge, TN 37831

Prices available from (423) 576-8401

http://apollo.osti.gov/bridge/

Available to the public from the

National Technical Information Service

U.S. Department of Commerce

5285 Port Royal Rd.,

Springfield, VA 22161

http://www.ntis.gov/

OR

Lawrence Livermore National Laboratory

Technical Information Department's Digital Library

http://www.llnl.gov/tid/Library.html 
Atmospheric Test Models and Numerical Experiments for the Simulation of the Global Distributions of Weather Data Transponders

III. Horizontal Distributions

Charles R. Molenkamp

and

Allen S. Grossman

Atmospheric Science Division

I awrence Livermore National Laboratory

\begin{abstract}
A network of small balloon-borne transponders which gather very high resolution wind and temperature data for use by modern numerical weather predication models has been proposed to improve the reliability of long-range weather forecasts. The global distribution of an array of such transponders is simulated using LLNL's atmospheric parcel transport model (GRANTOUR) with winds supplied by two different general circulation models. An initial study used winds from CCM3 with a horizontal resolution of about 3 degrees in latitude and longitude, and a second study used winds from NOGAPS with a 0.75 degree horizontal resolution. Results from both simulations show that reasonable global coverage can be attained by releasing balloons from an appropriate set of launch sites.
\end{abstract}





\section{INTRODUCTION}

To improve the accuracy and range of weather forecasts, growth in the size and speed of computers has allowed numerical weather prediction models (NWP) to use increased spatial resolution. Concurrent with this increased resolution is a requirement for closely spaced measurements of atmospheric winds and temperatures. Thesc data are nccessary for model initialization, data assimilation, and validation of forecasts. Teller et al. (1998) proposed a high density global network of balloon-borne atmospheric micro transponders that would measure wind and temperature at a spatial density up to $3 \mathrm{~km}$ horizontally and $0.1 \mathrm{~km}$ vertically, i.e., $\sim 10^{11}$ balloons.

A crucial question pertinent to an array of free-floating balloons is whether a global distribution can be produced and maintained. This report addresses that question by describing numerical simulations in which balloons were released and tracked for several weeks. One set of simulations starts with a uniform global distribution of balloons and watches it change with time. The other releases balloons daily from a realistic but low density set of launch sites and examines the global distribution after several weeks. As we concluded in an earlier initial investigation (Grossman and Molenkamp, 1999a), reasonable global coverage of transponders can be achieved by launching balloons from a globally distributed set of launch sites.

\section{MODELS AND PROCEDURES}

The goal of this study is simply to determine the feasibility of establishing and maintaining a global array of balloon-borne micro transponders. The procedure is to specify a launch scenario, calculate balloon transport using the LLNL GRANTOUR model with winds from a general circulation model (GCM) and then assess the global coverage of the balloons with time. Since this is a feasibility study, a modest number of balloons $\left(\sim 10^{5}\right)$ are tracked on ten standard pressure levels for 35 or 47 days depending on the GCM data available.

\section{A. Transport Model - GRANTOUR}

The LLNL GRANTOUR model (Walton, et al., 1988) was designed to study the transport, chemical interactions, and removal of atmospheric trace species. Among the trace species it has been used to simulate are tropospheric ozone (Penner et al., 1991, 1994; Atherton et al., 1995, 1996), atmospheric aerosols (Taylor and Penner, 1994; Chuang et al., 1996), and dust (Rau et al., 1994). GRANTOUR is a Lagrangian parcel model in which the atmosphere is treated as a set of constant-mass air parcels advected by wind fields input from a general circulation model. Many tests of the parcel transport component have validated its accuracy and make GRANTOUR an ideal model for simulating the movement of micro transponders in the atmosphere. 


\section{B. General Circulation Models}

The Atmospheric Science Division at LLNL is currently using the National Center for Atmospheric Research (NCAR) Community Climate Model (CCM3) (Kiehl et al., 1996) for application studies of climate change. We used CCM3 with T42/L18 resolution (64/128 latitude/longitude grid points, i.e. $\sim 2.8^{\circ}$, and 18 vertical levels) to calculate global flow fields for 35 days from September 1 through October 5, 1990. The three dimensional winds and surface pressures, the necessary meteorological input for GRANTOUR balloon trajectory calculations, were saved at 4-hour intervals on the CCM3 grid. Grossman and Molenkamp (1999a) presented preliminary results using this meteorological data, but those simulations ignored vertical motion and did not include the loss of the balloons by surface collisions. The new results presented here include those effects.

A second set of meteorological data was provided by the Naval Research Laboratory's (NRL) NOGAPS (Navy Operational Global Atmospheric Prediction System) model (Hogan and Rosmond, 1991). NOGAPS is a numerical weather prediction model (NWP), while CCM3 is a climate model. NRL provided data from their archive, the resolution is T159/LA2 (240/480 latitude/longitude grid points, i.e. $0.75^{\circ}$, and 24 vertical levels) and the time consisted of 47 days from August 15 through September 30, 1998 at 6-hour intervals.

The two sets of meteorological data cover different years so one cannot expect a direct correspondence between the balloon distributions. However, the data are for the same time of year (September) so seasonal differences should be small. Questions regarding seasonal variation should be addressed by simulation of a full annual cycle.

\section{Vertical Levels}

The global meteorological winds are read into GRANTOUR on the GCM's horizontal grid and hybrid vertical layers. GRANTOUR uses the same horizontal grid as the GCM, but it uses constant $\sigma=\mathrm{P} / \mathrm{P}_{\text {sfc }}$ levels in the vertical. Therefore, GRANTOUR must interpolate the winds from the global models' hybrid vertical layers to its constant $\sigma$ levels. The $\sigma$ 's used by GRANTOUR are selected to correspond to the global models' hybrid levels at standard sea level pressure $(1013.25 \mathrm{mb})$. Since terrain height is near sea level over most of the globe, the hybrid and $\sigma$ levels are usually very close to each other.

In these simulations balloons are assumed to move along constant pressure surfaces except for a small displacement caused by the drag of vertical air motion. This is a simplifying assumption, because, without vertical drag, a balloon would move at a height determined by its density rather than its pressure. However, if the balloon's temperature remains equal to the surrounding atmosphere's temperature, the balloon would still move along a constant pressure surface since the density and pressure would change together. We used ten floating-level pressures in these simulations, $925,850,775,700,600,500,400,300,200$, and $100 \mathrm{mb}$; each balloon is assigned one of these. 


\section{Vertical Motion}

GRANTOUR provides a fully three-dimensional trajectory for its constant mass atmospheric parcels. Horizontal motion of micro transponders is the same as GRANTOUR's parcels, but the balloons do not move up and down with the vertical air velocity. In a companion report (Grossman and Molenkamp, 1999b) we consider the vertical motion of constant density atmospheric balloons and conclude that small micro transponder balloons would be tightly coupled to the reference density or pressure level with a displacement of less than $100 \mathrm{~m}$ for nonconvective vertical velocities. equation,

In this study we assumed balloon vertical motion is given by a simple restoring velocity

$$
\frac{d \sigma}{d t}=-k\left(\sigma-\sigma_{e}\right)
$$

where $\sigma$ is the vertical coordinate, $k$ is a relaxation time coefficient, and $\sigma_{e}$, is the equilibrium vertical coordinate of the balloon. This equations simply forces the balloon to move to its equilibrium vertical coordinate exponentially with time. We further assume that

$$
\sigma_{e}=\sigma_{0}+\frac{\dot{\sigma}}{k}
$$

where $\sigma_{0}$ is the specified floating-level pressure in $\sigma$ coordinates and $\dot{\sigma}$ is the vertical air velocity. With an assumed value of $1 \mathrm{~h}^{-1}$ for $k$, balloons are occasionally found as far as $30 \mathrm{mb}$ from their floating-level pressures. This is larger than the $100 \mathrm{~m}(10-20 \mathrm{mb})$ displacement indicated by the more complete analysis of vertical motion in Grossman and Molenkamp (1999b). In later plots of balloon locations, those more than $30 \mathrm{mb}$ above their floating-level pressure are marked with a small plus symbol instead of a dot.

\section{E. Terrain Effects}

In our earlier report (Grossman and Molenkamp, 1999a) we ignored collisions of balloons with terrain. In this study we assume that a balloon hits terrain and is disabled when its calculated pressure is larger than the surface (terrain) pressure. Because terrain height is averaged over the area of each grid cell, terrain pressure depends very significantly on the resolution of the GCM. Since high mountains generally occupy small areas, mountains are taller (terrain pressures are smaller) for the higher resolution (smaller grid area) NOGAPS case than for CCM3. This can be clearly seen by comparing topography for the two models at the same pressure level in the later plots of balloon locations. Even the NOGAPS simulation has a tendency to underestimate the loss of balloons via terrain collisions because the roughness of topography permits many mountains to extend above the resolved terrain and it takes only one impact to destroy a balloon. 


\section{F. Uniform Initial Distribution}

The first scenario we considered was the deterioration of an initially uniform global distribution of balloons with time. At the beginning of the simulation 8192 balloons were placed at each of the ten floating-level pressures using the following procedure. First the globe was divided into 80 equal latitude bands. Next a number of balloons, $N_{b}$, equal to the fractional area of each band times 8192 was assigned to that band. Finally, at the central latitude of each band, $\mathrm{N}_{\mathrm{b}}$ balloons were placed at longitude intervals of $360^{\circ} / \mathrm{N}_{\mathrm{b}}$. The initial uniform distribution is shown in Figure 1. All the global plots in this report are equal area projections in which equal map areas represent equal global surface areas. This allows direct comparison of balloons densities at different locations on the map; however the shapes of continents and other map features are distorted.

\section{G. Daily Release Scenario}

The other scenario we examined was designed to simulate an operational global release of micro-transponder balloons, but for only a modest number of sites. Another constraint was to put a number of sites in each $10^{\circ}$ latitude band proportional to its fractional area. Realizing that most of the globe is ocean, coastal areas were preferred for continental sites. Islands were used to disperse sites over the oceans and to provide global coverage. Still, significant occanic arcas have no islands and polar regions have no inhabitants, so we included seven aircraft routes to expand the global coverage of launch sites. From each launch site one balloon for each of the floatinglevel pressures was released at the beginning of each day during the simulation. Table 1 lists the

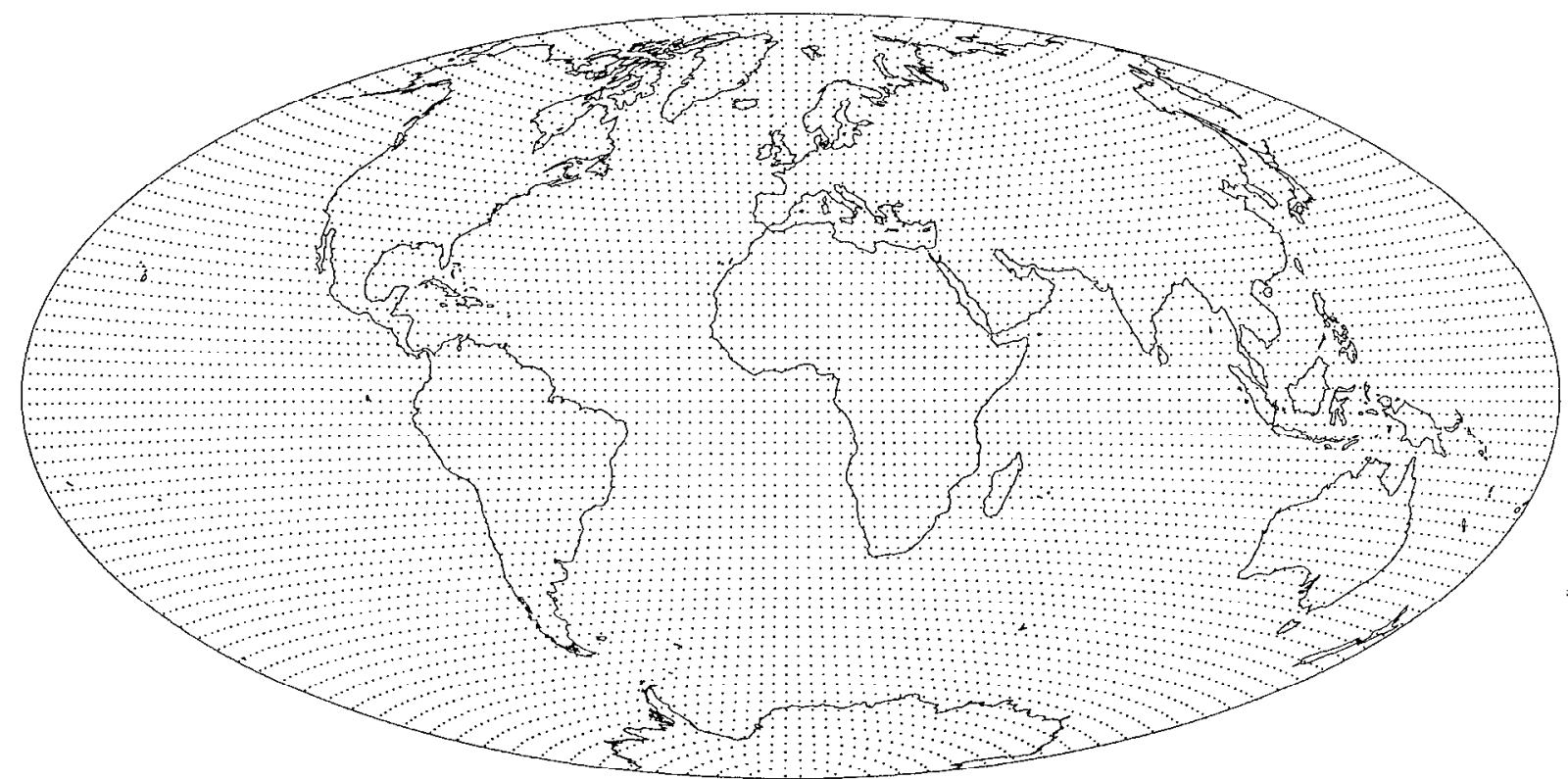

Figure 1. Initial balloon locations for the uniform global distribution. The base map is an equal area projection, i.e., equal map areas represent equal global surface areas; however continental shapes are distorted. 
Table 1. Location of Launch Sites

\begin{tabular}{rrll} 
Lat & Lon & Name \\
80 & 20 & Svalbard Islands \\
76 & -69 & Thule, Greenland \\
74 & -82 & Dundas Harbor, Canada \\
74 & 111 & Nordvik, Siberia \\
73 & -55 & Upernavk, Greenland \\
73 & 55 & Novaya Zemlya, Siberia \\
71 & -157 & Barrow, Alaska \\
71 & -119 & Fort Collinson, Canada \\
70 & -21 & Scorbysand, Greenland \\
69 & 20 & Tromso, Norway \\
69 & 162 & Ambarchik, Siberia \\
68 & 72 & Novyy Port, Siberia \\
66 & -118 & Great Bear Lake, Canada \\
64 & -166 & Nome, Alaska \\
64 & -51 & Godthaab, Greenland \\
64 & -21 & Reykjavik, Iceland \\
63 & -68 & Frobisher Bay, Canada \\
62 & 100 & Tura, Russia \\
61 & -135 & Whitehorse, Canada \\
60 & 5 & Bergen, Norway \\
60 & 150 & Magadan, Russia \\
60 & 169 & Kavacha, Russia \\
59 & -63 & Ramah, Labrador \\
59 & 30 & St. Petersberg, Russia \\
58 & -94 & Churchill, Canada \\
58 & -3 & Aberdeen, Scotland \\
57 & -153 & Kodiak, Alaska \\
55 & 61 & Chelaybinsk, Russia \\
54 & -113 & Edmonton, Canada \\
54 & 124 & Skovordino, Russia \\
53 & -167 & Unalaska, Alaska \\
53 & -61 & Goose Bay, Labrador \\
53 & 22 & Warsaw, Poland \\
53 & 158 & Petropavlosk, Kamchatka \\
50 & -97 & Winnipeg, Manitoba \\
50 & -6 & Land's End, UK \\
50 & 80 & Semipalatinsk, Russia \\
49 & -150 & Airplane8-4 \\
\hline 63 & Saint John's, Newfoundland \\
\hline 6 & & Munich, Germany \\
\hline 6
\end{tabular}

\begin{tabular}{rrl} 
Lat & Lon & Name \\
47 & 106 & Ulan Bator, Mongolia \\
47 & 143 & Sakhalin, Russia \\
46 & -123 & Portland, Oregon \\
46 & 30 & Odessa, Ukraine \\
45 & 126 & Harbein, Mongolia \\
43 & -8 & LaCaruna, Spain \\
43 & 6 & Marseille, France \\
43 & 46 & Groznyy, Georgia \\
43 & 76 & Alma-ata \\
43 & 141 & Sapporo, Japan \\
42 & -88 & Chicago, Illinois \\
42 & -71 & Boston, Mass. \\
41 & -152 & Airplane8-3 \\
40 & 100 & Tingshin, China \\
40 & 117 & Peking, China \\
39 & -28 & Azores \\
39 & 88 & Charhlik, China \\
38 & 24 & Athens, Greece \\
38 & 58 & Ashkabad, Turkmenistan \\
37 & -121 & Livermore, California \\
37 & -76 & Norfolk, Virginia \\
37 & 3 & Algiers, Algeria \\
37 & 127 & Seoul, Korea \\
36 & -6 & Gibralter, Spain \\
36 & 140 & Tokyo, Japan \\
35 & -90 & Memphis, Tennessee \\
35 & 33 & Cyprus \\
34 & 69 & Kabul, Afghanistan \\
33 & -153 & Airplanc8-2 \\
33 & -118 & San Diego, California \\
33 & 13 & Tripoli, Libya \\
33 & 44 & Baghdad, Iraq \\
32 & -65 & Bermuda \\
31 & 121 & Shanghai, China \\
30 & 31 & Cairo, Egypt \\
30 & 108 & Chunking, China \\
29 & -119 & Guadalupe Island \\
29 & -15 & Canary Islands \\
28 & -177 & Midway Island \\
& & Laredo, Texas \\
\hline 4
\end{tabular}


Table 1. (Cont.)

\begin{tabular}{rrl} 
Lat & Lon & Name \\
28 & 77 & Delhi, India \\
27 & -155 & Airplane8-1 \\
26 & -80 & Miami, Florida \\
26 & 128 & Okinawa \\
25 & 22 & Buzaymah, Libya \\
25 & 47 & Riyadh, Saudia Arabia \\
25 & 57 & Trucial Coast \\
24 & 10 & Djanet, Algeria \\
24 & 67 & Karachi, Pakistan \\
23 & -110 & Cabo San Lucas, Mexico \\
23 & -65 & Bahama \\
23 & 80 & Jabalpur, India \\
22 & -159 & Lihue, Hawaii \\
22 & 32 & Wadi Halfa, Sudan \\
22 & 97 & Mandalay, Burma \\
21 & -87 & Cancun, Mexico \\
21 & -17 & Port Etienne \\
21 & 106 & Hanoi, Vietnam \\
20 & 59 & Oman \\
20 & 145 & Asuncion Island \\
19 & -156 & South Point, Hawaii \\
19 & -111 & Revilla Gigedo Island \\
19 & -99 & Mexico City, Mexico \\
19 & 73 & Bombay, India \\
19 & 167 & Wake Island \\
18 & -65 & Saint Thomas, Virgin Island \\
17 & -170 & Johnson Island \\
17 & -25 & Cape Verde Island \\
17 & -3 & Timbuktu, Mali \\
15 & -143 & Airplane1-1 \\
15 & -17 & Dakar, Senegal \\
15 & 64 & Airplane9-5 \\
15 & 121 & Manila, Phillipines \\
14 & 33 & Khartoum, Sudan \\
14 & 145 & Guam \\
13 & -60 & Barbados \\
13 & 80 & Madras, India \\
12 & -107 & Clipperton Island \\
12 & -87 & Managua, Nicaragua \\
12 & 15 & Fort Lamy, Chad \\
\hline & &
\end{tabular}

$\begin{array}{rrl}\text { Lat } & \text { Lon } & \text { Name } \\ 12 & 53 & \text { Socotra Island } \\ 12 & 72 & \text { Lacoadive Island, India } \\ 12 & 93 & \text { Andamar Islands, India } \\ 11 & 106 & \text { Saigon, Vietnam } \\ 10 & -67 & \text { Caracas, Venezuela } \\ 10 & 170 & \text { Marshall Islands } \\ 9 & -130 & \text { Airplane1-2 } \\ 9 & -79 & \text { Panama City } \\ 8 & 134 & \text { Palau Island } \\ 7 & -162 & \text { Palmyra Islands } \\ 7 & -58 & \text { Georgetown, British Guiana } \\ 7 & 49 & \text { Garod, Somalia } \\ 7 & 80 & \text { Colombo, Ceylon } \\ 7 & 152 & \text { Truk Island } \\ 6 & -11 & \text { Monrovia, Liberia } \\ 6 & -5 & \text { Abidjan, Ivory Coast } \\ 5 & -74 & \text { Bogota, Columbia } \\ 5 & -52 & \text { Cayenne, French Guiana } \\ 5 & 18 & \text { Bangui, Central African Rep. } \\ 5 & 32 & \text { Mongalla, Sudan } \\ 5 & 95 & \text { Kutaradju, Sumatra } \\ 5 & 115 & \text { Brunei } \\ 4 & -124 & \text { Airplanel-3 } \\ 2 & -156 & \text { Christmas Island } \\ 2 & 46 & \text { Mogadiscio, Madagascar } \\ 2 & 73 & \text { Maldive Island } \\ 1 & -70 & \text { Mitu, Columbia } \\ 1 & 9 & \text { Libreville, Zaire } \\ 1 & 104 & \text { Diego-Suarez, Malagasy Rep. } \\ 0 & -174 & \text { Baker Island } \\ 0 & -78 & \text { Quito, Ecuador } \\ 0 & 170 & \text { Gilbert Islands } \\ -1 & -91 & \text { Galapagos Islands } \\ -1 & 80 & \text { Airplane9-4 } \\ -2 & -117 & \text { Airplane1-4 } \\ -2 & -50 & \text { Belem, Brazil } \\ -2 & 30 & \text { Rwanda } \\ -2 & 138 & \text { Mataboor, West Irian } \\ -4 & -33 & \text { Fernando de Noronha Island } \\ -4 & 15 & \text { Brazzaville, Congo } \\ & & \\ & & \\ 1 & \end{array}$


Table 1. (Cont.)

\begin{tabular}{|c|c|c|c|c|c|}
\hline Lat & Lon & Name & Lat & Lon & Name \\
\hline-4 & 55 & Seychelles & -20 & -41 & Vitoria, Brazil \\
\hline-4 & 122 & Kendari, Celebes & -20 & 35 & Beira, Mozambique \\
\hline-6 & 72 & Chagas Island & -20 & 58 & Mauritius Island \\
\hline-6 & 107 & Djakarta, Indonesia & -20 & 119 & Port Hedland, Australia \\
\hline-6 & 155 & Bougainville, Solomon Islands & -21 & -175 & Tonga, Island \\
\hline-7 & -173 & Phoenix Island & -21 & 102 & Airplane9-1 \\
\hline-7 & -110 & Airplane 1-5 & -22 & 15 & Walvis Bay, S. Africa \\
\hline-7 & -80 & Chiclago, Peru & -22 & 149 & Mackay, Australia \\
\hline-7 & 39 & Dar es Salaam, Tanganyika & -22 & 166 & Noumea, New Caledonia \\
\hline-8 & -149 & Papeete, Tahiti & -23 & -70 & Antofagasta, Chile \\
\hline-8 & -35 & Recife, Brazil & -23 & -43 & Rio de Janeiro, Brazil \\
\hline-8 & -14 & Ascension Island & -23 & 134 & Alice Springs, Australia. \\
\hline-8 & 86 & Airplane9-3 & -25 & -136 & Pitcairn Island \\
\hline-9 & 13 & Luanda, angola & -25 & -125 & Ducie Island \\
\hline-9 & 25 & Kamina, Congo & -25 & -58 & Asunsion, Paraguay \\
\hline-10 & -140 & Marquesas Island & -25 & 45 & Cape Saint Marie, Malagasy Rep. \\
\hline-10 & 147 & Port Moresby, New Guinea & -25 & 114 & Carnarvon, Australia \\
\hline-10 & 160 & Guadalcanal & -26 & -80 & San Felix Island \\
\hline-11 & -69 & Mogadiscio, Somalia & -26 & -30 & Airplane3-1 \\
\hline-11 & -49 & Porto Nacional, Brazil & -26 & 28 & Pretoria, S. Africa \\
\hline-12 & -103 & Airplane 1-6 & -27 & -110 & Easter Island \\
\hline-12 & -77 & Lima, Peru & -27 & 170 & Norfolk Island \\
\hline-12 & 49 & Diego-Suarez, Malagasy Rep. & -28 & 153 & Brisbane, Australia \\
\hline-12 & 96 & Cocas Island & -29 & 17 & Alexander Bay \\
\hline-12 & 131 & Darwin, Australia & -30 & -177 & Raoul I., Kermadec I. \\
\hline-13 & -38 & Salvador, Brazil & -30 & -51 & Porto Alegre, Brazil \\
\hline-14 & -172 & Apia, Samoa & -30 & 32 & Durban, S. Africa \\
\hline-15 & 12 & Mocamedes, Angola & -31 & -64 & Cordoba, Argentina \\
\hline-15 & 168 & Espiritu Santo, New IIebrides & -31 & -30 & Airplane3-2 \\
\hline-16 & -56 & Cuiaba, Brazil & -31 & 134 & Tarcoola, Australia \\
\hline-16 & -7 & St Helena Island & -32 & 116 & Perth, Australia \\
\hline-16 & 40 & Antonio Enes, Mozambique & -33 & -71 & Santiago, Chile \\
\hline-16 & 127 & Derby, Australia & -34 & -87 & Juan Fernando Island \\
\hline-17 & -140 & Tuamotu Island & -34 & 18 & Capetown, S. Africa \\
\hline-17 & -97 & Airplane 1-7 & -34 & 151 & Sydney, Australia \\
\hline-17 & 96 & Airplane9-2 & -35 & -57 & Montevideo, Uruguay \\
\hline-17 & 146 & Cairns, Australia & -35 & 173 & North Cape, NZ \\
\hline-18 & -70 & Tacna, Peru & -36 & -30 & Airplane3-3 \\
\hline-18 & 26 & Victoria Falls, S. Rhodesia & -37 & -12 & Tristan da Cuhna Island \\
\hline-18 & 178 & Sava, Fiji & -37 & 116 & Airplane2-1 \\
\hline
\end{tabular}


Table 1. (Cont.)

$\begin{array}{rrlrrl}\text { Lat } & \text { Lon } & \text { Name } & \text { Lat } & \text { Lon } & \text { Name } \\ -37 & 175 & \text { Auckland, NZ } & -52 & 168 & \text { Airplane4-D } \\ -38 & -62 & \text { Bahia Blanca, Argentina } & -53 & -71 & \text { Punta Arenas, Chile } \\ -38 & 20 & \text { Airplane4-1 } & -53 & -57 & \text { Palmer Station } \\ -38 & 78 & \text { Amsterdam Island } & -54 & -37 & \text { South Georgia Island } \\ -38 & 145 & \text { Melbourne, Australia } & -55 & 159 & \text { Macquarie Island } \\ -40 & -71 & \text { Valdivia, Chile } & -57 & -110 & \text { Airplane6-9 } \\ -40 & -11 & \text { Gough Island } & -57 & 28 & \text { Airplane4-5 } \\ -41 & -30 & \text { Airplane3-4 } & -57 & 70 & \text { Airplane6-2 } \\ -41 & 175 & \text { Wellington, NZ } & -57 & 119 & \text { Airplane2-5 } \\ -42 & -110 & \text { Airplane6-C } & -58 & -80 & \text { Airplane2-9 } \\ -42 & 116 & \text { Airplane2-2 } & -62 & -110 & \text { Airplane6-8 } \\ -42 & 147 & \text { Hobart, Tasmania } & -62 & -60 & \text { South Shetland Islands } \\ -43 & 22 & \text { Airplane4-2 } & -62 & 33 & \text { Airplane4-6 } \\ -44 & -176 & \text { Chatham Island } & -62 & 70 & \text { Airplane6-3 } \\ -44 & 173 & \text { Christchurch, NZ } & -62 & 160 & \text { Airplane4-C } \\ -46 & -67 & \text { Comodoro Rivadavia, Argentin } & -64 & 120 & \text { Airplane2-6 } \\ -46 & -30 & \text { Airplane3-5 } & -67 & -110 & \text { Airplane6-7 } \\ -47 & -110 & \text { Airplane6-B } & -67 & 39 & \text { Airplane4-7 } \\ -47 & 38 & \text { Prince Edward Island } & -67 & 70 & \text { Airplane6-4 } \\ -47 & 51 & \text { Crozet Island } & -67 & 155 & \text { Airplane4-B } \\ -47 & 117 & \text { Airplane2-3 } & -68 & -80 & \text { Airplane2-8 } \\ -47 & 168 & \text { Half-moon Bay, NZ } & -71 & 145 & \text { Airplane4-A } \\ -48 & 24 & \text { Airplane4-3 } & -72 & -110 & \text { Airplane6-6 } \\ -49 & 69 & \text { Kerguelen Island } & -72 & 50 & \text { Airplane4-8 } \\ -52 & -110 & \text { Airplane6-A } & -77 & -160 & \text { Little America } \\ -52 & -60 & \text { Falkland Island } & -77 & 165 & \text { McMurdo Sound } \\ -52 & 25 & \text { Airplane4-4 } & -78 & 100 & \text { Airplane4-9 } \\ -52 & 70 & \text { Airplane6-1 } & -79 & -75 & \text { Airplane2-7 } \\ -52 & 118 & \text { Airplane2-4 } & -88 & 70 & \text { Airplane6-5 } \\ & & & & & \end{array}$


Table 2. Daily Aircraft Flights

\begin{tabular}{clc}
\hline Flight & \multicolumn{1}{c}{ Route } & Sites \\
\hline 1 & Honolulu-Santiago, Chile & 7 \\
2 & Punta Arenas, Chile-Perth, Australia & 9 \\
3 & Rio de Janeiro (South Atlantic) & 5 \\
4 & Capetown-Christchurch, NZ & 13 \\
6 & Easter Island-Kerguelen Island & 12 \\
8 & Honolulu-Anchorage & 4 \\
9 & Bombay, India-Perth, Australia & 5 \\
\hline
\end{tabular}

298 ground and aircraft launch sites; Table 2 identifies each aircraft route and its corresponding number of launch sites. The release sites are shown in Figure 2. Beyond the simple assumptions given above, no attempt was made to optimize the daily release scenario.

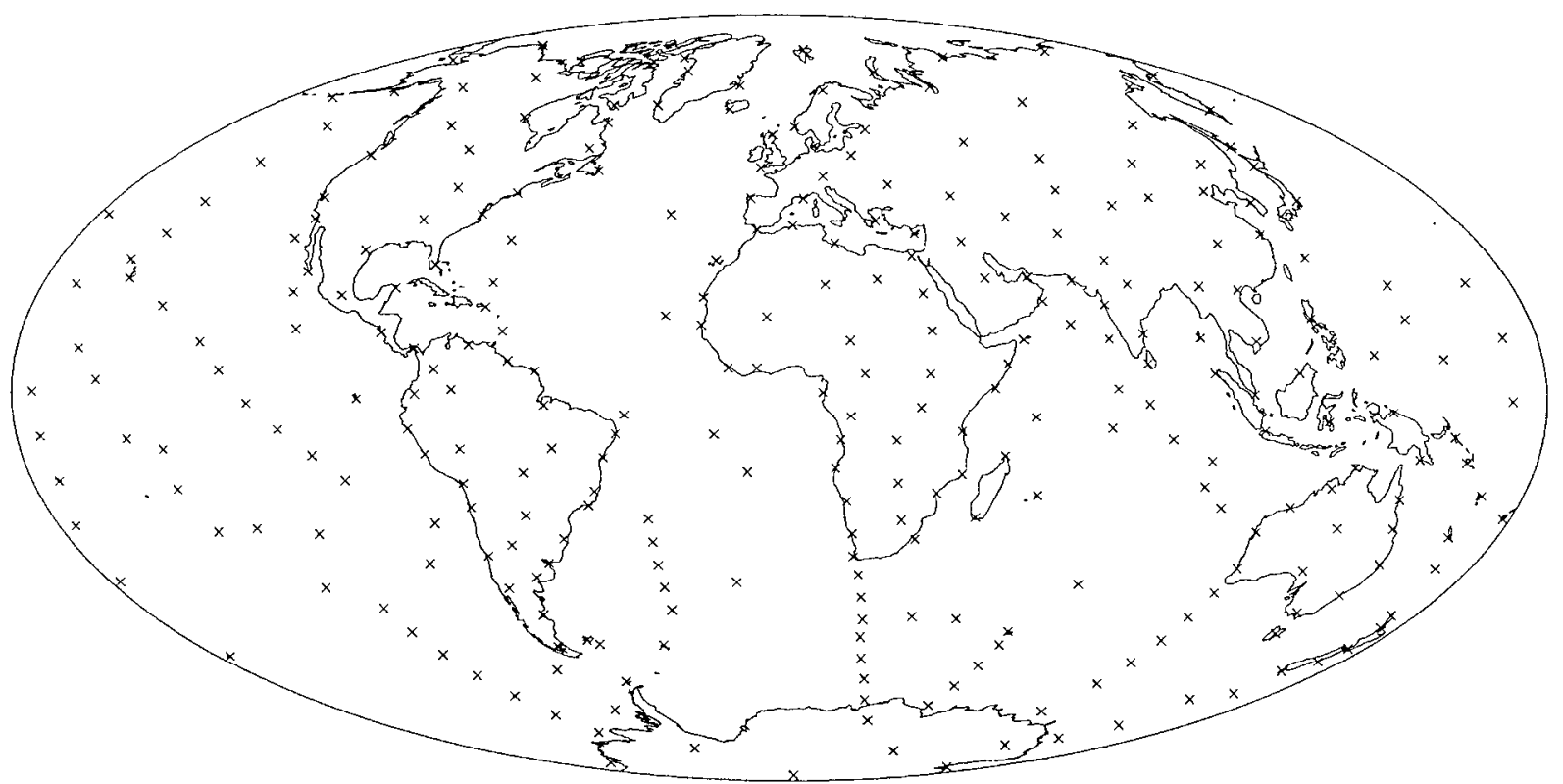

Figure 2. Daily release sites. 


\section{SIMULATION STUDIES}

\section{A. Uniform Initial Distribution}

\section{CCM3/GRANTOUR}

The CCM3/GRANTOUR simulation of the uniform initial distribution runs for 35 days. Balloon locations at the end of this period are shown in Figures 3-12 for each of the ten vertical levels from lowest $(925 \mathrm{mb})$ to highest $(100 \mathrm{mb})$. Balloons are represented by dots in these equal area projections.

The number of balloons allocated to each floating-layer pressure is 8192 , but some balloons with large floating-layer pressures would be below terrain and are not released. In addition balloons with large floating-layer pressures are lost due to collisions with terrain. Table 3 gives the number of balloons initially released at each pressure after deducting those below terrain and it gives the number of balloons still aloft at the end of 35 days. Since no terrain penetrates above $500 \mathrm{mb}$ all 8192 balloons allocated to these layers are released and remain aloft for 35 days.

Inspection of the plots in Figures 3-12 indicates that the uniform distribution deteriorates in all layers, but it deteriorates more rapidly in some layers than in others. Layers near the surface develop areas with very sparse coverage quite rapidly. This decay is due to loss of balloons by collisions with terrain and to horizontal divergence and convergence in the large scale flow. At mid-latitudes in both the southern and northern hemispheres, the predominant zonal flow transports balloons west to east around the globe with high terrain areas removing balloons as they pass. Consequently, massive areas downwind of the mountains such as the eastern United

Table 3. Number of Balloons Released and Aloft after 35 Days

\begin{tabular}{|c|c|c|c|c|c|c|}
\hline \multirow{2}{*}{$\begin{array}{c}\text { Levels } \\
(\mathrm{mb})\end{array}$} & \multicolumn{3}{|c|}{ CCM3/GRANTOUR } & \multicolumn{3}{c|}{ NOGAPS/GRANTOUR } \\
\cline { 2 - 7 } & Allocated & Released & Aloft & Allocated & Released & Aloft \\
\hline $100-500$ & 8192 & 8192 & 8192 & 8192 & 8192 & 8192 \\
\hline 600 & 8192 & 8168 & 7906 & 8192 & 8157 & 7779 \\
\hline 700 & 8192 & 8070 & 7694 & 8192 & 8030 & 6971 \\
\hline 775 & 8192 & 7995 & 7164 & 8192 & 7933 & 6181 \\
\hline 850 & 8192 & 7862 & 6080 & 8192 & 7739 & 4395 \\
\hline 925 & 8192 & 7378 & 3390 & 8192 & 7257 & 2168 \\
\hline
\end{tabular}


States, South America, and Asia have almost no balloons. In mid-latitudes balloons tend to gather in clusters or ribbons along convergence lines, presumably in frontal zones, since the clusters and ribbons move from day to day. One shortcoming of these simulations is a lack of any diffusive component to the flow field; i.e., the balloons are transported solely with the large-scale winds. Therefore, once balloons converge they have no way of moving away from each other, and the simulation over-estimates balloon clustering.

In the tropics, vast areas are almost completely without balloons while several small areas have collected many balloons. These convergence areas include the Carribean Sea, northern Arabian Sea, central India, and the South China Sea. The equatorial zone is nearly free of balloons while a surplus exists in the inter-tropical convergence zone. This is consistent with divergence in the central tropics and convergence just to the north and south.

The north-polar region has quite good coverage after 35 days except at the lowest level $(925 \mathrm{mb})$ where the mountains in Greenland and northern Canada/Alaska have removed many balloons. Terrain near the south pole is all above $700 \mathrm{mb}$ so no low elevation balloons are found there.

Balloons with floating-level pressures in the middle of the atmosphere (between 775 and $400 \mathrm{mb}$ ) maintain good global distributions, although the spacings do not stay very uniform. The distributions are particularly good in mid-latitudes and in polar regions. Nevertheless, coverage problems still exist in the tropics, especially for balloons assigned to 775 and $700 \mathrm{mb}$.

The global distribution of balloons with floating-level pressures near the tropopause (300 and $200 \mathrm{mb}$ ) is poor after 35 days. The tropics are almost completely devoid of balloons probably due to upper level divergence associated with the Hadley circulation. The balloons advected out of the tropics are found primarily along meandering lines at the edge of the tropics, particularly for balloons with floating-level pressures of $200 \mathrm{mb}$. The mid-latitudes and polar regions have very good coverage with the number of balloons enhanced by transport from the tropics.

Balloons with floating-level pressures of $100 \mathrm{mb}$ preserve very good global coverage; however, the reliability of the simulation at this level is subject to uncertainty because GCM's, designed to simulated the troposphere, may not accurately calculate flow fields in the stratosphere.

\section{NOGAPS/GRANTOUR}

The NOGAPS/GRANTOUR uniform distribution simulation was run for 47 days from August 15 to September 30, 1998. Balloon locations at each pressure level after 35 days are shown in Figures 13-22 for comparison with the CCM3/GR ANTOUR simulation and after 47 days in Figures 23-32. Comparison of terrain represented by the gray shaded areas in Figures 3-7 with Figures 13-17 at corresponding pressure levels reveals the higher spatial resolution of the NOGAPS topography and the greater extent of areas of high mountains. For example, the Andes 


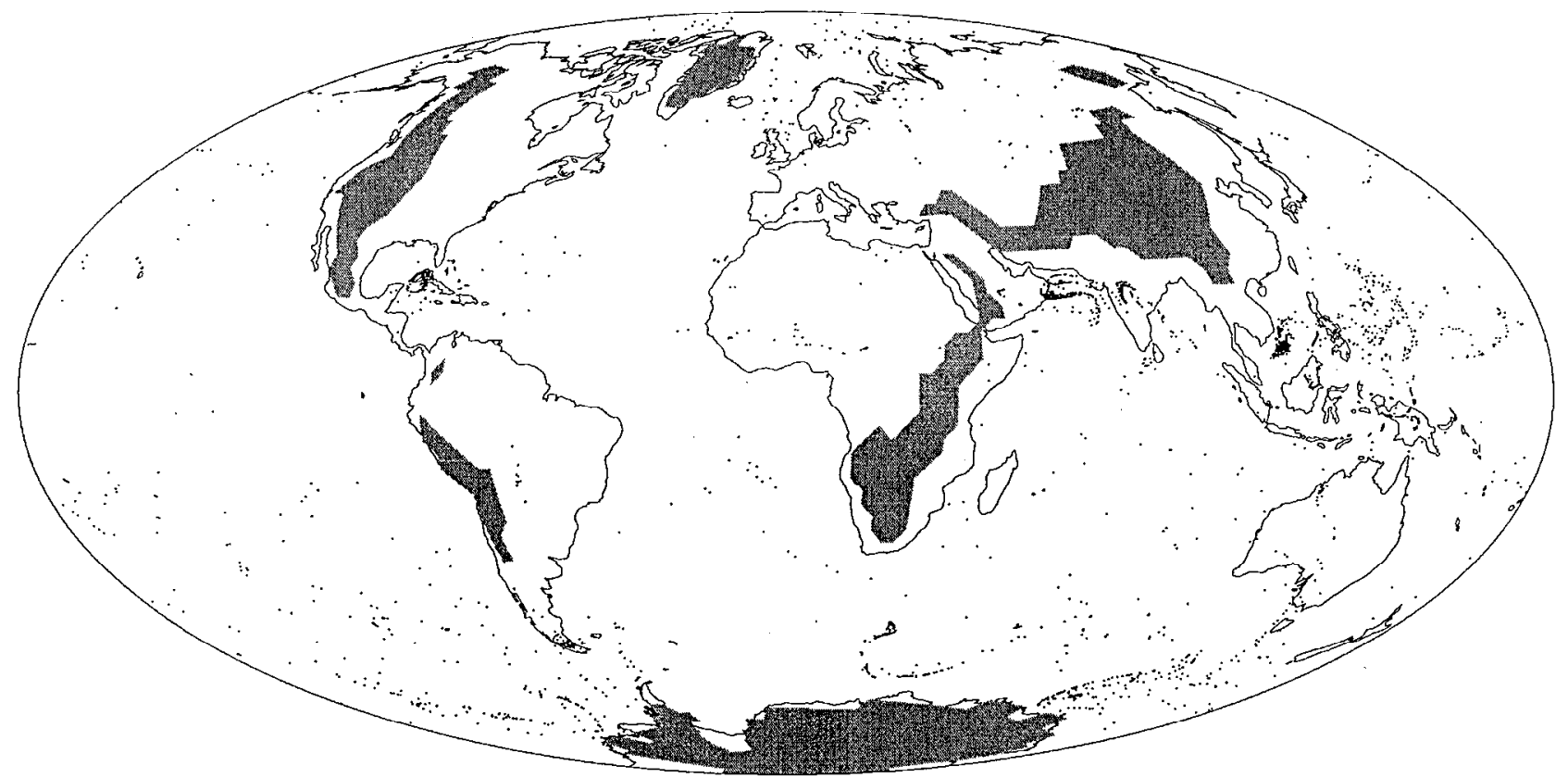

Figure 3. Location of balloons set for $925 \mathrm{mb} 35$ days after release as an initially uniform distribution. Terrain above $925 \mathrm{mb}$ is shaded in gray. 7387 balloons released, 3390 still aloft, 3997 hit terrain.

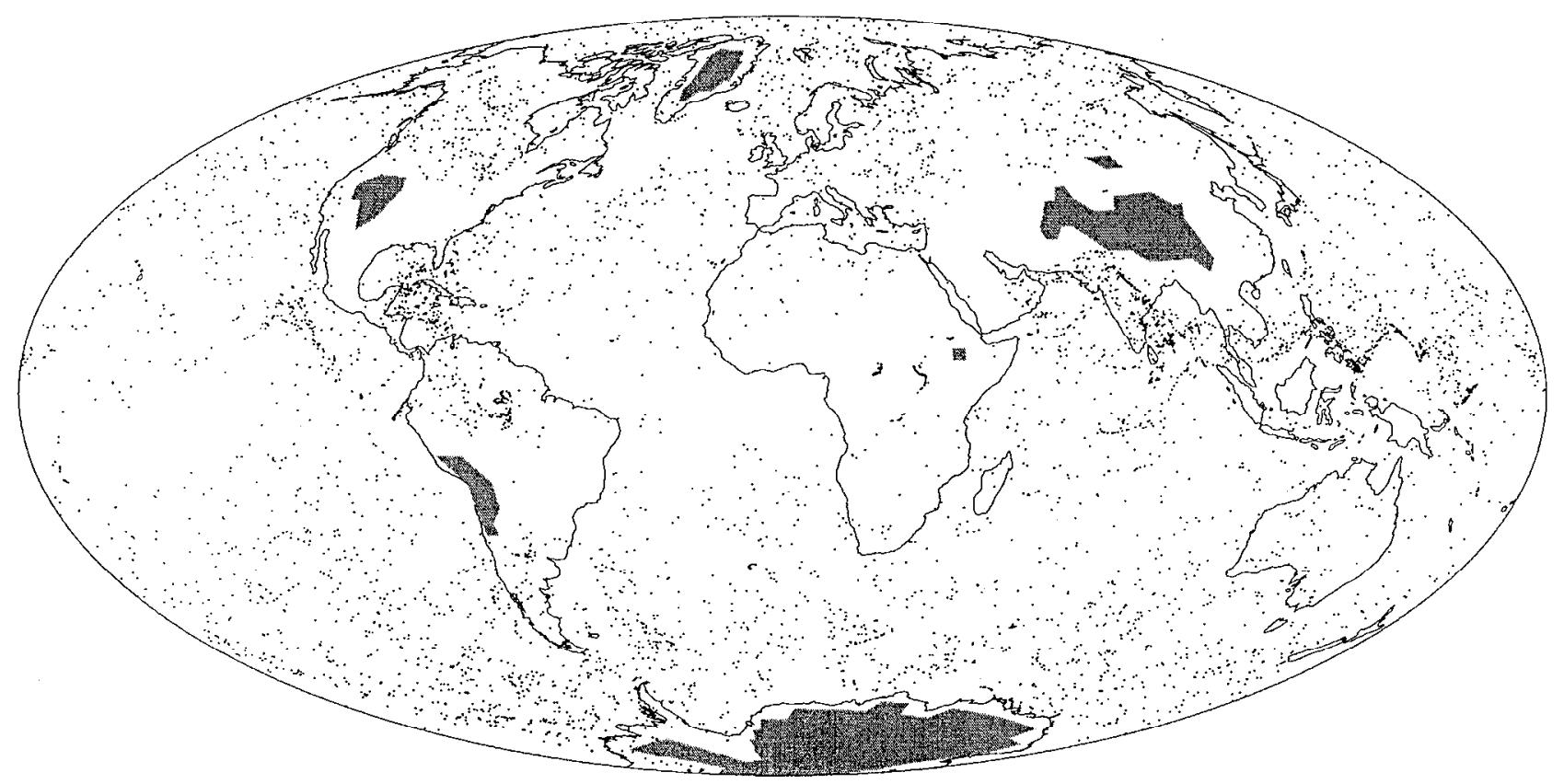

Figure 4. Location of balloons set for $850 \mathrm{mb} 35$ days after release as an initially uniform distribution. Terrain above $850 \mathrm{mb}$ is shaded in gray. 7862 balloons released, 6080 still aloft, 1782 hit terrain. 


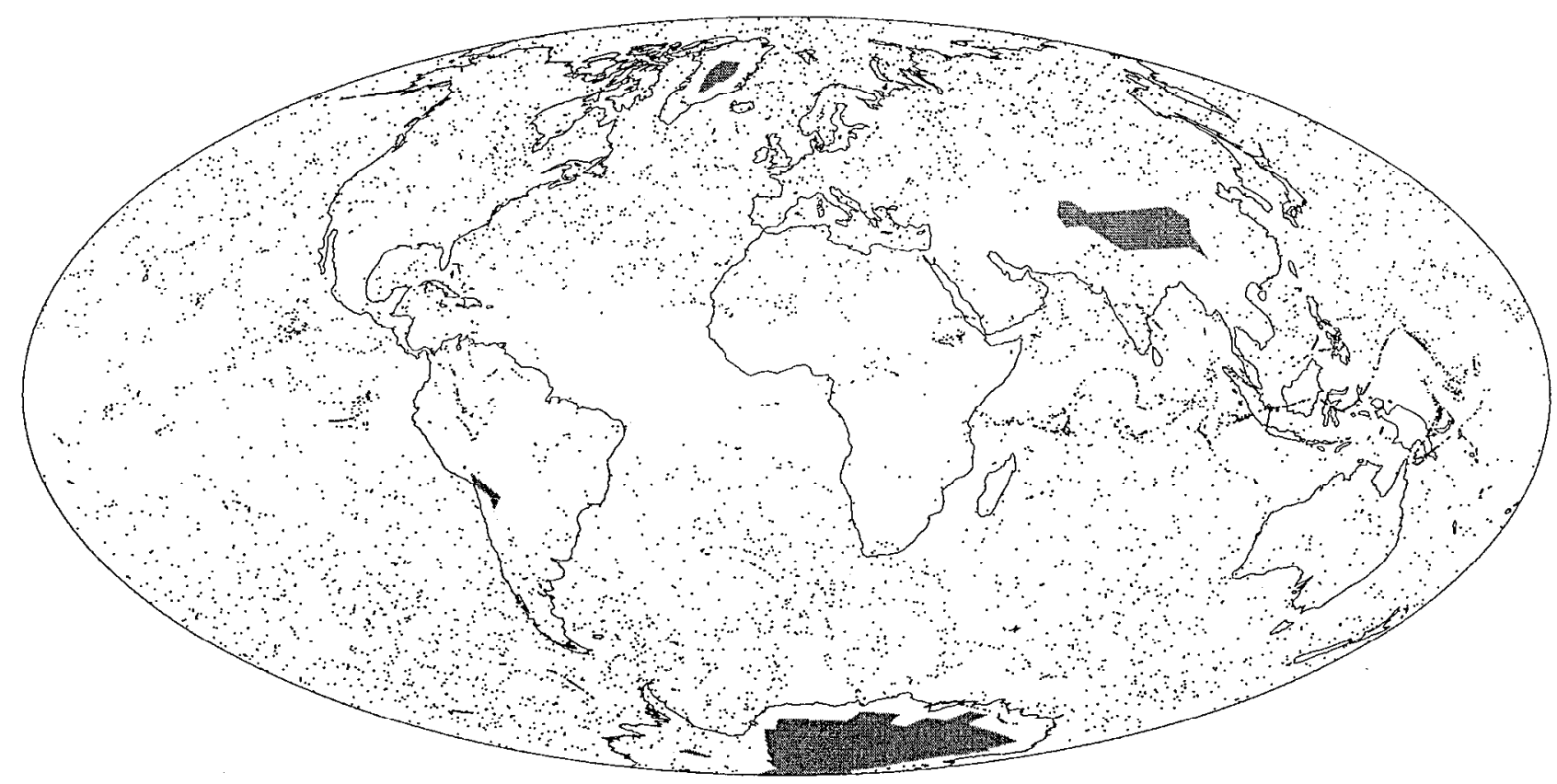

Figure 5. J .ocation of balloons set for $775 \mathrm{mb} 35$ days after release as an initially uniform distribution. Terrain above $775 \mathrm{mb}$ is shaded in gray. 7995 balloons released, 7164 still aloft, 831 hit terrain.

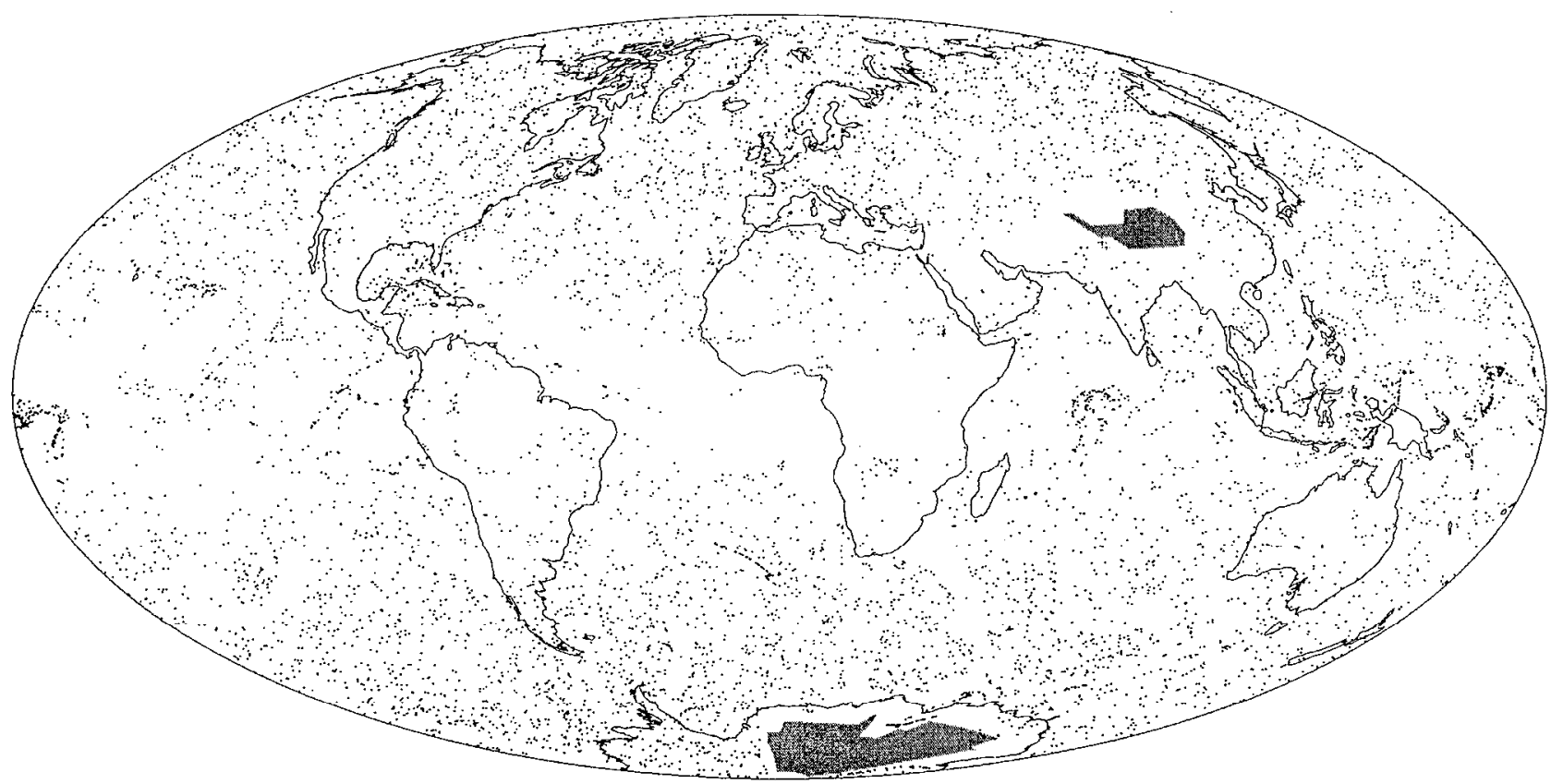

Figure 6. Location of balloons set for $700 \mathrm{mb} 35$ days after release as an initially uniform distribution. Terrain above $700 \mathrm{mb}$ is shaded in gray. 8070 balloons released, 7897 still aloft, 376 hit terrain. 


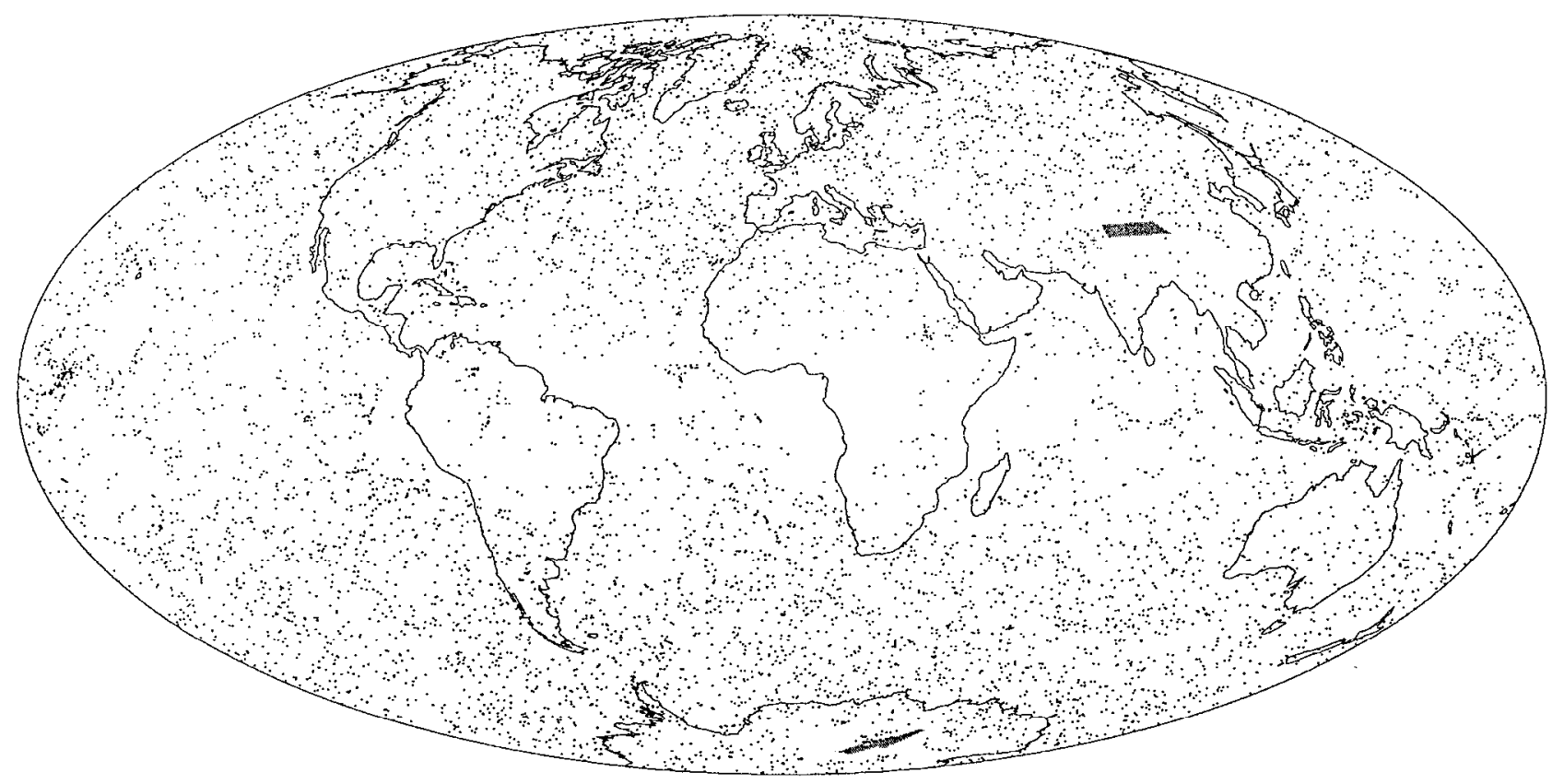

Figure 7. Location of balloons set for $600 \mathrm{mb} 35$ days after release as an initially uniform distribution. Terrain above $600 \mathrm{mb}$ is shaded in gray. 8168 balloons released, 7906 still aloft, 262 hit terrain.

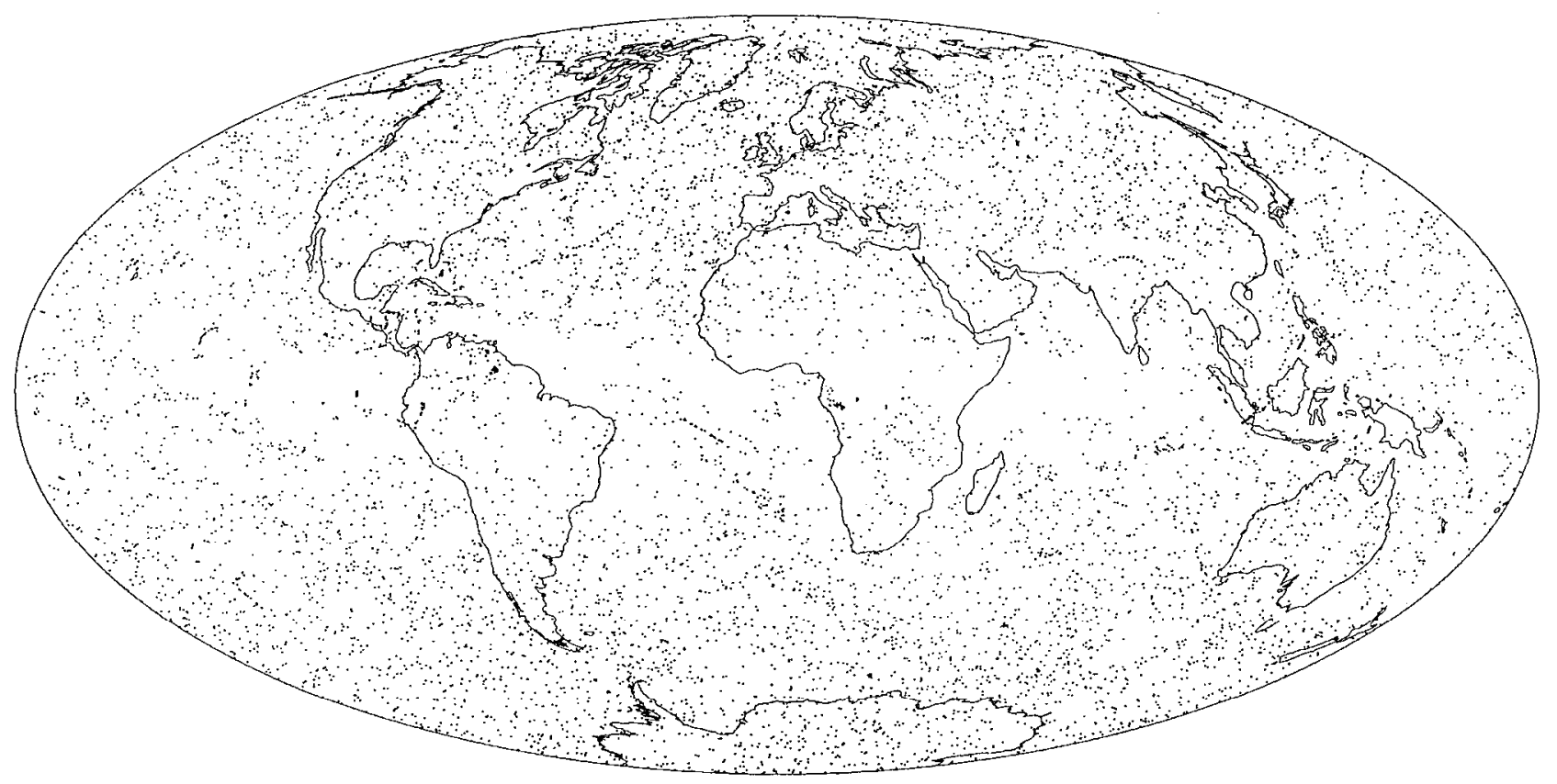

Figure 8. Location of balloons set for $500 \mathrm{mb} 35$ days after release as an initially uniform distribution. 8192 balloons released and still aloft. 


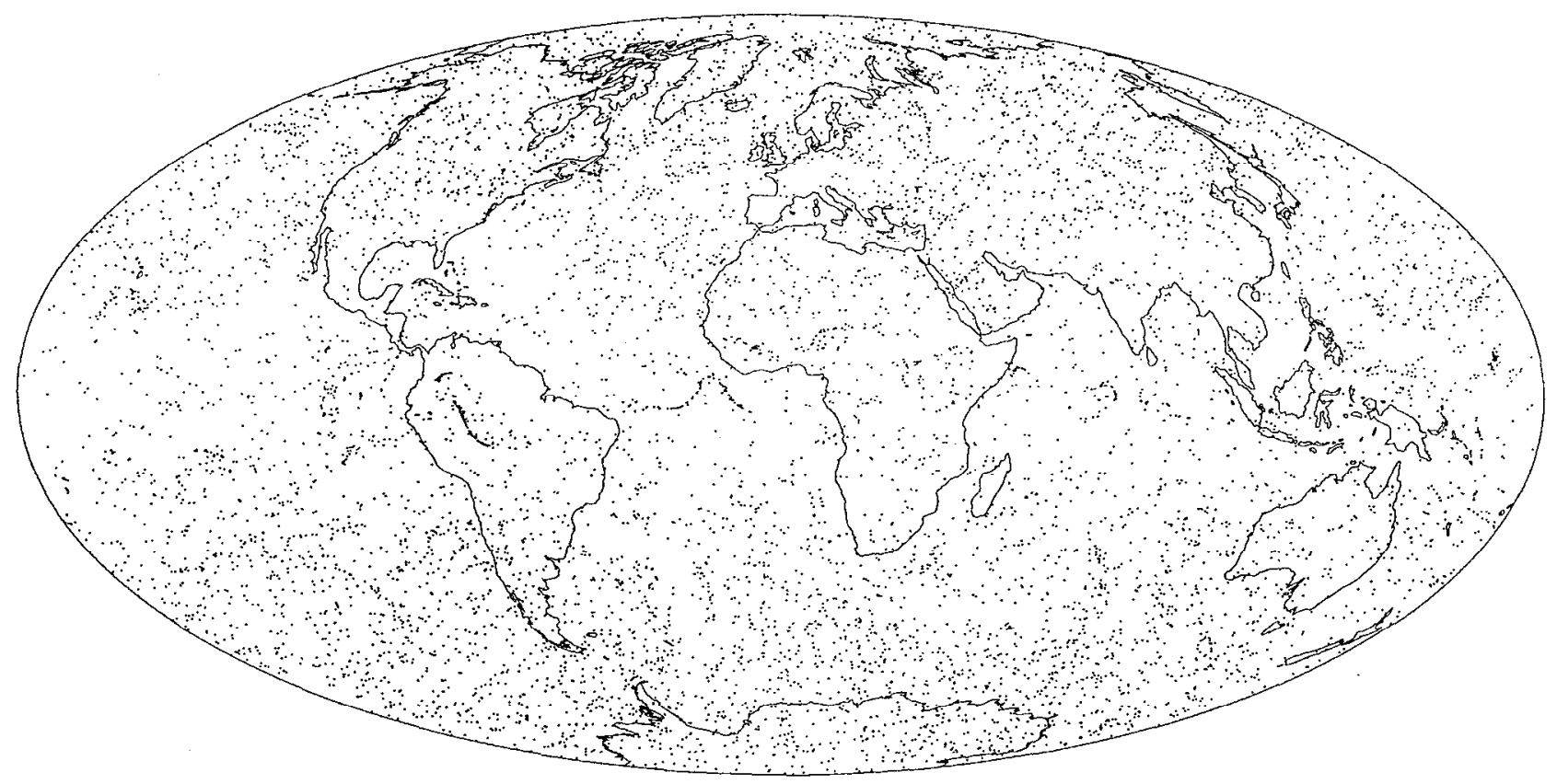

Figure 9. Location of balloons set for $400 \mathrm{mb} 35$ days after release as an initially uniform distribution. 8192 balloons released and still aloft.

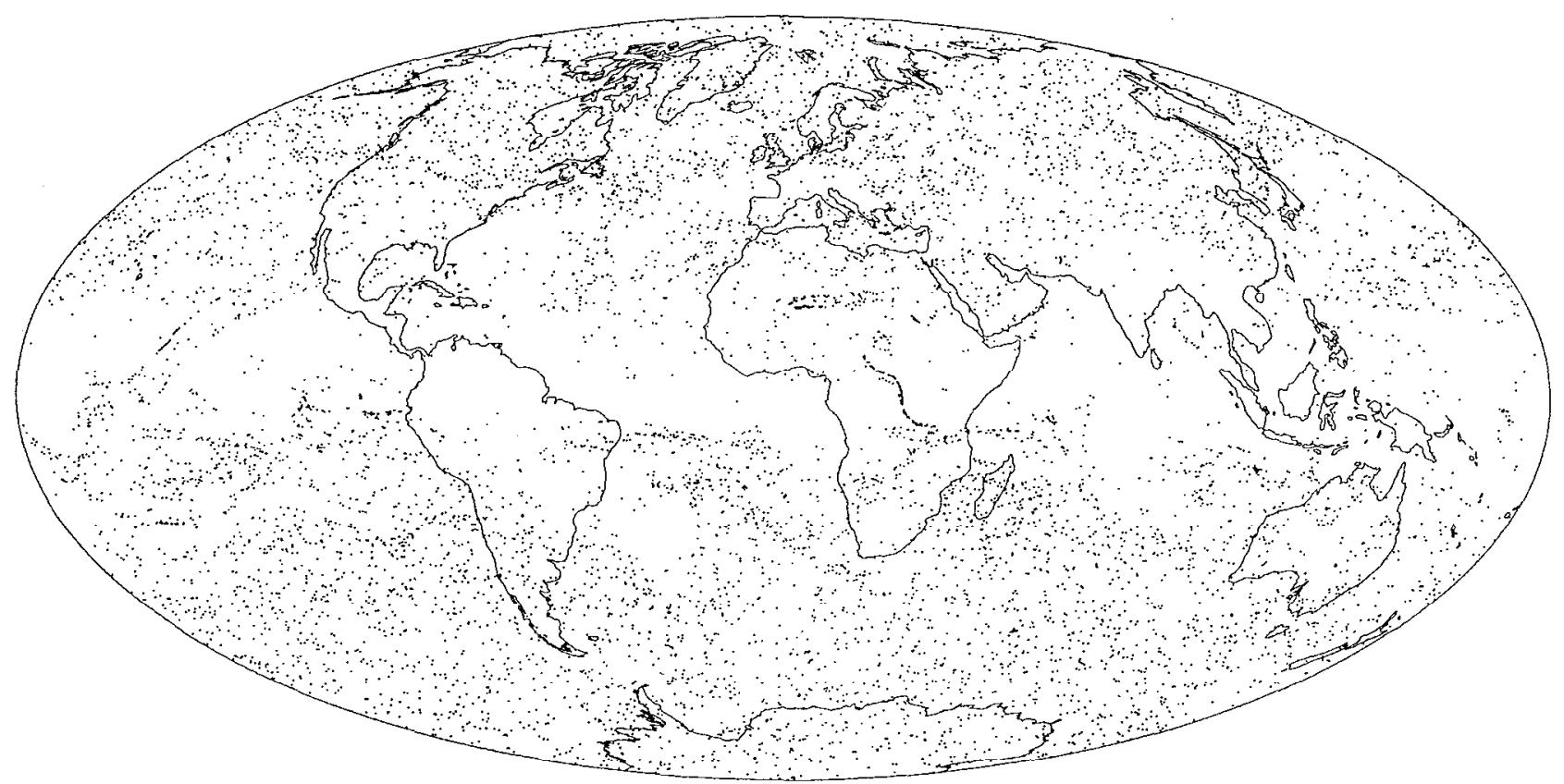

Figure 10. Location of balloons set for $300 \mathrm{mb} 35$ days after release as an initially uniform distribution. 8192 balloons released and still aloft. 


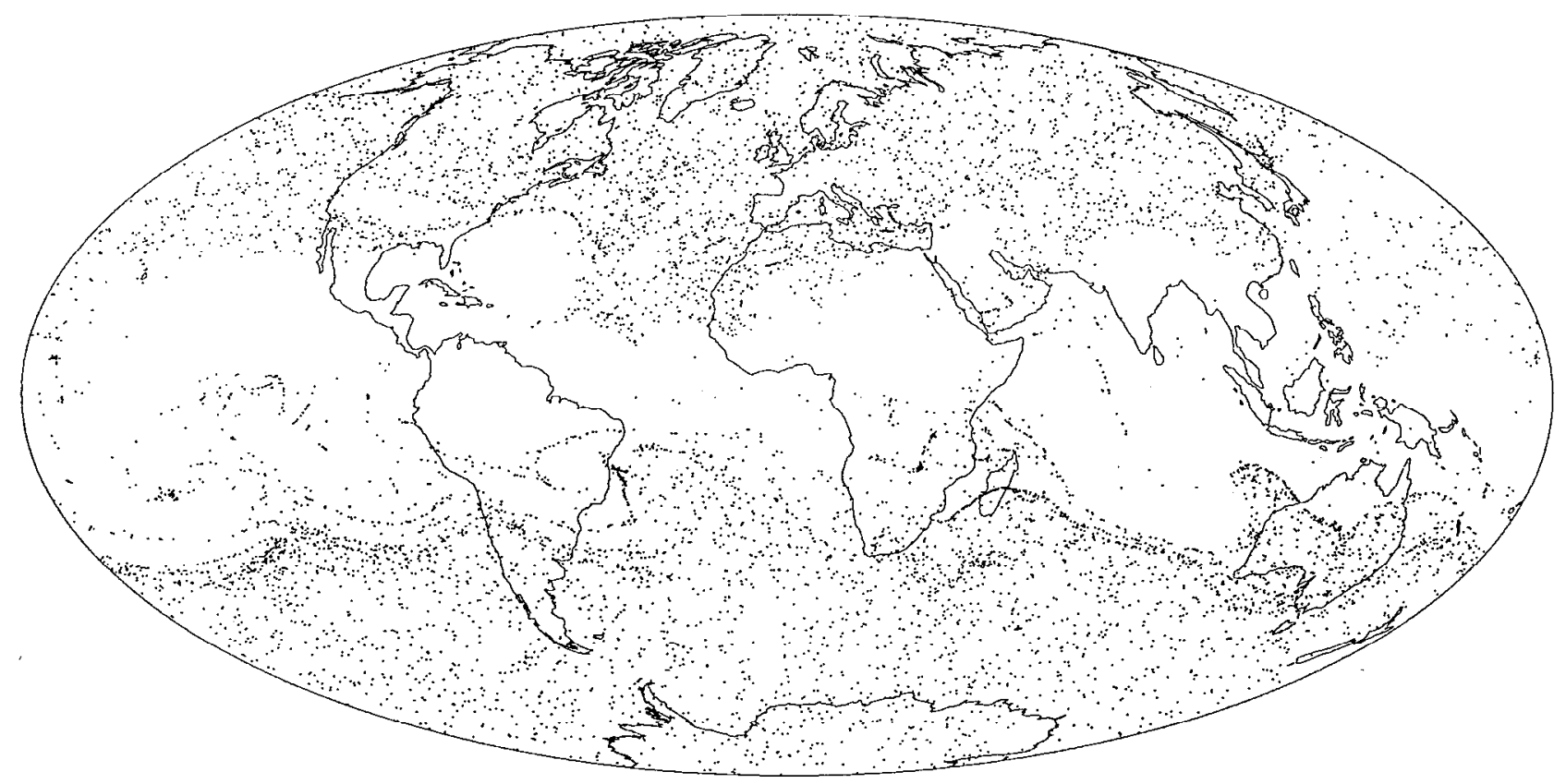

Figure 11. Location of balloons set for $200 \mathrm{mb} 35$ days after release as an initially uniform distribution. 8192 balloons released and still aloft.

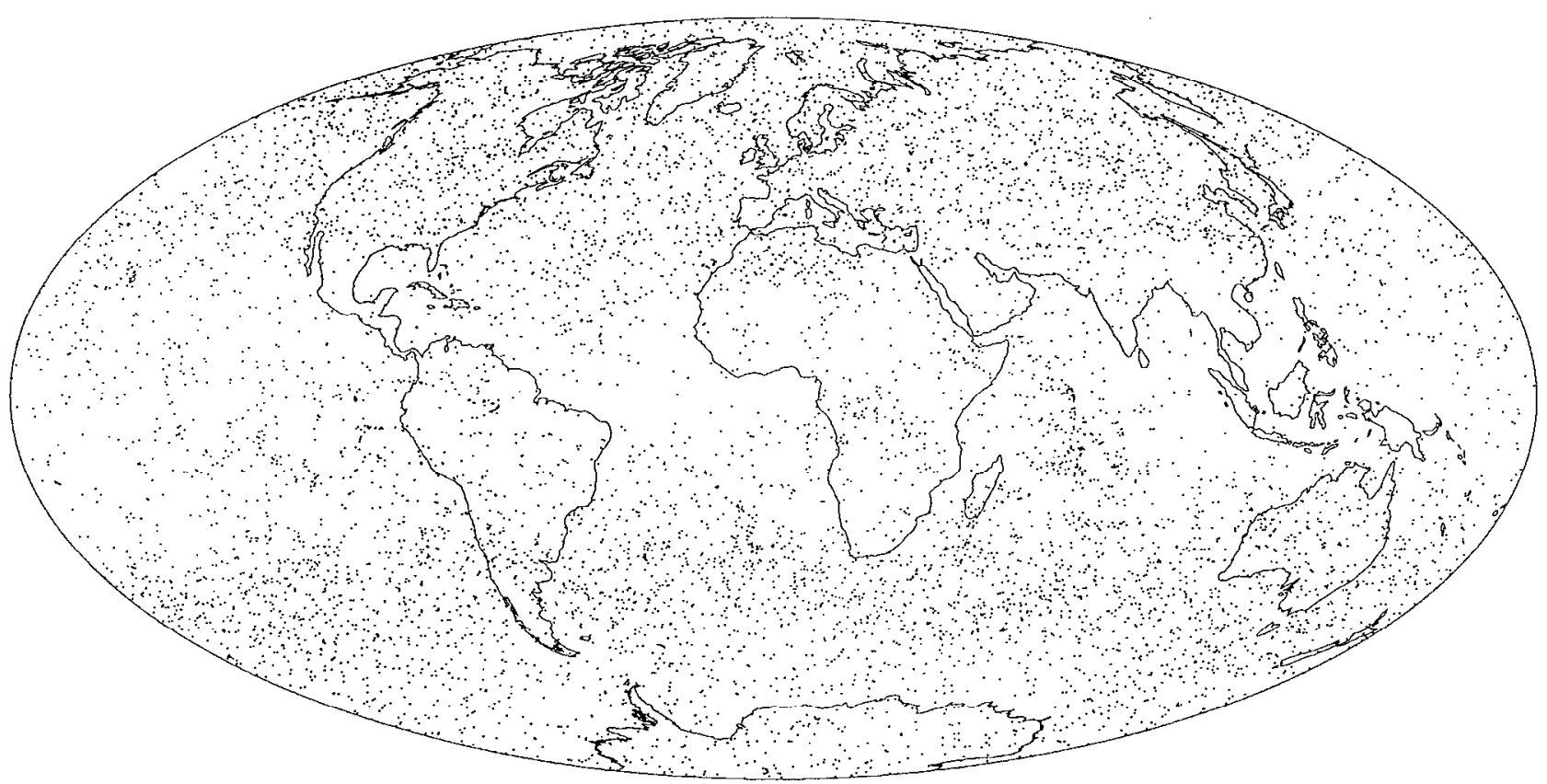

Figure 12. Location of balloons set for $100 \mathrm{mb} 35$ days after release as an initially uniform distribution. 8192 balloons released and still aloft. 


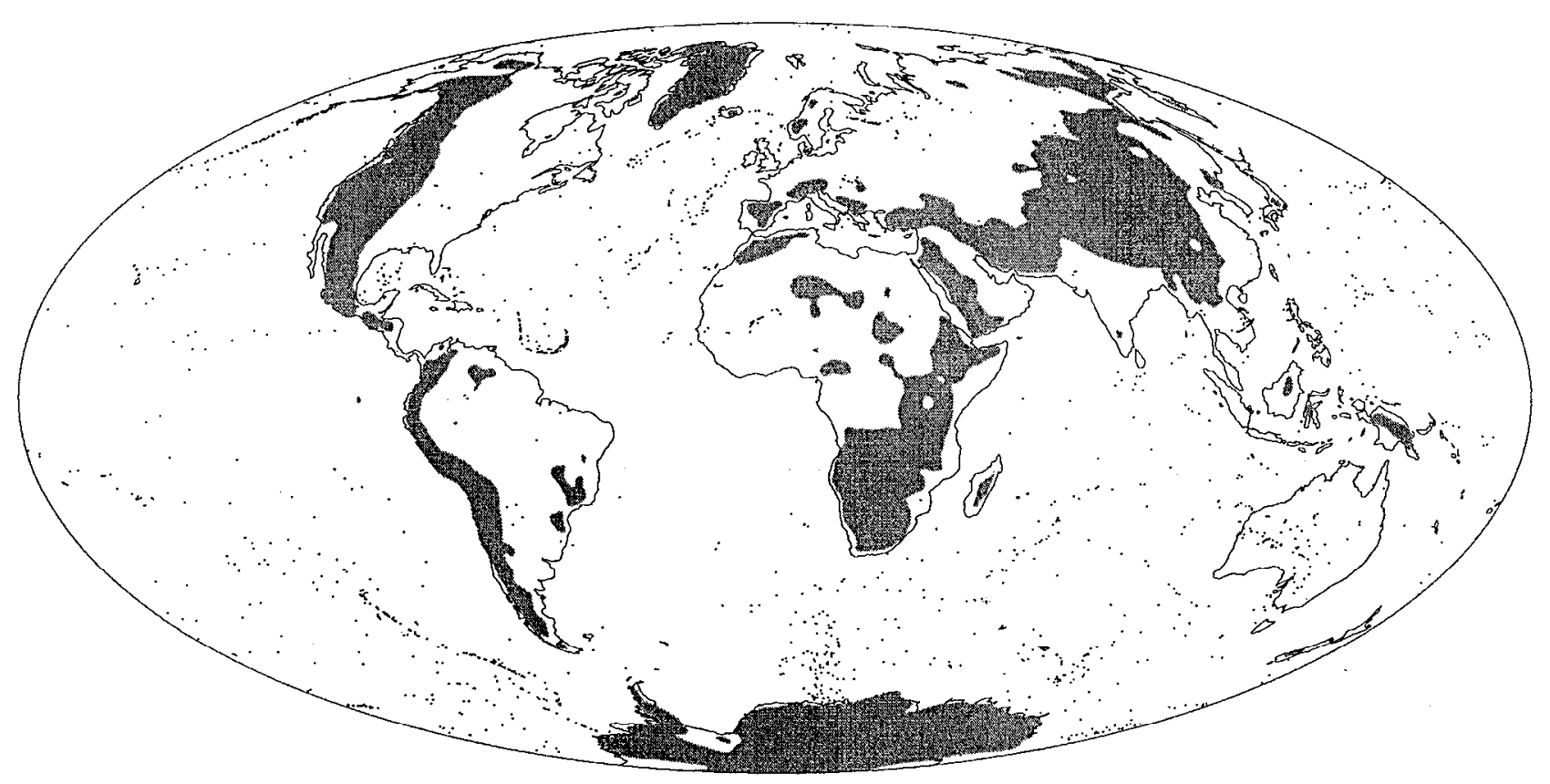

Figure 13. Location of balloons set for $925 \mathrm{mb} 35$ days after release as an initially uniform distribution. Terrain above $925 \mathrm{mb}$ is shaded in gray. 7257 balloons released, 2168 still aloft, 5089 hit terrain.

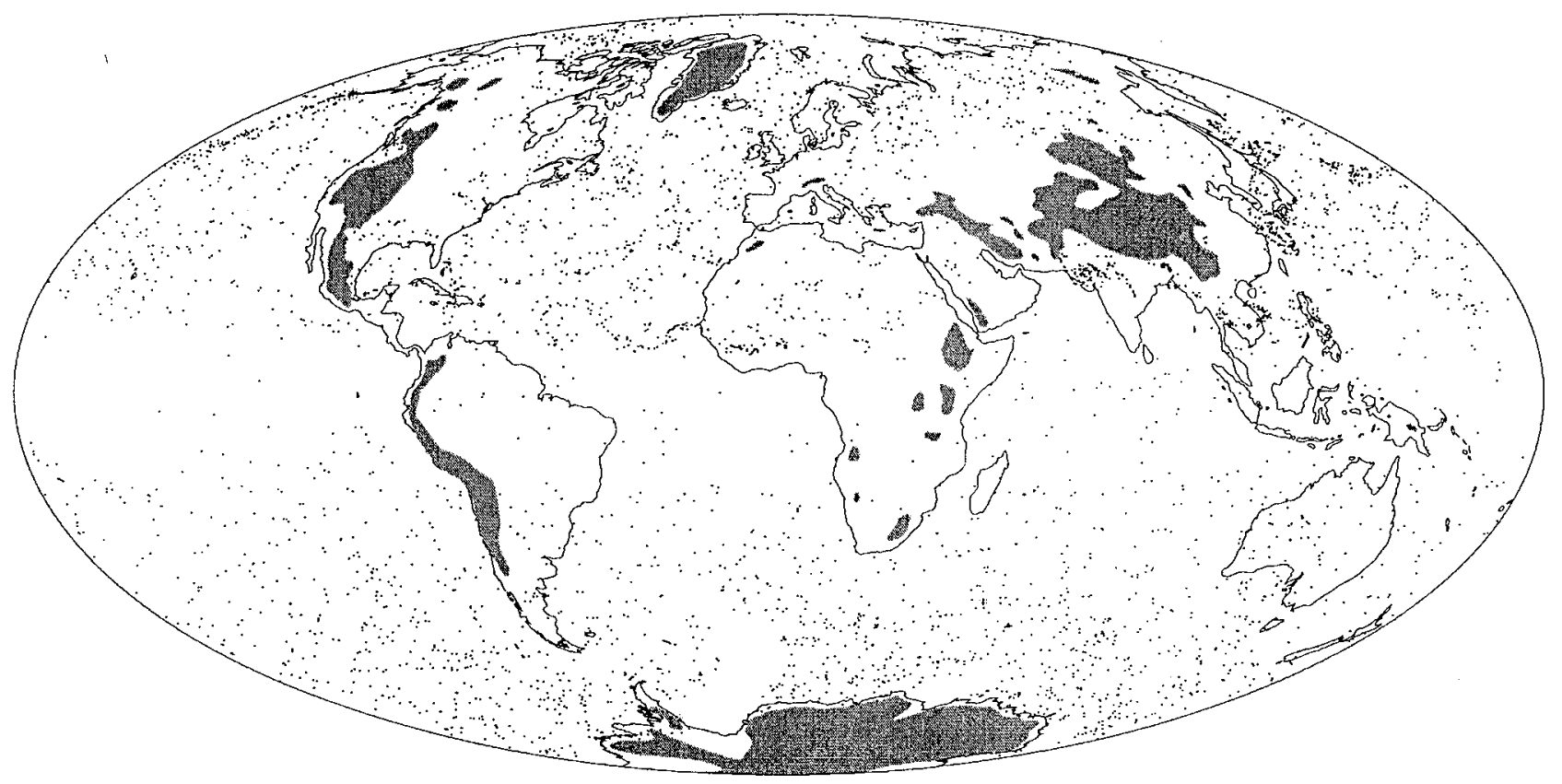

Figure 14. Location of balloons set for $850 \mathrm{mb} 35$ days after release as an initially uniform distribution. Terrain above $850 \mathrm{mb}$ is shaded in gray. 7739 balloons released, 4395 still aloft, 3344 hit terrain. 


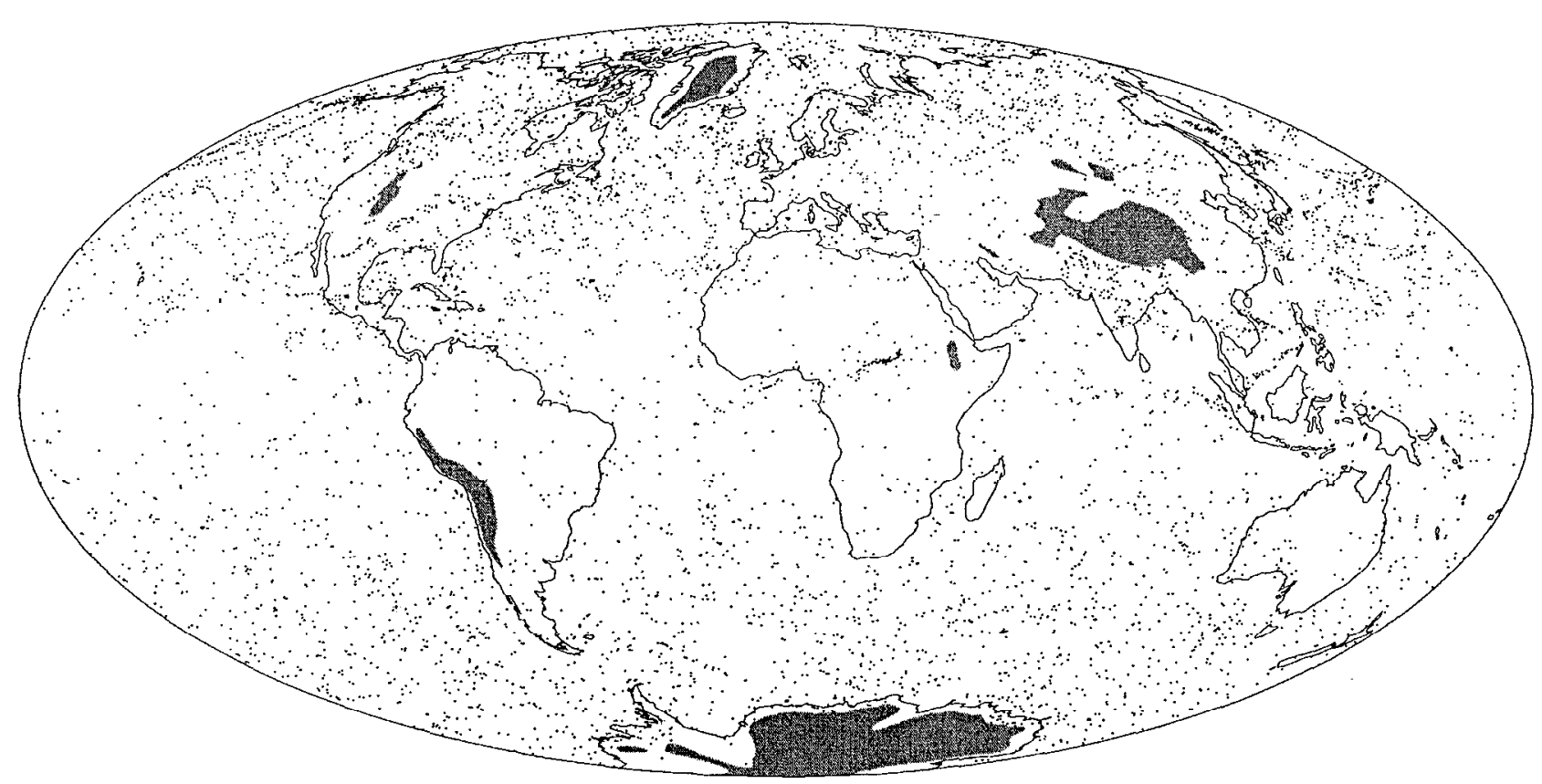

Figure 15. Location of balloons set for $775 \mathrm{mb} 35$ days after release as an initially uniform distribution. Terrain above $775 \mathrm{mb}$ is shaded in gray. 7933 balloons released, 6181 still aloft, 1752 hit terrain.

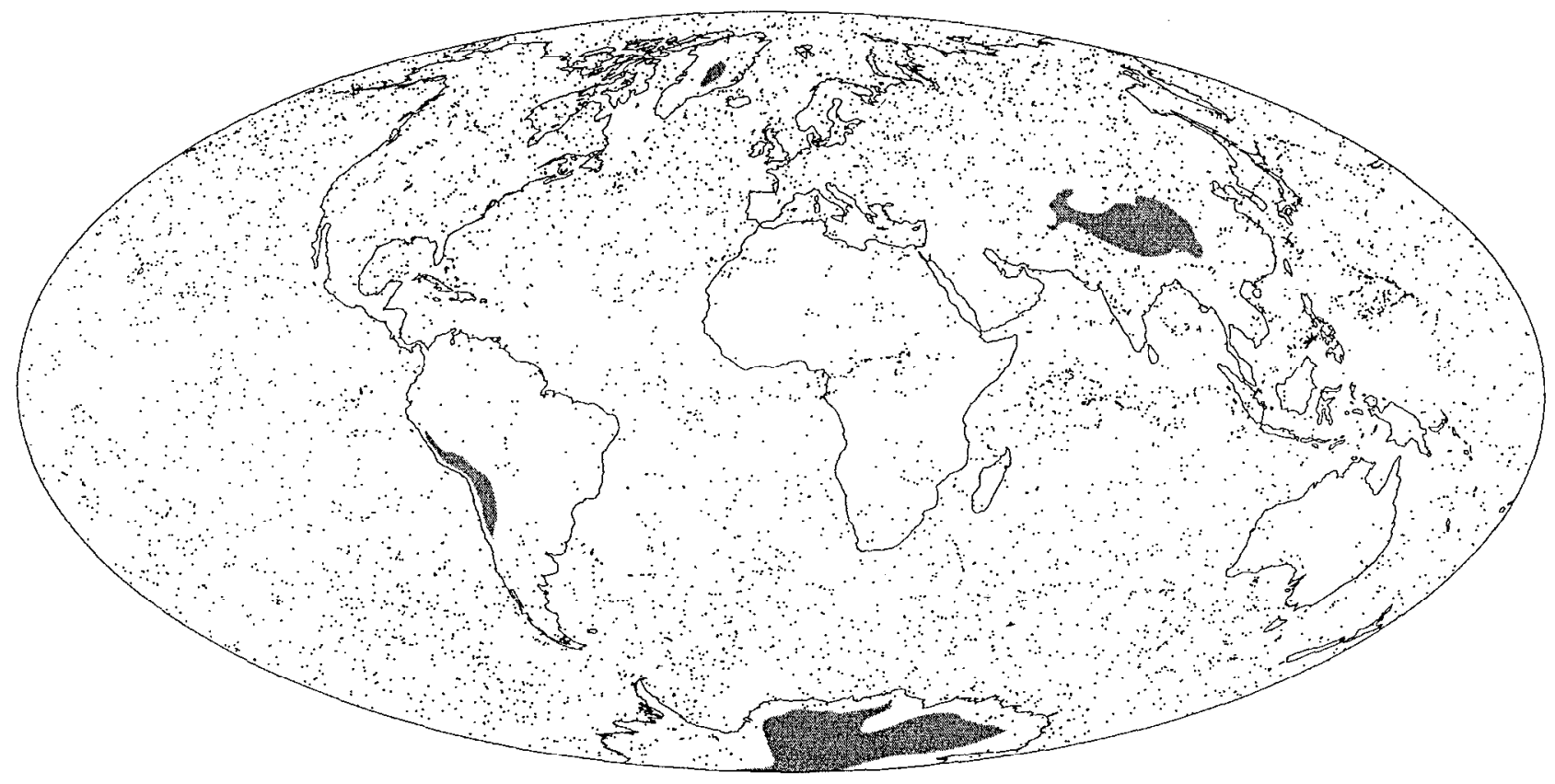

Figure 16. Location of balloons set for $700 \mathrm{mb} 35$ days after release as an initially uniform distribution. Terrain above $700 \mathrm{mb}$ is shaded in gray. 8030 balloons released, 6971 still aloft, 1059 hit terrain. 


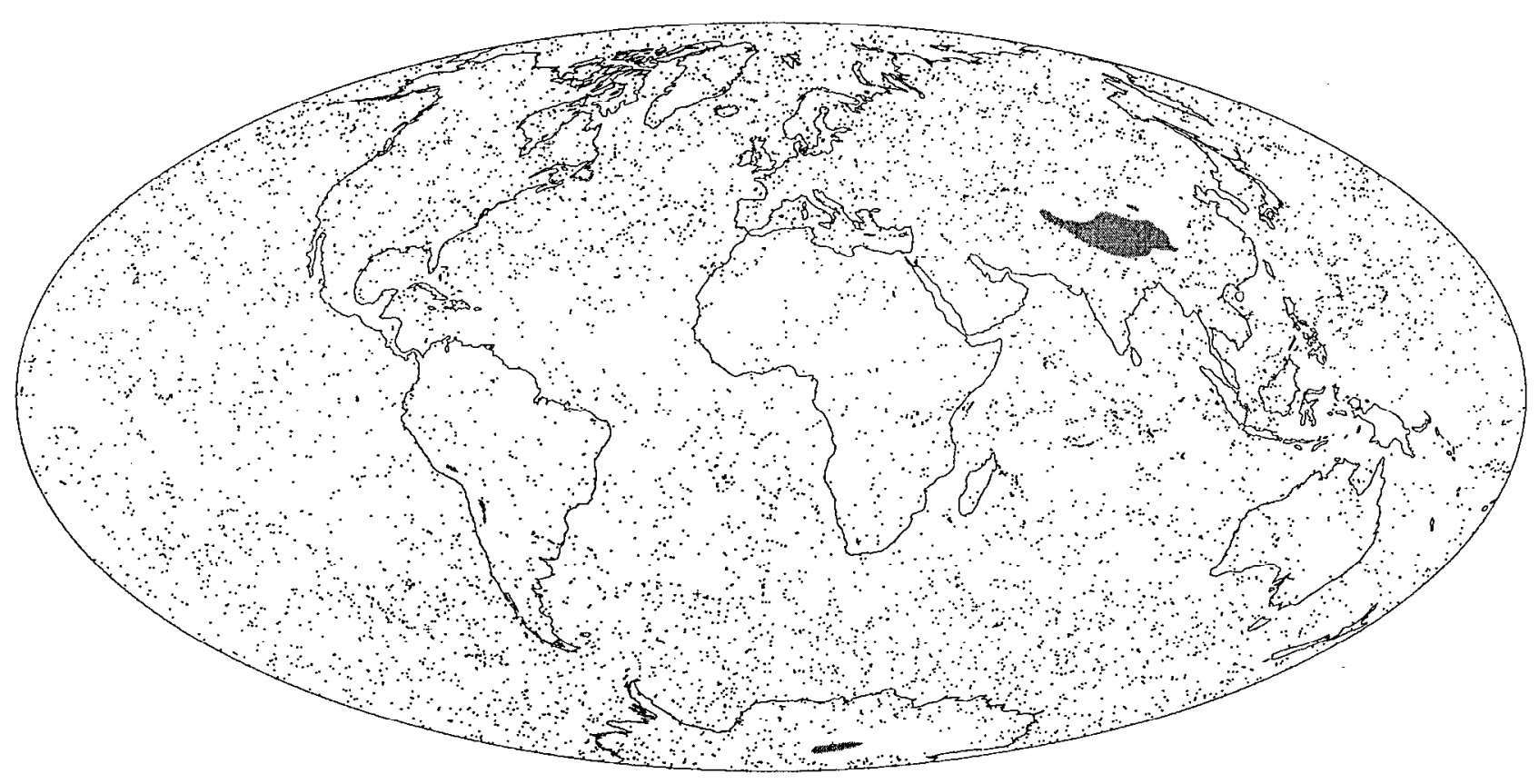

Figure 17. Location of balloons set for $600 \mathrm{mb} 35$ days after release as an initially uniform distribution. Terrain above $600 \mathrm{mb}$ is shaded in gray. 8157 balloons released, 7779 still aloft, 378 hit terrain.

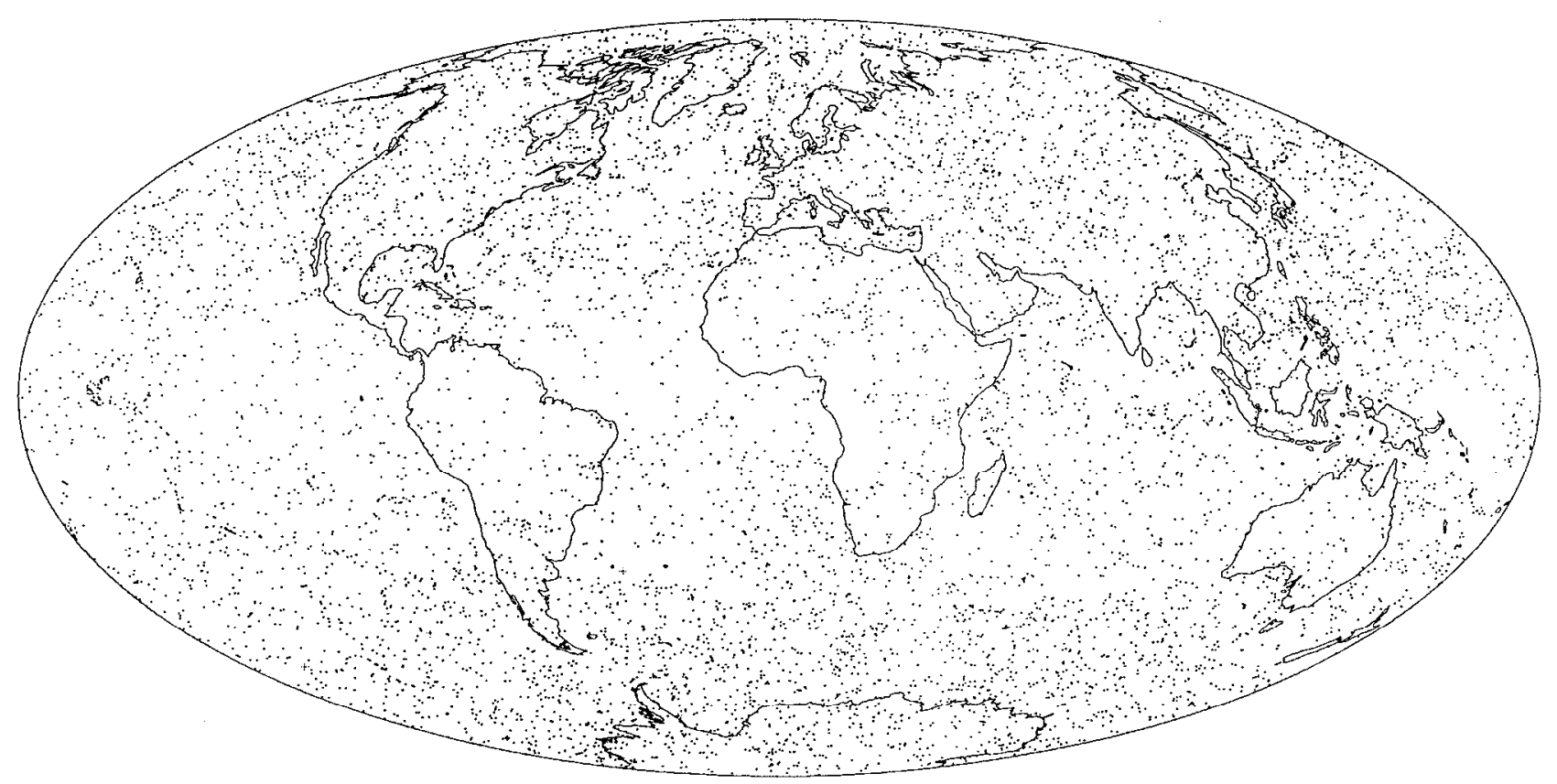

Figure 18. Location of balloons set for $500 \mathrm{mb} 35$ days after release as an initially uniform distribution. 8192 balloons released and still aloft. 


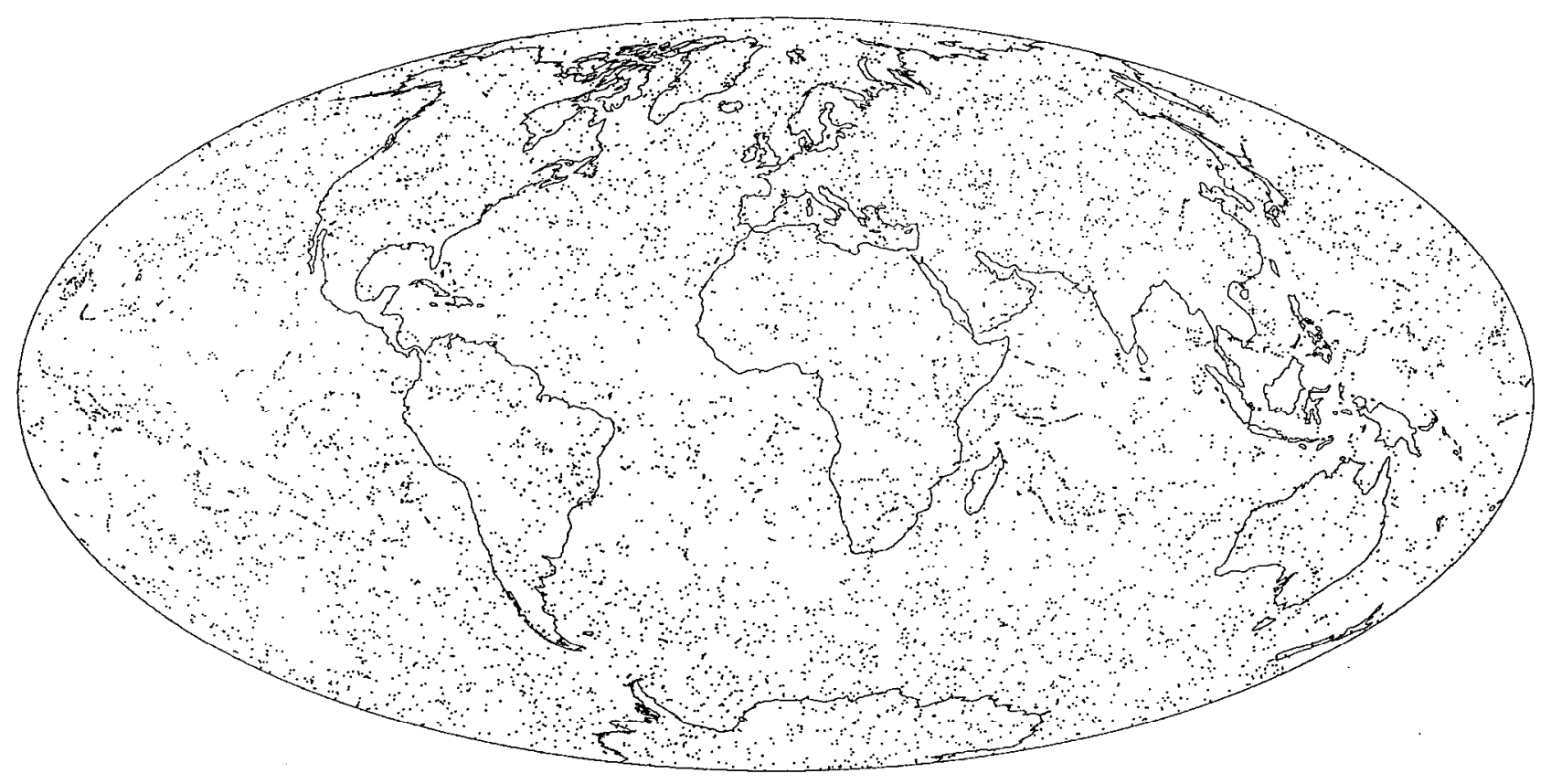

Figure 19. Location of balloons set for $400 \mathrm{mb} 35$ days after release as an initially uniform distribution. 8192 balloons released and still aloft.

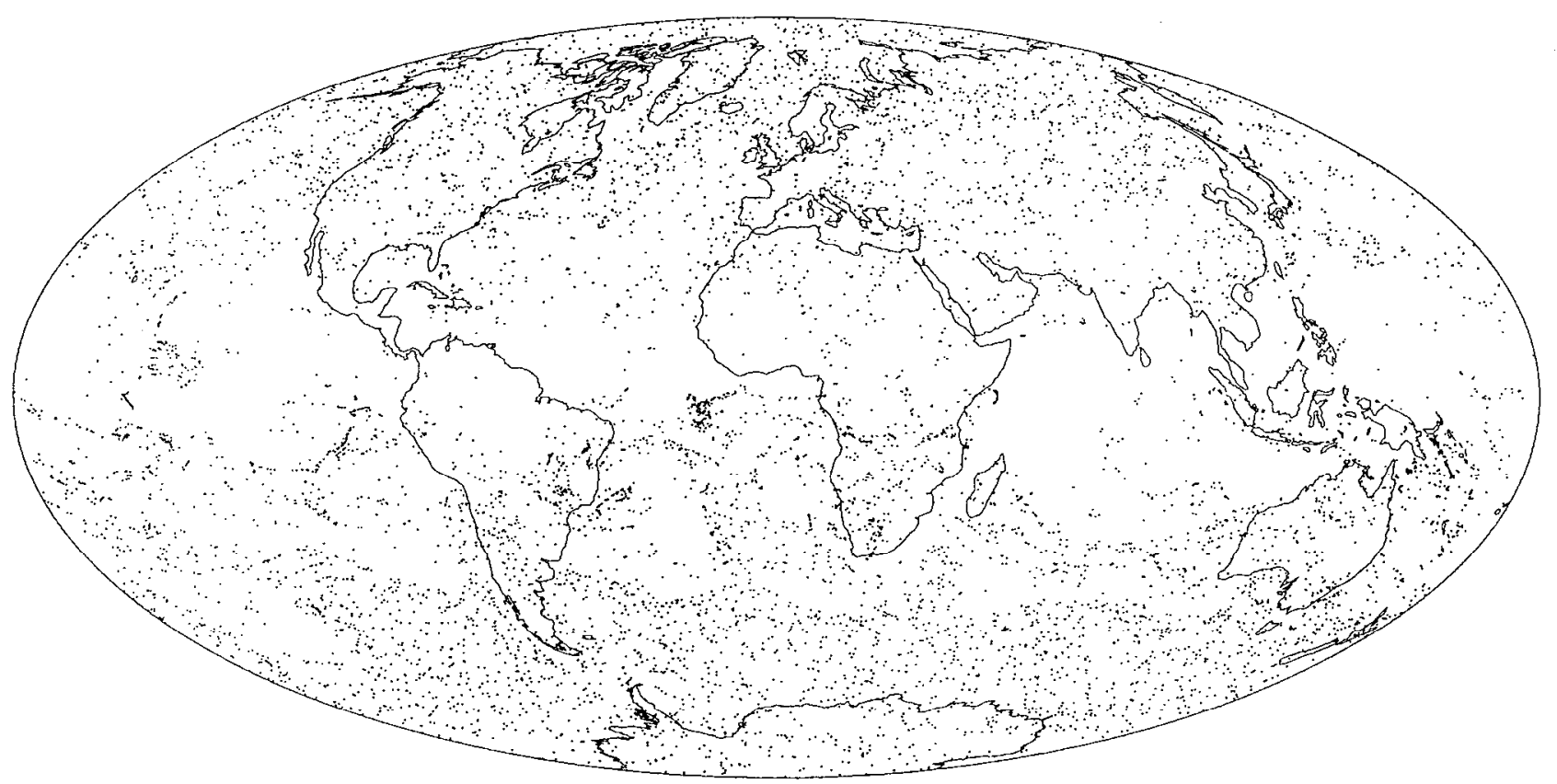

Figure 20. Location of balloons set for $300 \mathrm{mb} 35$ days after release as an initially uniform distribution. 8192 balloons released and still aloft. 


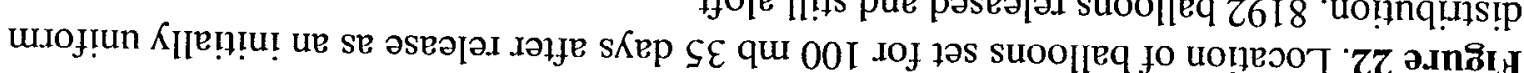

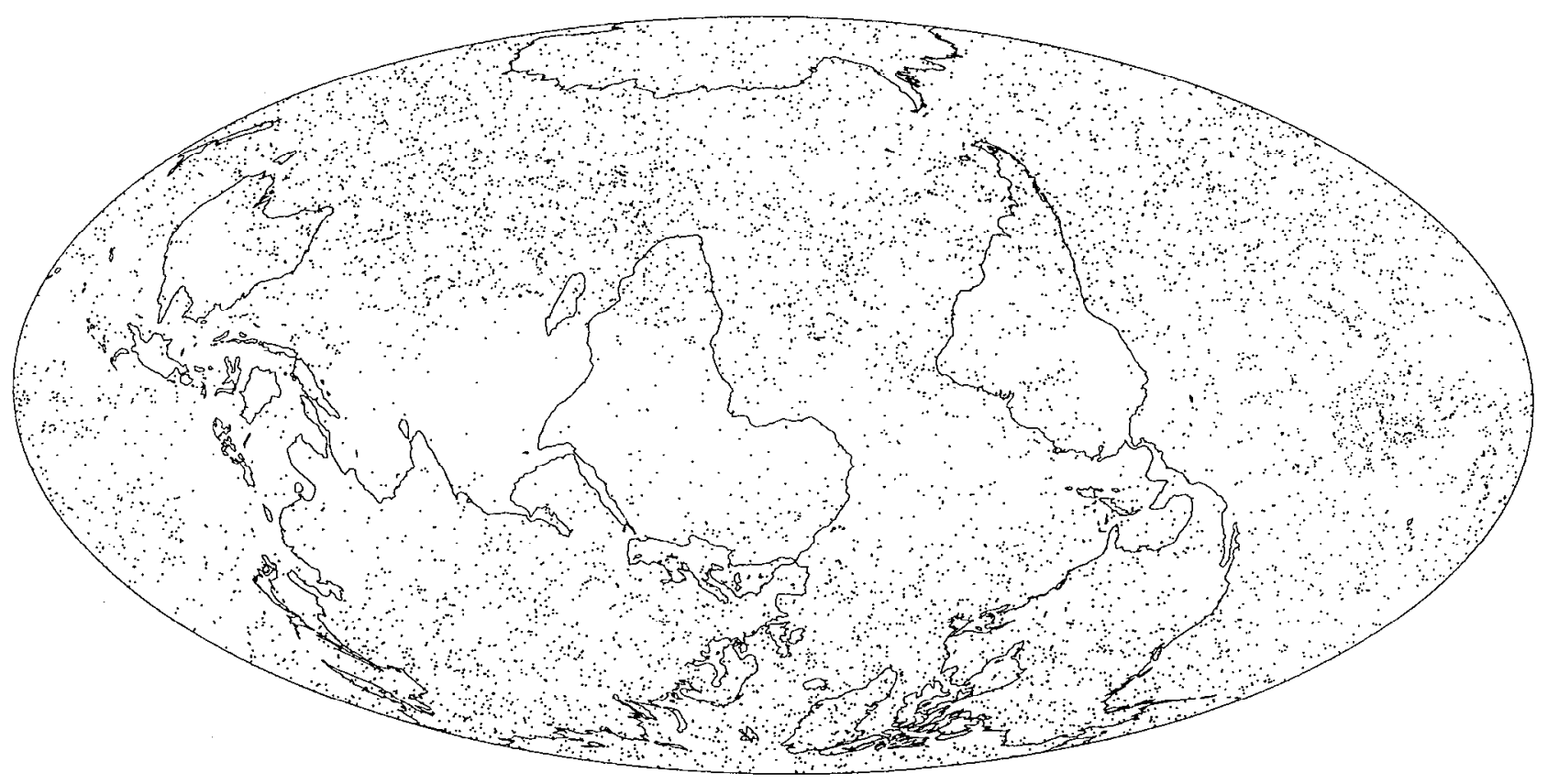

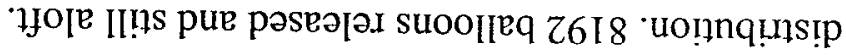

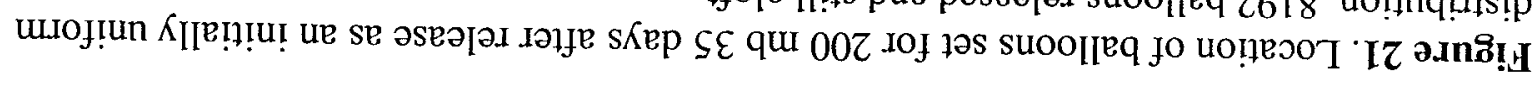

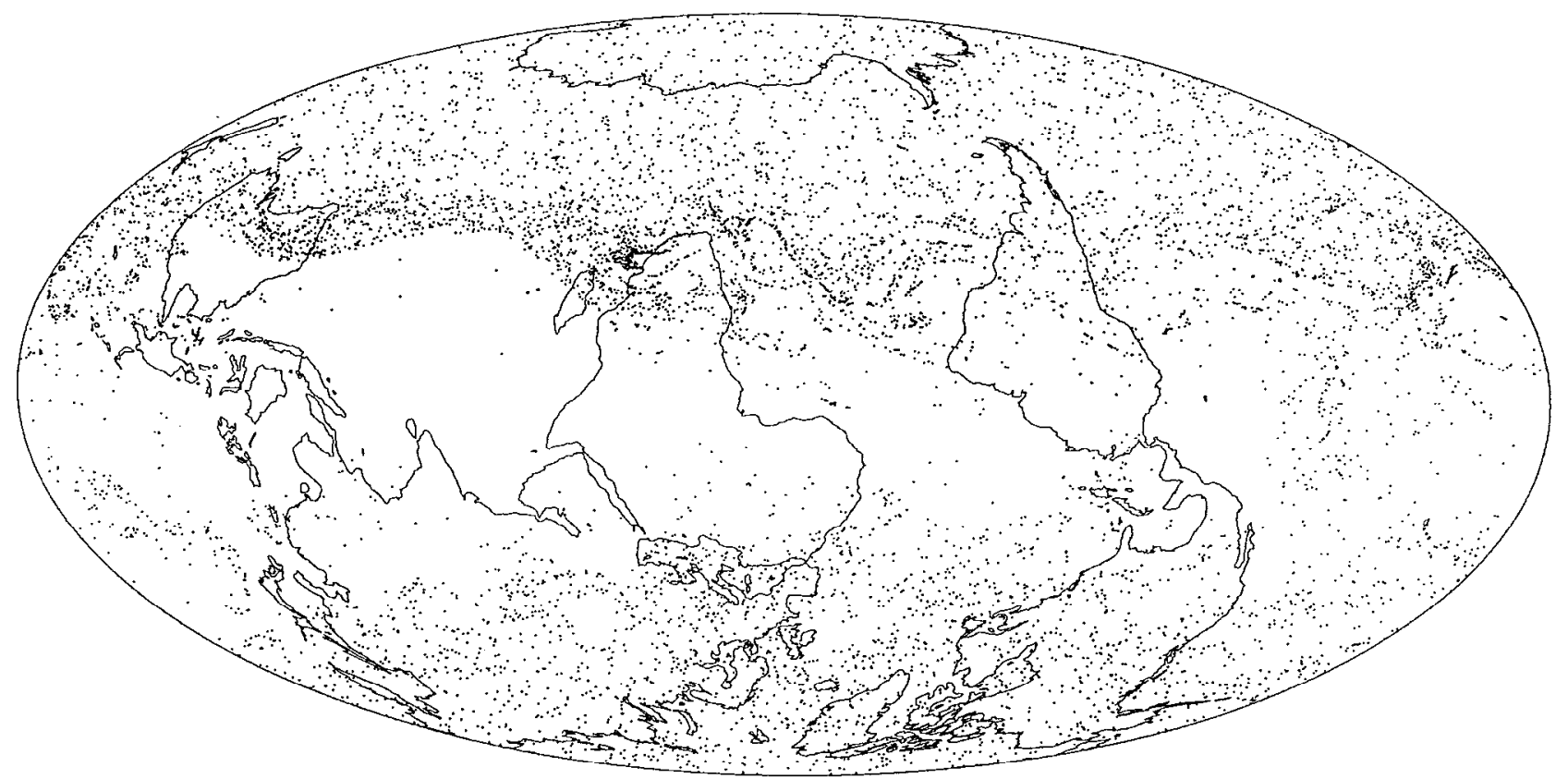




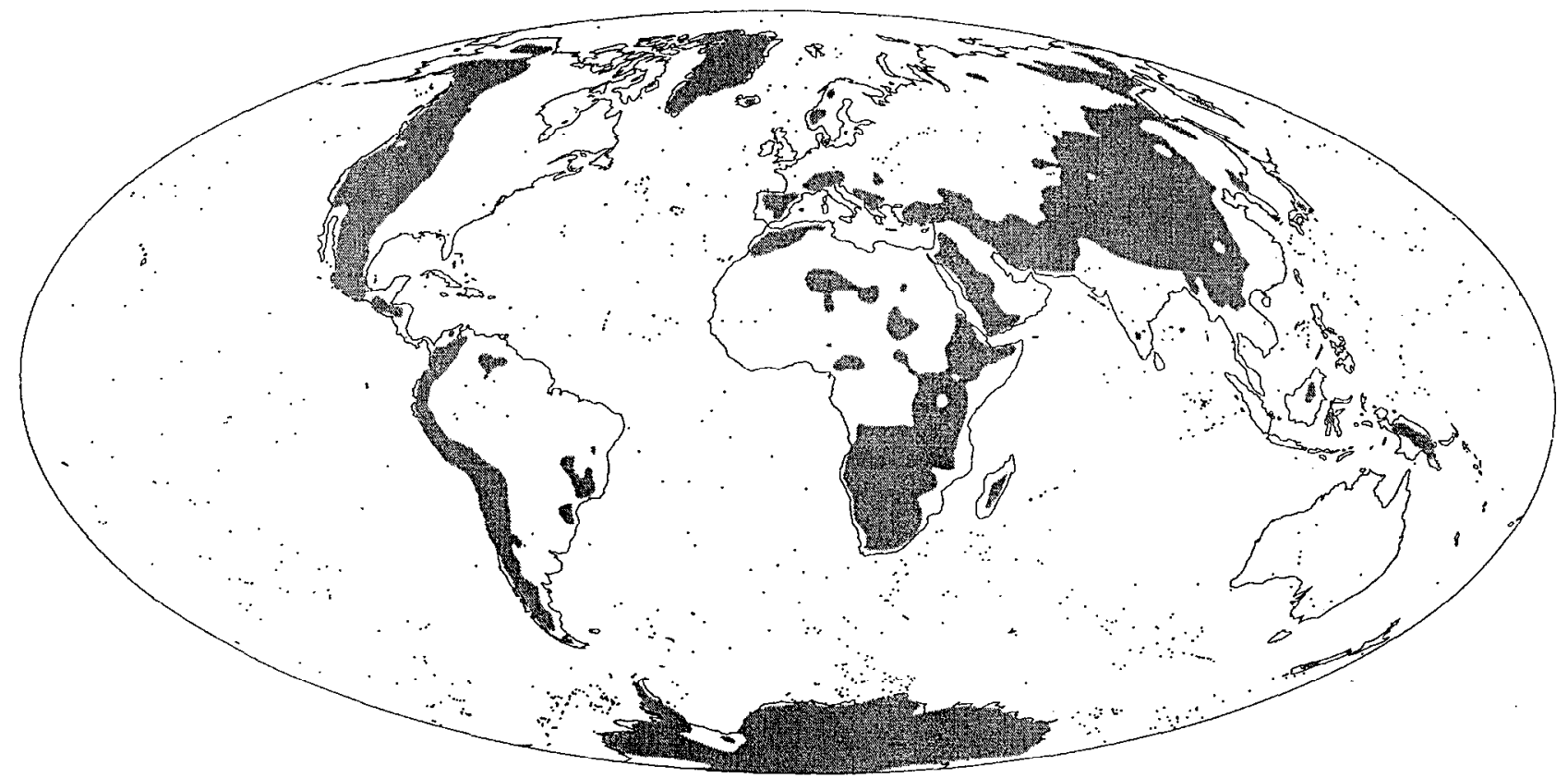

Figure 23. Location of balloons set for $925 \mathrm{mb} 47$ days after release as an initially uniform distribution. Terrain above $925 \mathrm{mb}$ is shaded in gray. 7257 balloons released, 1508 still aloft, 5749 hit terrain.

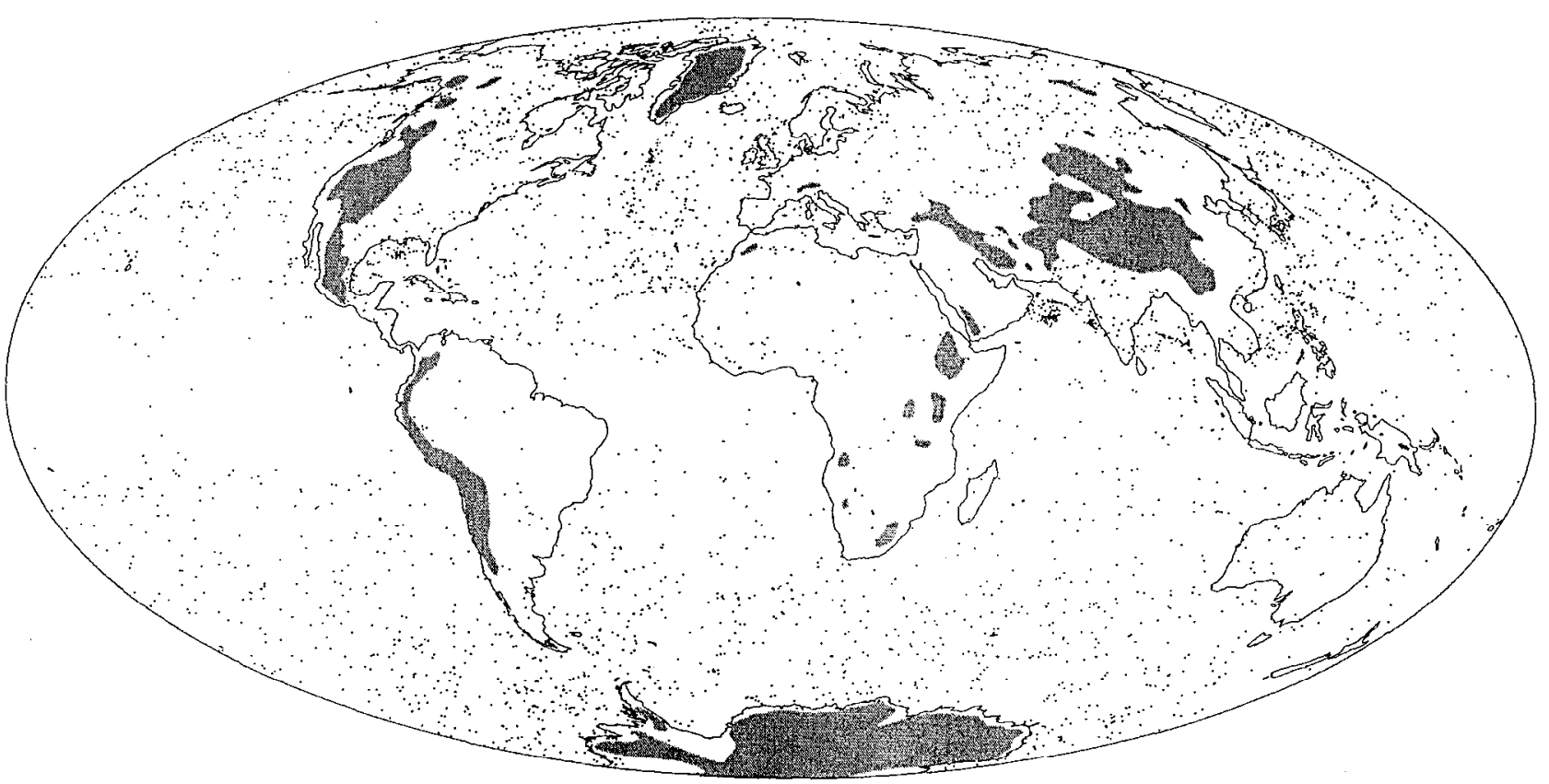

Figure 24. Location of balloons set for $850 \mathrm{mb} 47$ days after release as an initially uniform distribution. Terrain above $850 \mathrm{mb}$ is shaded in gray. 7739 balloons released, 3729 still aloft, 4010 hit terrain. 


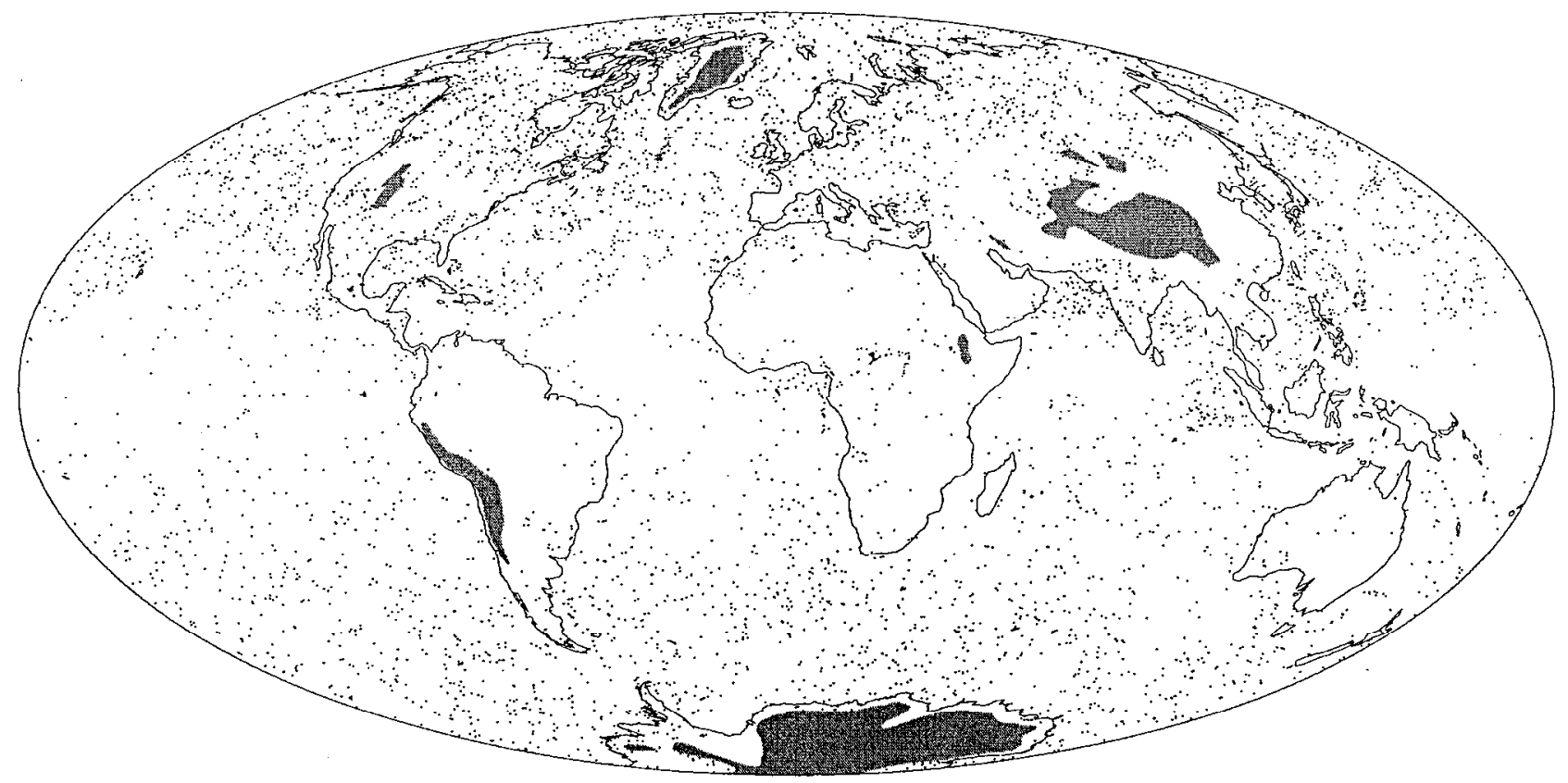

Figure 25. Location of balloons set for $775 \mathrm{mb} 47$ days after release as an initially uniform distribution. Terrain above $775 \mathrm{mb}$ is shaded in gray. 7933 balloons released, 5741 still aloft, 2192 hit terrain.

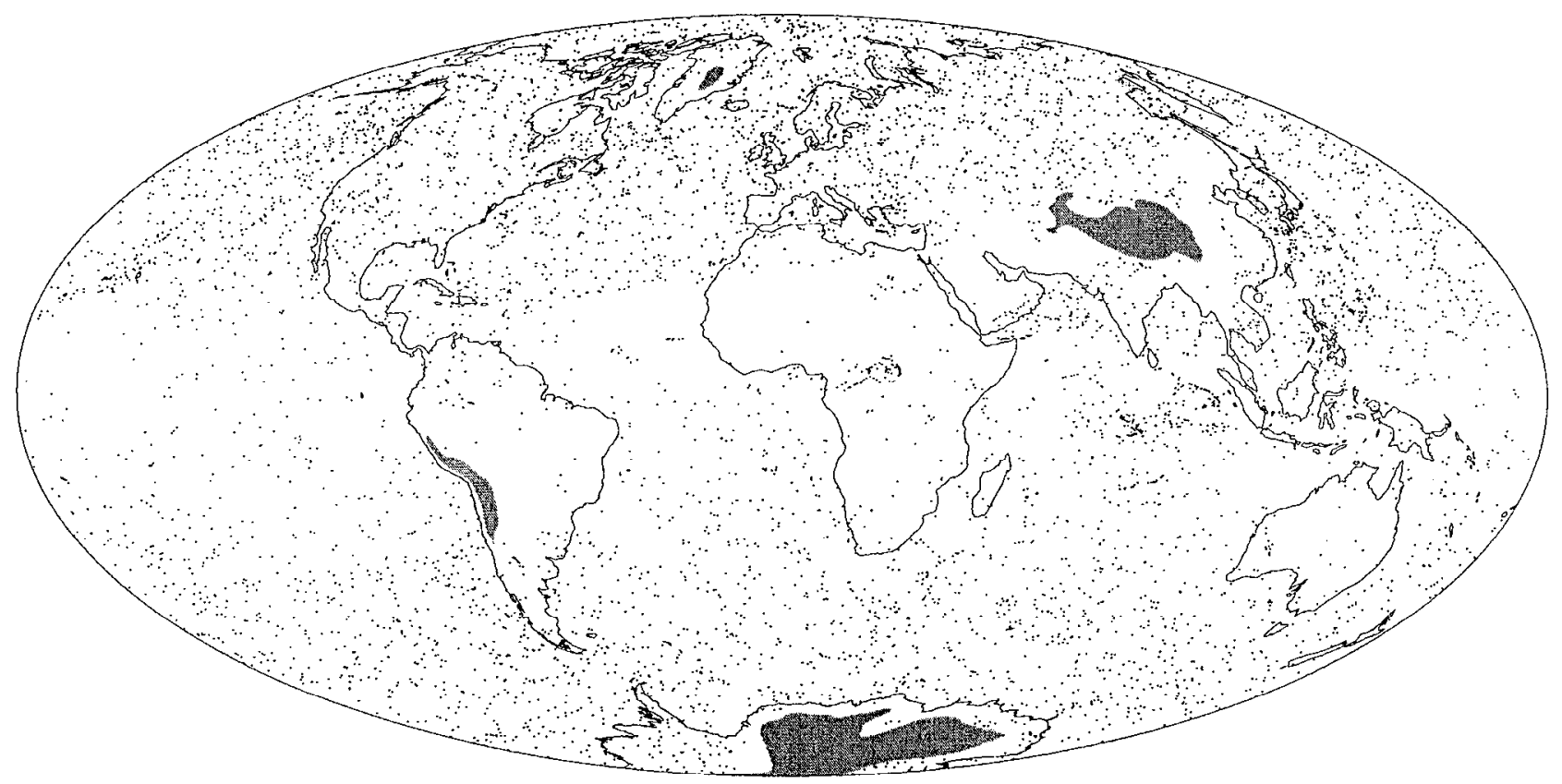

Figure 26. Location of balloons set for $700 \mathrm{mb} 47$ days after release as an initially uniform distribution. Terrain above $700 \mathrm{mb}$ is shaded in gray. 8030 balloons released, 6771 still aloft, 1259 hit terrain. 


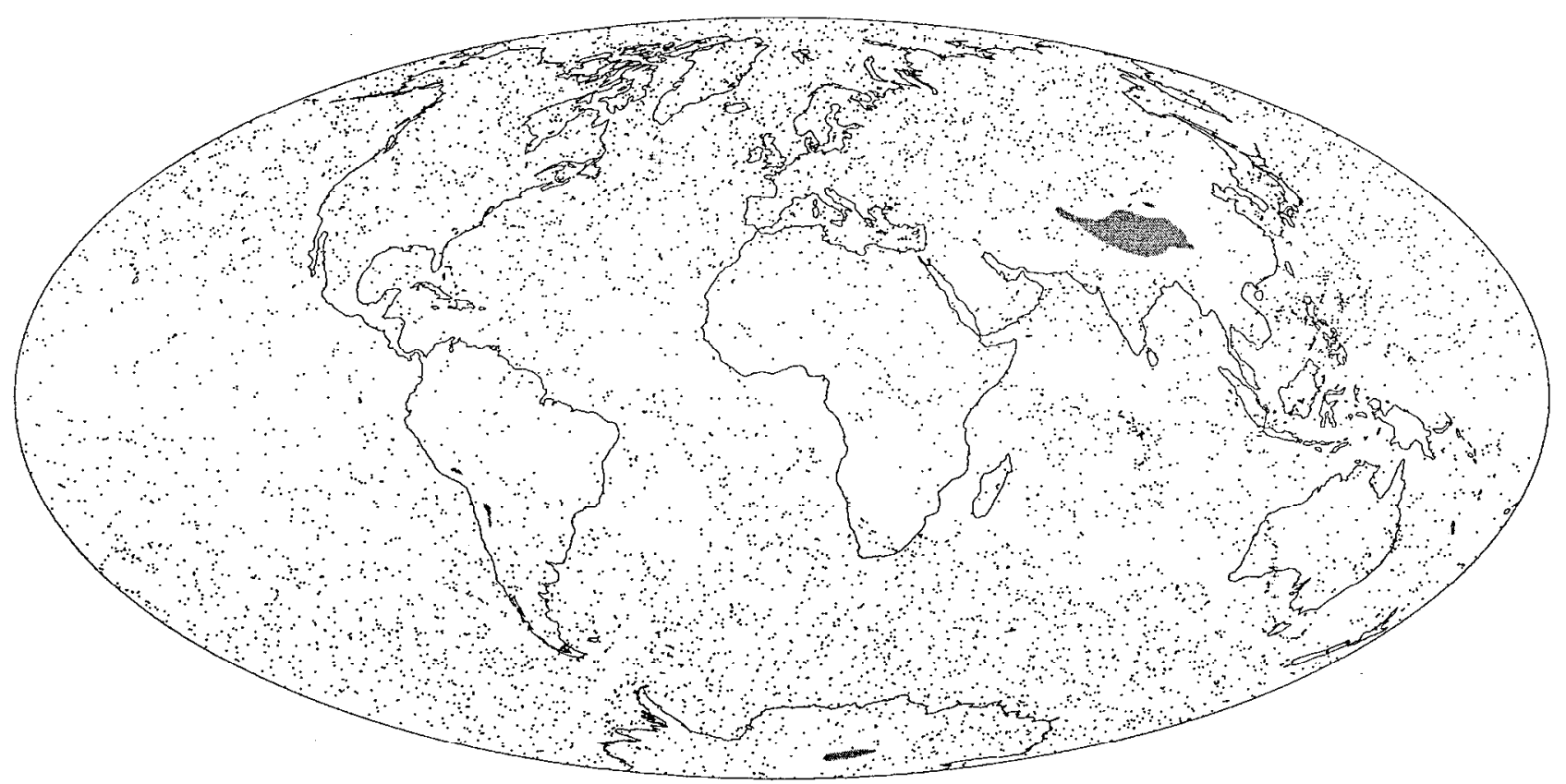

Figure 27. Location of balloons set for $600 \mathrm{mb} 47$ days after release as an initially uniform distribution. Terrain above $600 \mathrm{mb}$ is shaded in gray. 8157 balloons released, 7650 still aloft, 507 hit terrain.

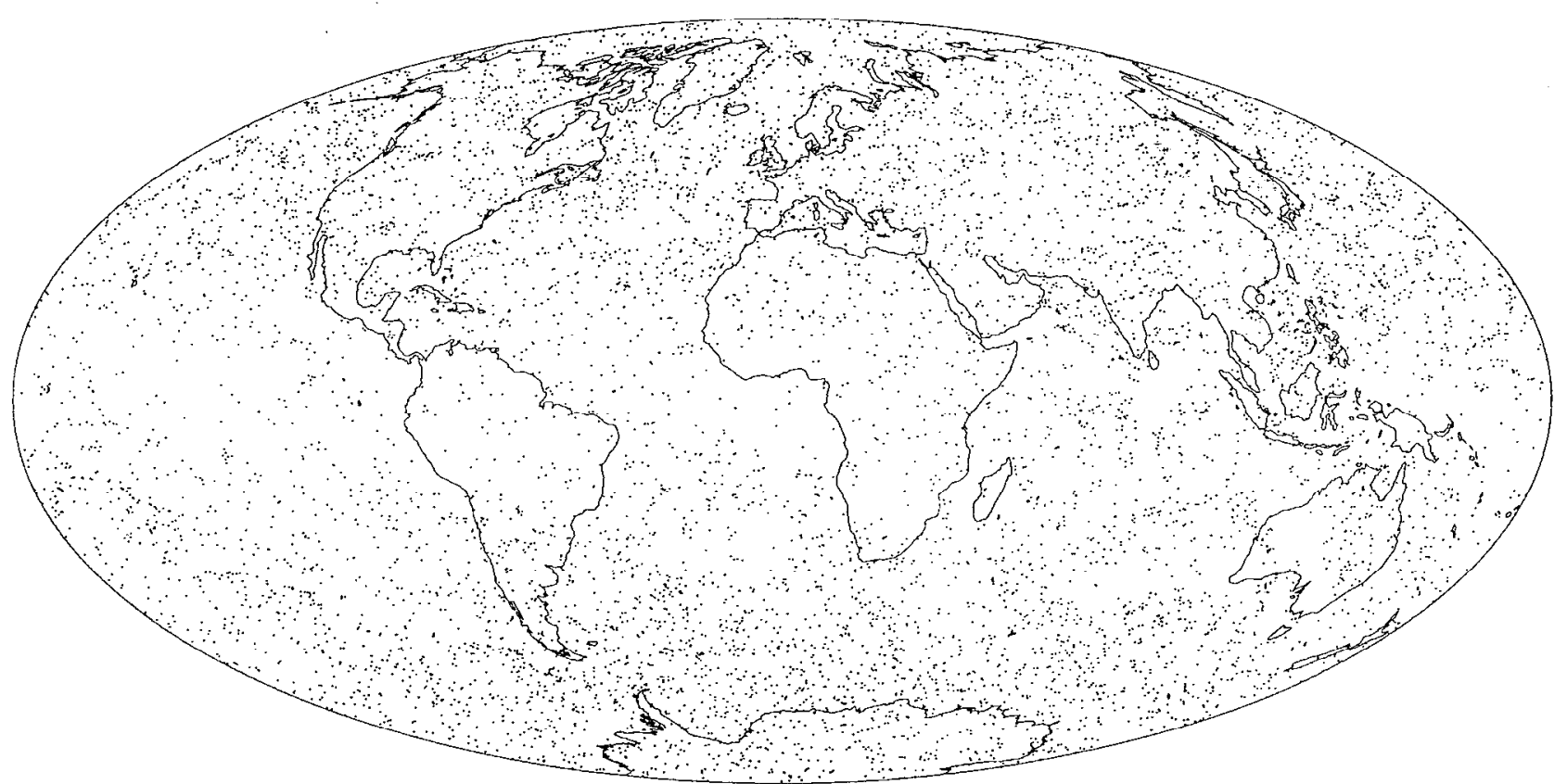

Figure 28. Location of balloons set for $500 \mathrm{mb} 47$ days after release as an initially uniform distribution. 8192 balloons released and still aloft. 


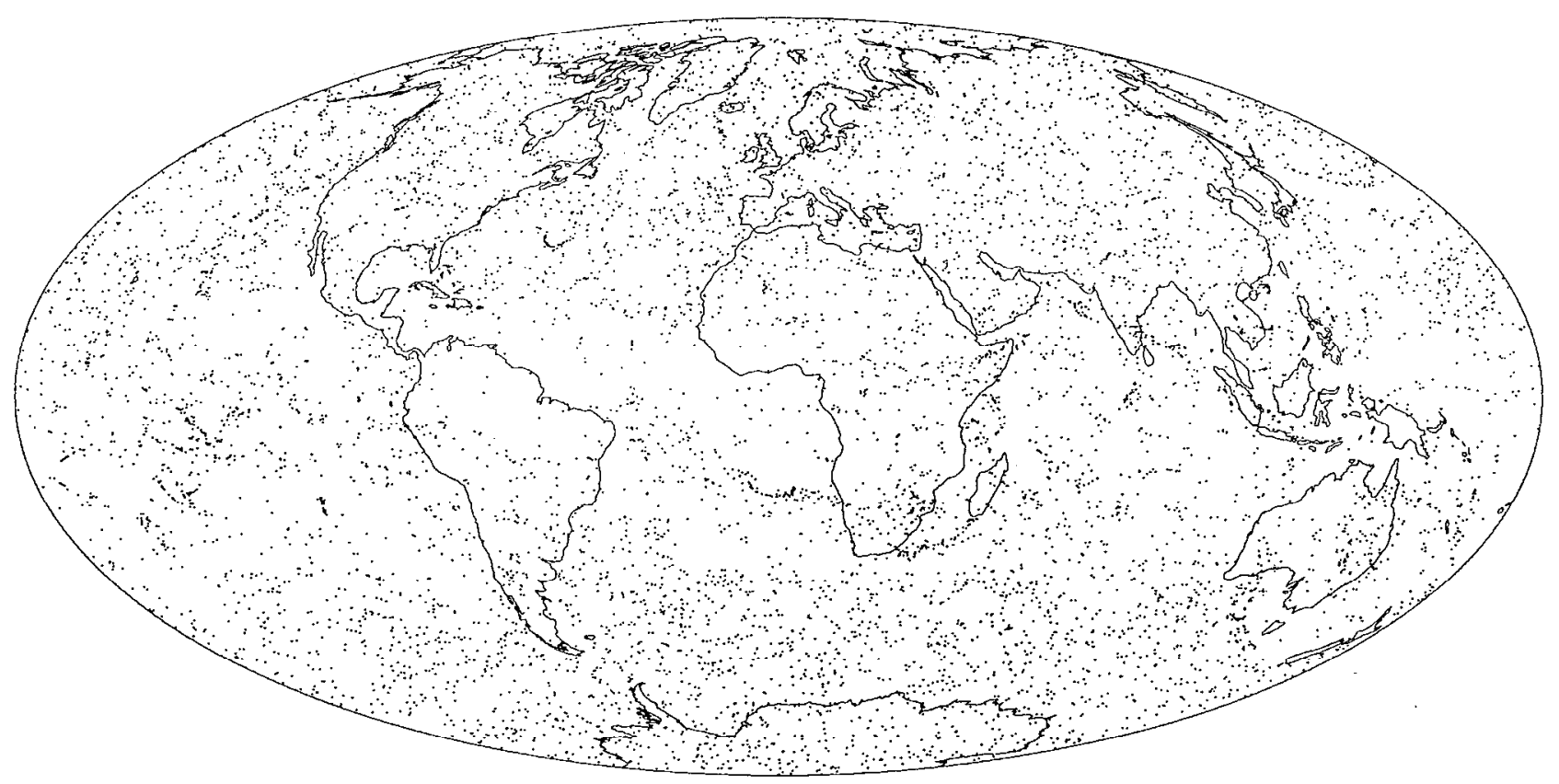

Figure 29. Location of balloons set for $400 \mathrm{mb} 47$ days after release as an initially uniform distribution. 8192 balloons released and still aloft.

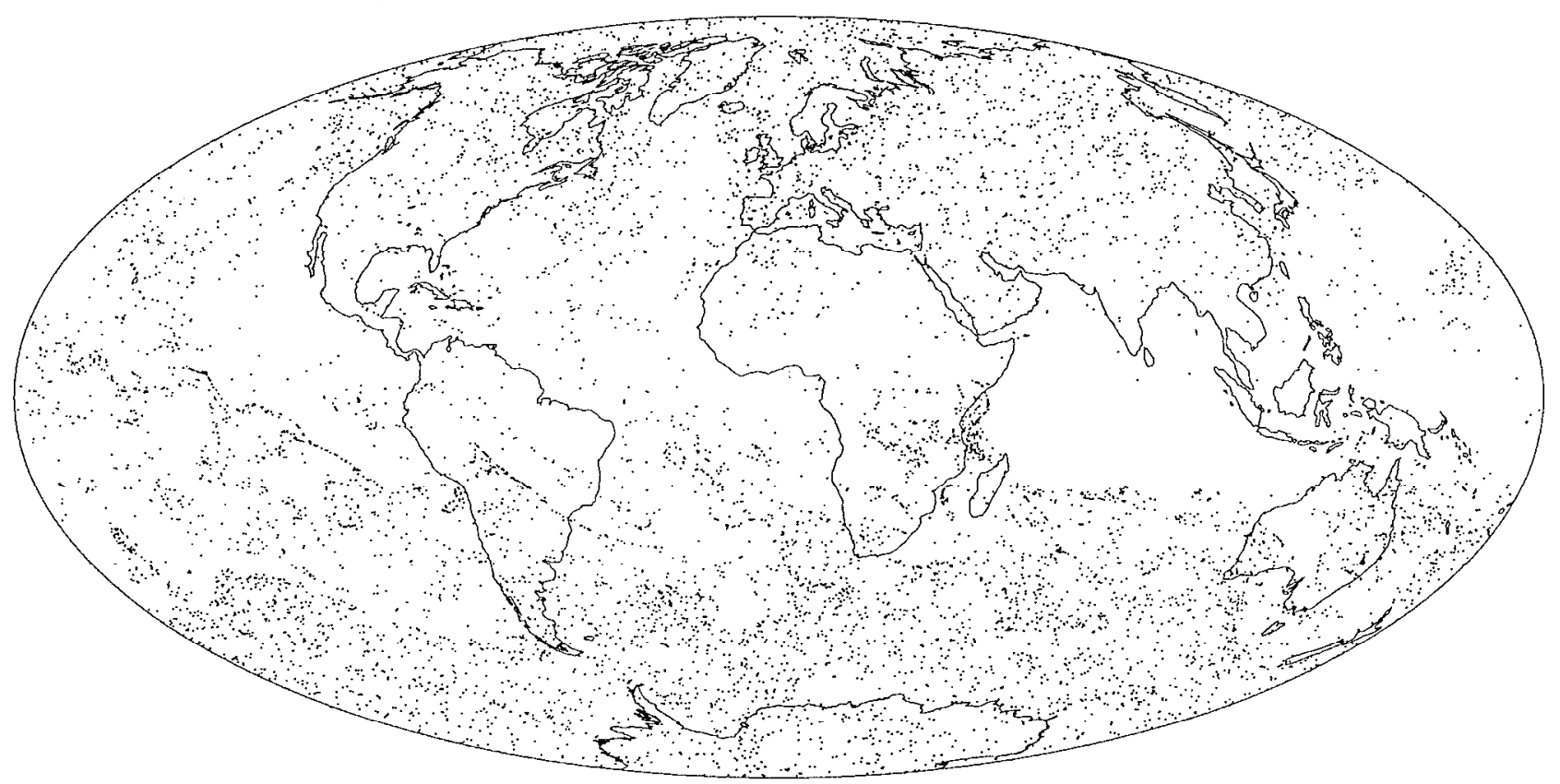

Figure 30. Location of balloons set for $300 \mathrm{mb} 47$ days after release as an initially uniform distribution. 8192 balloons released and still aloft. 


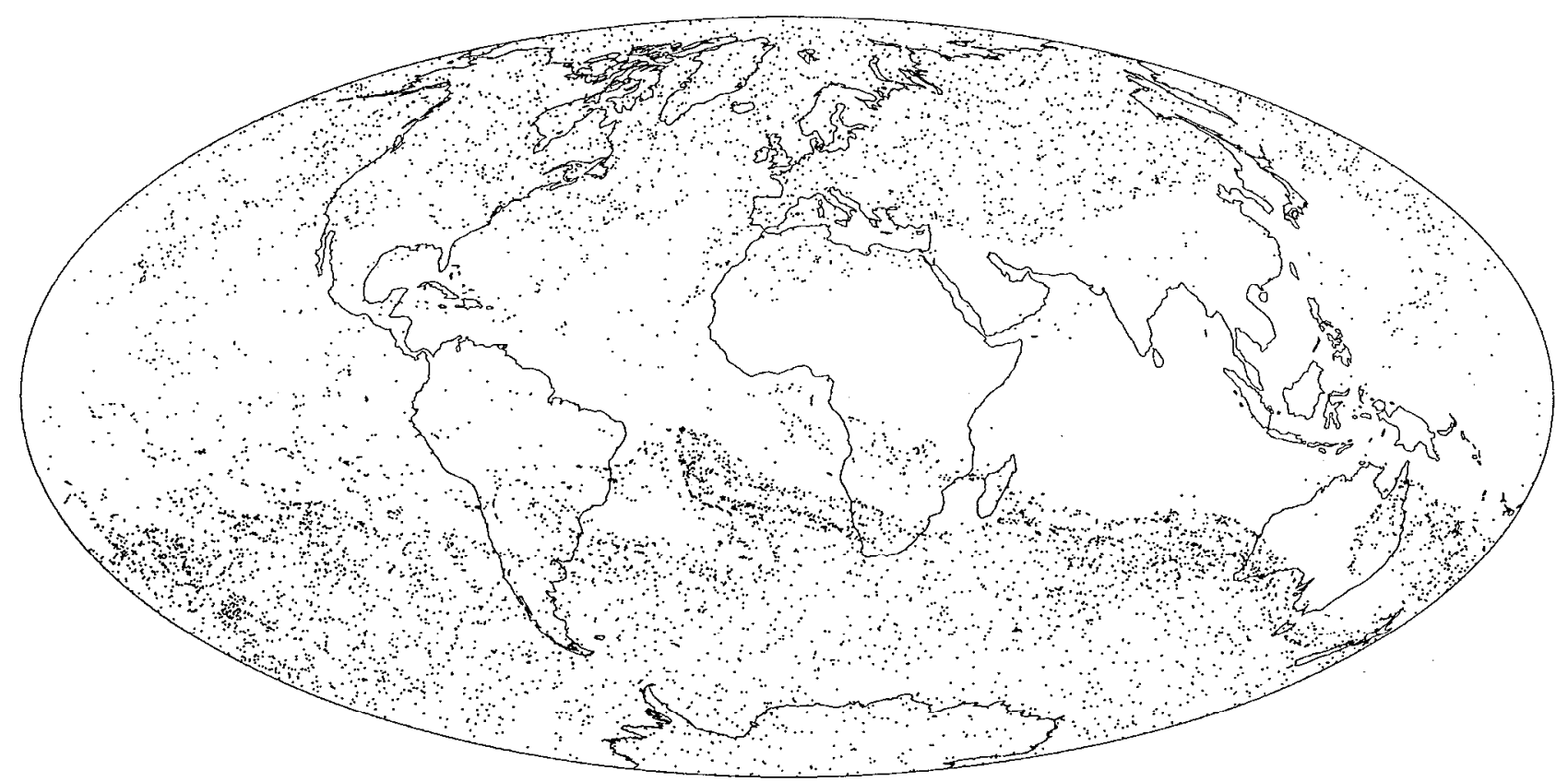

Figure 31. Location of balloons set for $200 \mathrm{mb} 47$ days after release as an initially uniform distribution. 8192 balloons released and still aloft.

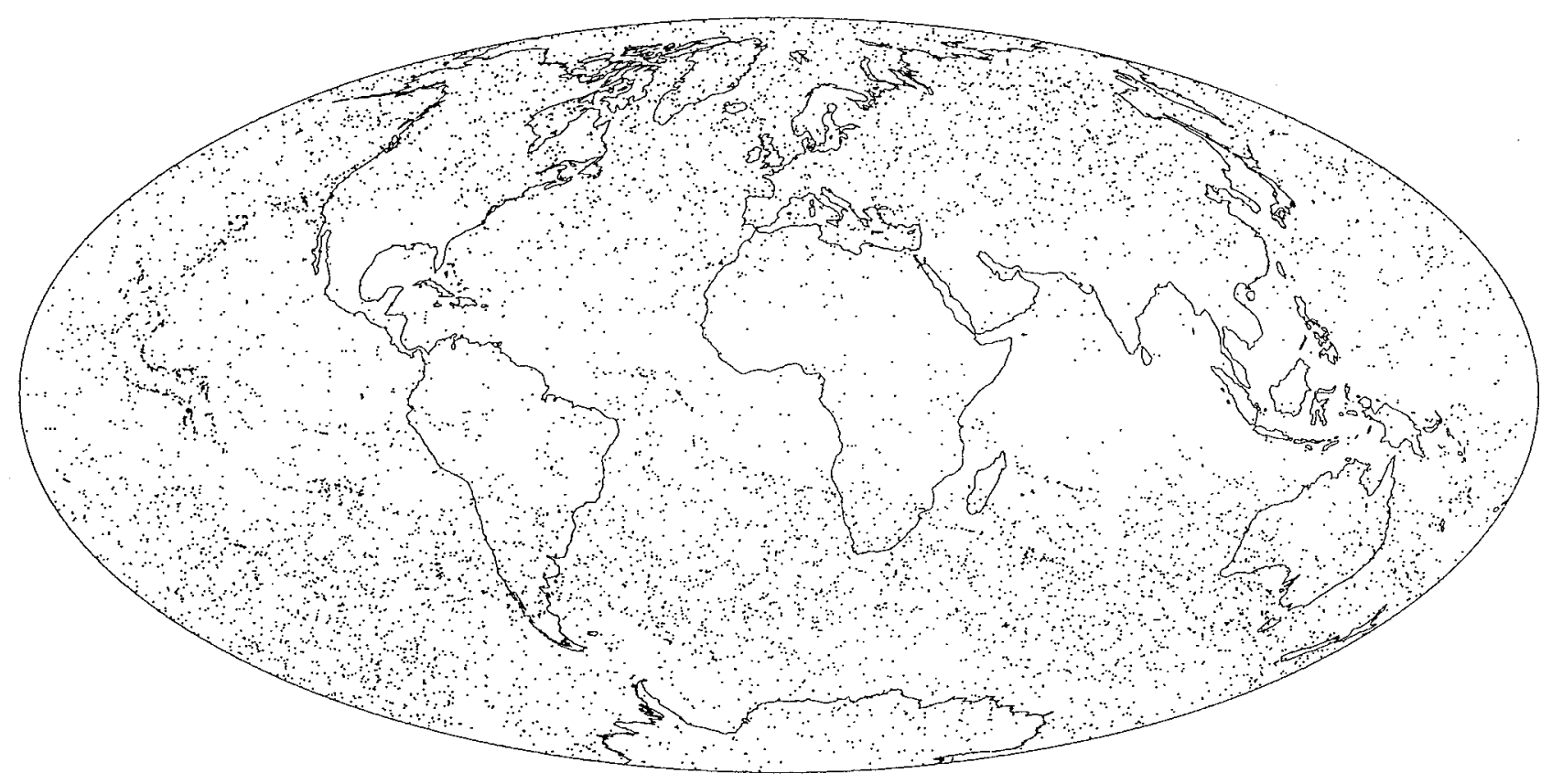

Figure 32. Location of balloons set for $100 \mathrm{mb} 47$ days after release as an initially uniform distribution. 8192 balloons released and still aloft. 
run almost the entire length of South America in Figure 13 while they cover only the middle half of the continent in Figure 3, and the Zagros Mountains extend from the Persian Gulf in Iran to Turkey in Figure 14 while they are completely missing in Figure 4. Comparison of the balloon release and aloft data in Table 3 reveals that the higher terrain in the NOGAPS simulation causes a small decrease in the number of balloons released and a greatly enhanced attrition rate due to terrain collisions. After 47 days at a floating-level pressure of $925 \mathrm{mb}$ only 1508 balloons are still aloft; clearly low level transponders must be replaced often.

The main conclusions of the CCM3/GRANTOIJR simulation are confirmed by this calculation. At $925 \mathrm{mb}$ the coverage is very poor. Over 70 per cent of the released balloons have becn lost by collisions with terrain. In addition convergence/divergence patterns in the flow produce small areas and lines with very many balloons, clusters, and ribbons, and vast areas with almost no balloons. Comparison of the 35 day and 47 day locations illustrate the movement of these clusters and ribbons from day to day. At $850 \mathrm{mb}$ the coverage is much better, and balloons remain spread over much of the globe. However, regions downwind of the mountains and some tropical areas have sparse coverage. The global distribution at mid-troposphere levels is quite good, especially at 600, 500, and $400 \mathrm{mb}$; however, there are some sparse areas in the tropics. Top of the troposphere divergence produces large areas in the tropics with very few balloons. These sparse areas terminate sharply, particularly in the southern hemisphere, along a line where balloon density is high, and this boundary meanders with time.

Comparison of Figures 13-22 at 35 days with Figures 23-32 at 47 days reveals little worsening in the global balloon distributions except the additional loss of balloons via terrain collisions, i.e., most of the deterioration occurred earlier. Early temporal decay of the initially uniform distribution is shown by the balloon location plots for days $1,2,3,4,5,7,10$, and 15 at $850 \mathrm{mb}$ in Figures 33-40 and at $200 \mathrm{mb}$ in Figures 41-48. By two or three days any sense of regularity in the release pattern has disappeared. Within one week one sees significant regions where balloons have collected and where they have left. By two weeks the main features and deficiencies noted at the end of the runs are already evident. The rate at which upper level $(200 \mathrm{mb})$ balloons leave the tropical Indian Ocean area is amazing; this charactcristic shows up for both CCM3 and NOGAPS winds.

\section{Vertical Sounding Coverage}

While the three-dimensional spacing of transponders is the primary issue, an additional question is the feasibility of measuring atmospheric vertical profiles of wind and temperature at enough points to provide input for NWP's. This has particular relevance to early deployment of a degraded transponder network to provide input to current NWP's which have much better capabilities for assimilating column or sounding data than randomly spaced observations. This question can be addressed by dividing the atmosphere into uniform vertical columns and then counting the number of floating-level layers within each column that contain at least one balloon. By selecting a column size correlated with a NWP's horizontal resolution and assuming some minimum number of occupied vertical layers for an adequate sounding, one can estimate the 


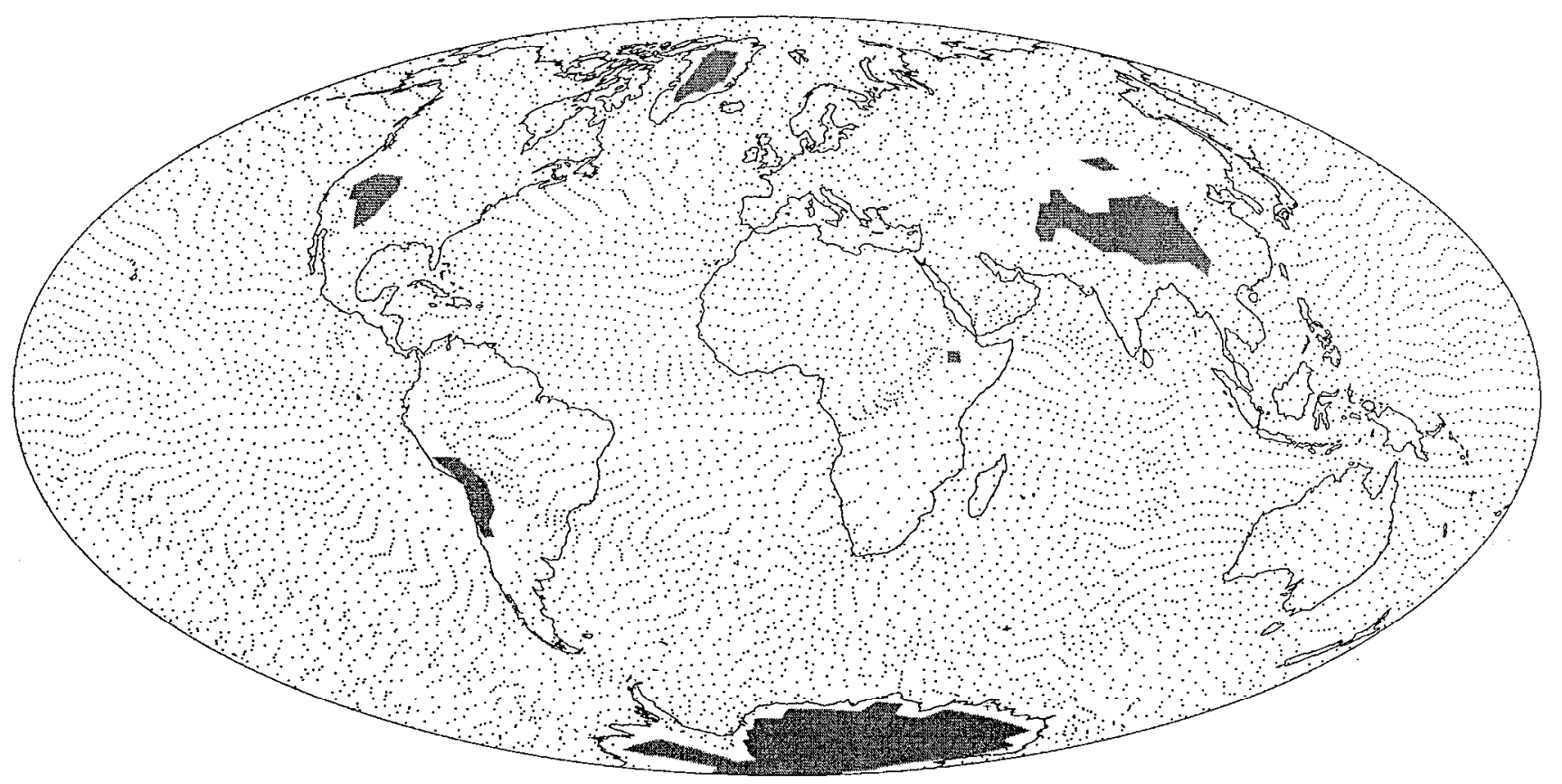

Figure 33. Location of balloons set for $850 \mathrm{mb} 1$ day after release as an initially uniform distribution. Terrain above $850 \mathrm{mb}$ is shaded in gray. 7862 balloons released, 7791 still aloft, 71 hit terrain.

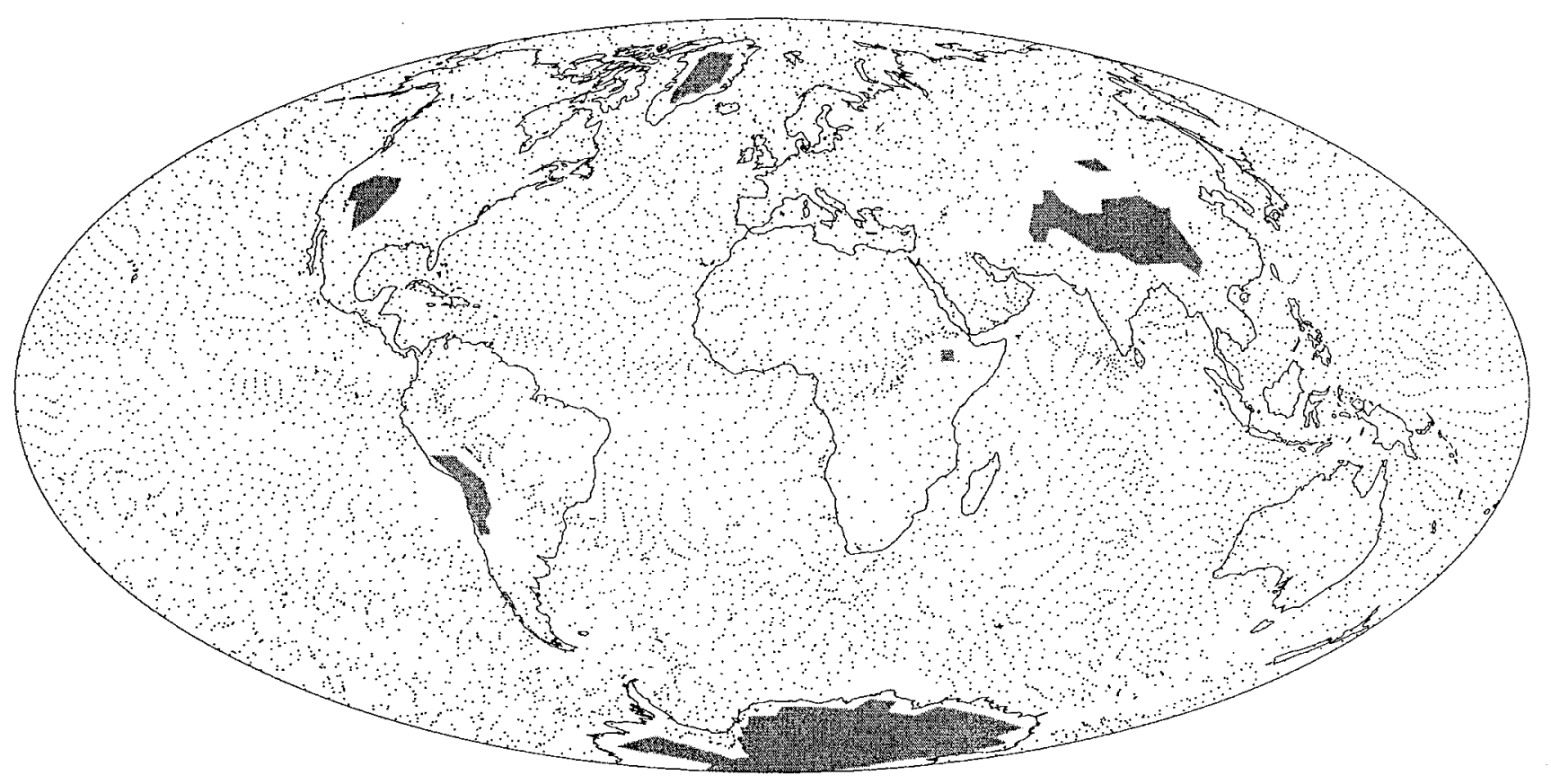

Figure 34. Location of balloons set for $850 \mathrm{mb} 2$ days after release as an initially uniform distribution. Terrain above $850 \mathrm{mb}$ is shaded gray. 7862 balloons released, 7729 still aloft, 133 hit terrain. 


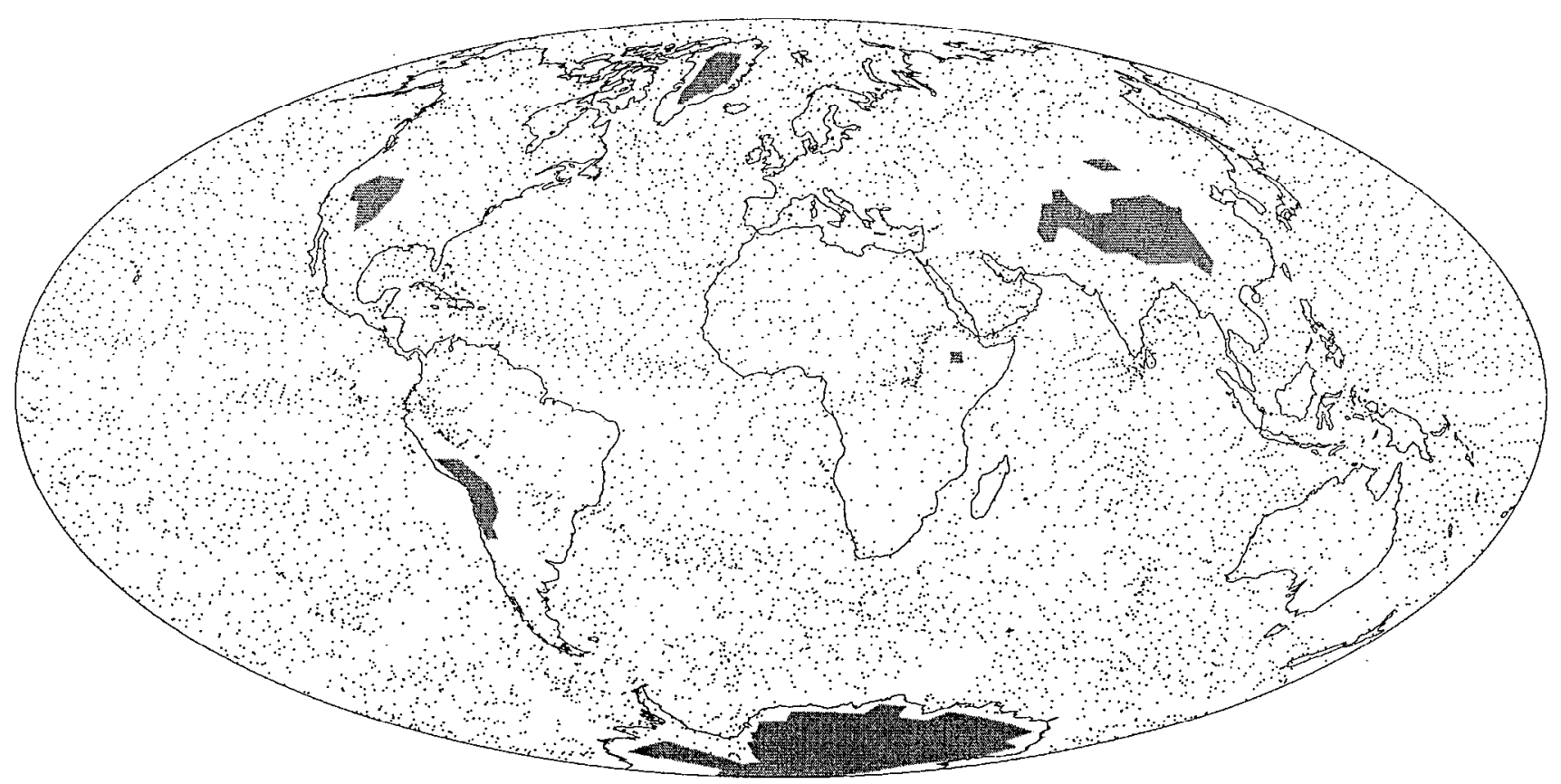

Figure 35. Location of balloons set for $850 \mathrm{mb} 3$ days after release as an initially uniform distribution. Terrain above $850 \mathrm{mb}$ is shaded gray. 7862 balloons released, 7676 still aloft, 186 hit terrain.

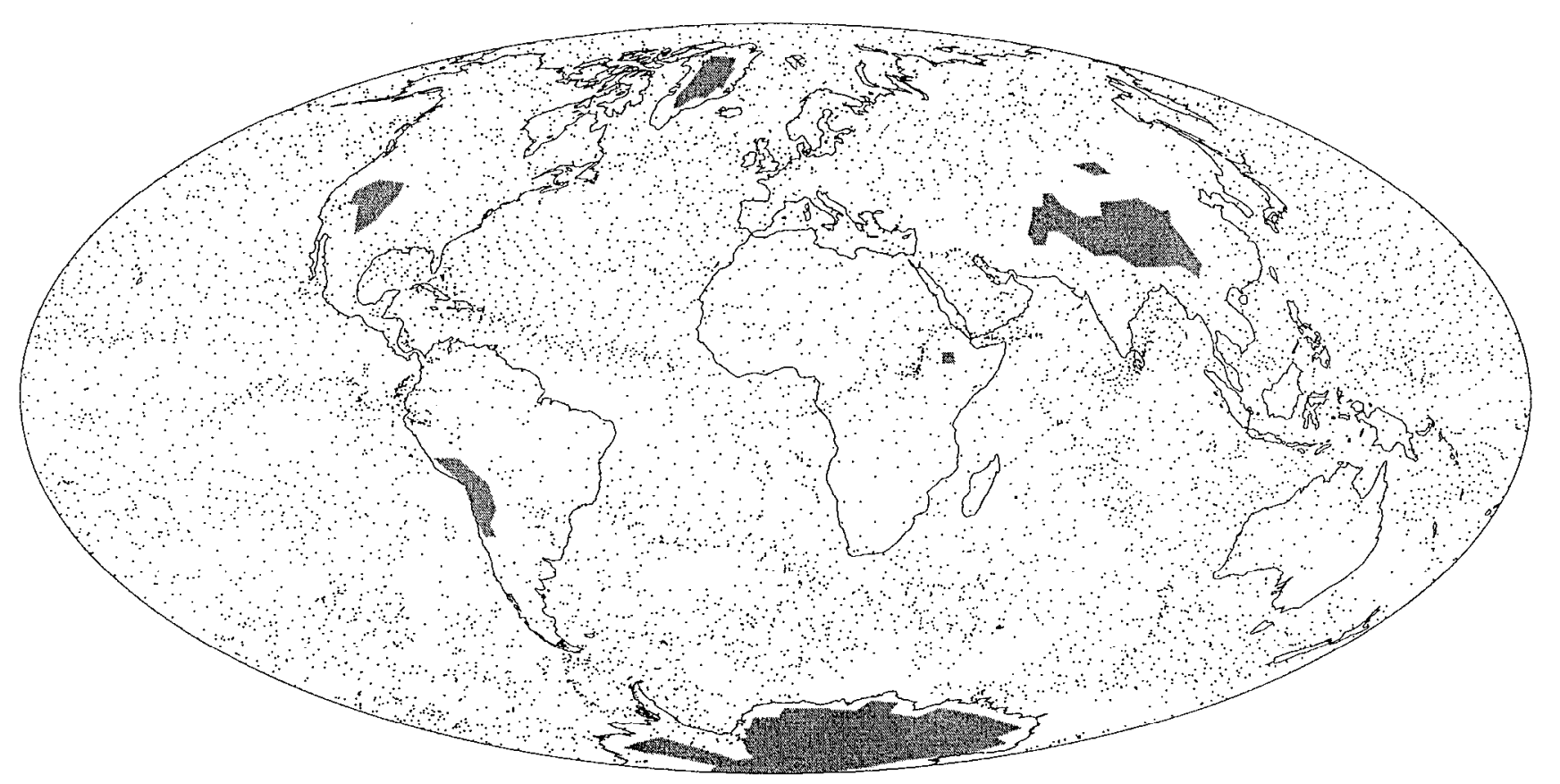

Figure 36. Location of balloons set for $850 \mathrm{mb} 4$ days after release as an initially uniform distribution. Terrain above $850 \mathrm{mb}$ is shaded gray. 7862 balloons released, 7651 still aloft, 211 hit terrain. 


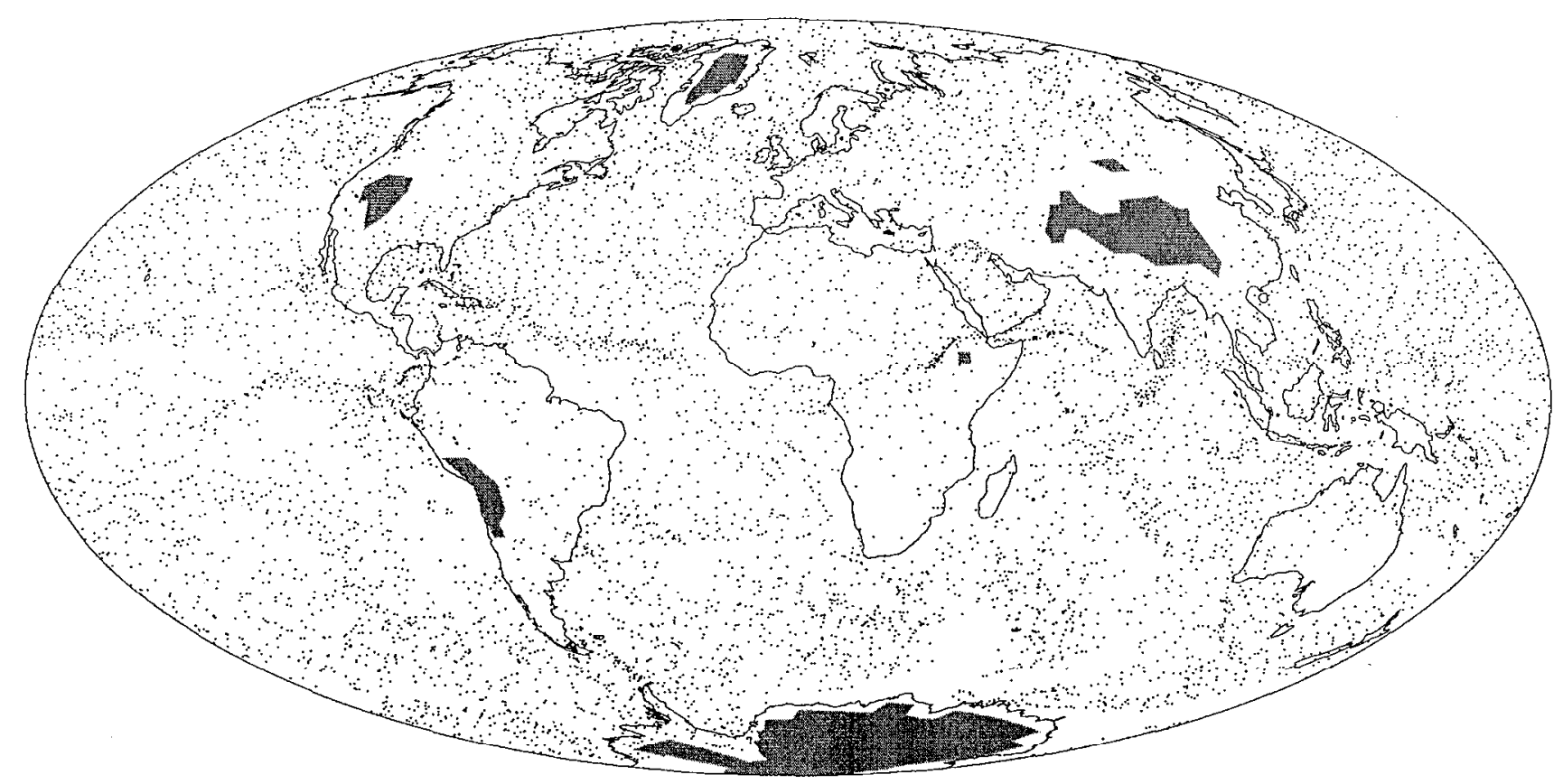

Figure 37. Location of balloons set for $850 \mathrm{mb} 5$ days after release as an initially uniform distribution. Terrain above $850 \mathrm{mb}$ is shaded in gray. 7862 balloons released, 7613 still aloft, 249 hit terrain.

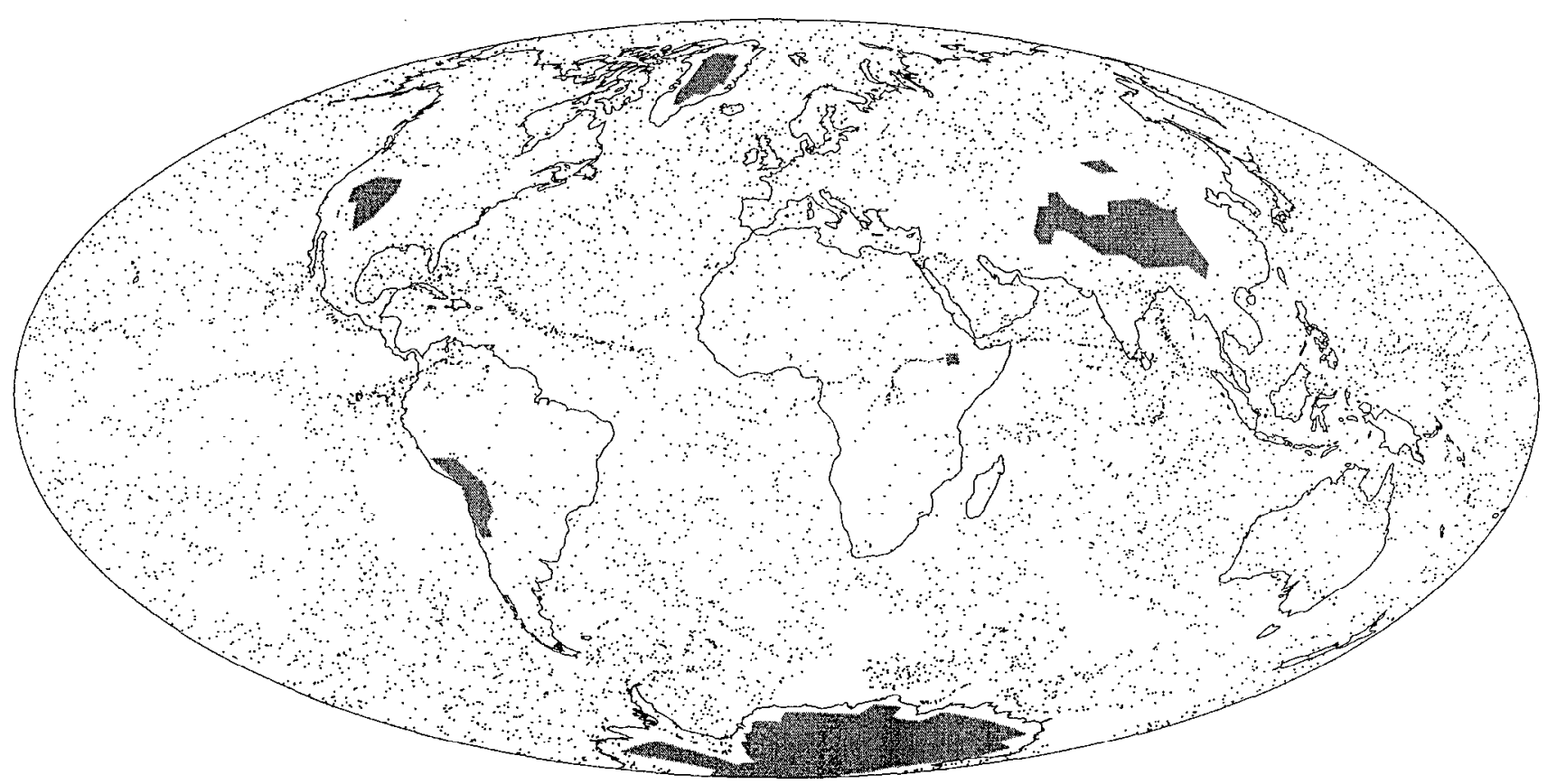

Figure 38. Location of balloons set for $850 \mathrm{mb} 7$ days after release as an initially uniform distribution. Terrain above $850 \mathrm{mb}$ is shaded in gray. 7862 balloons released, 7533 still aloft, 329 hit terrain. 


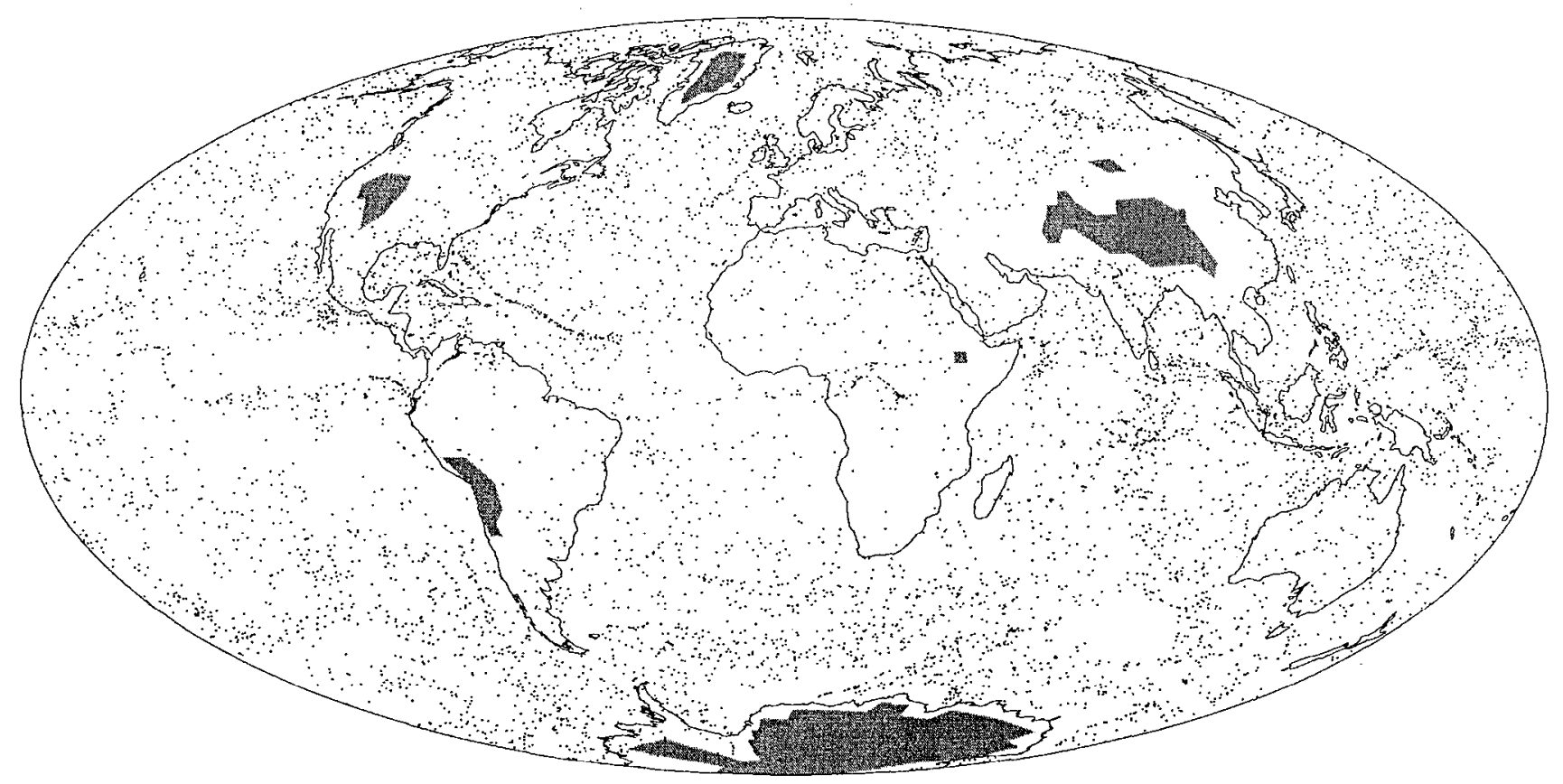

Figure 39.Location of balloons set for $850 \mathrm{mb} 10$ days after release as an initially uniform distribution. Terrain above $850 \mathrm{mb}$ is shaded in gray. 7862 balloons released, 7383 still aloft, 479 hit terrain.

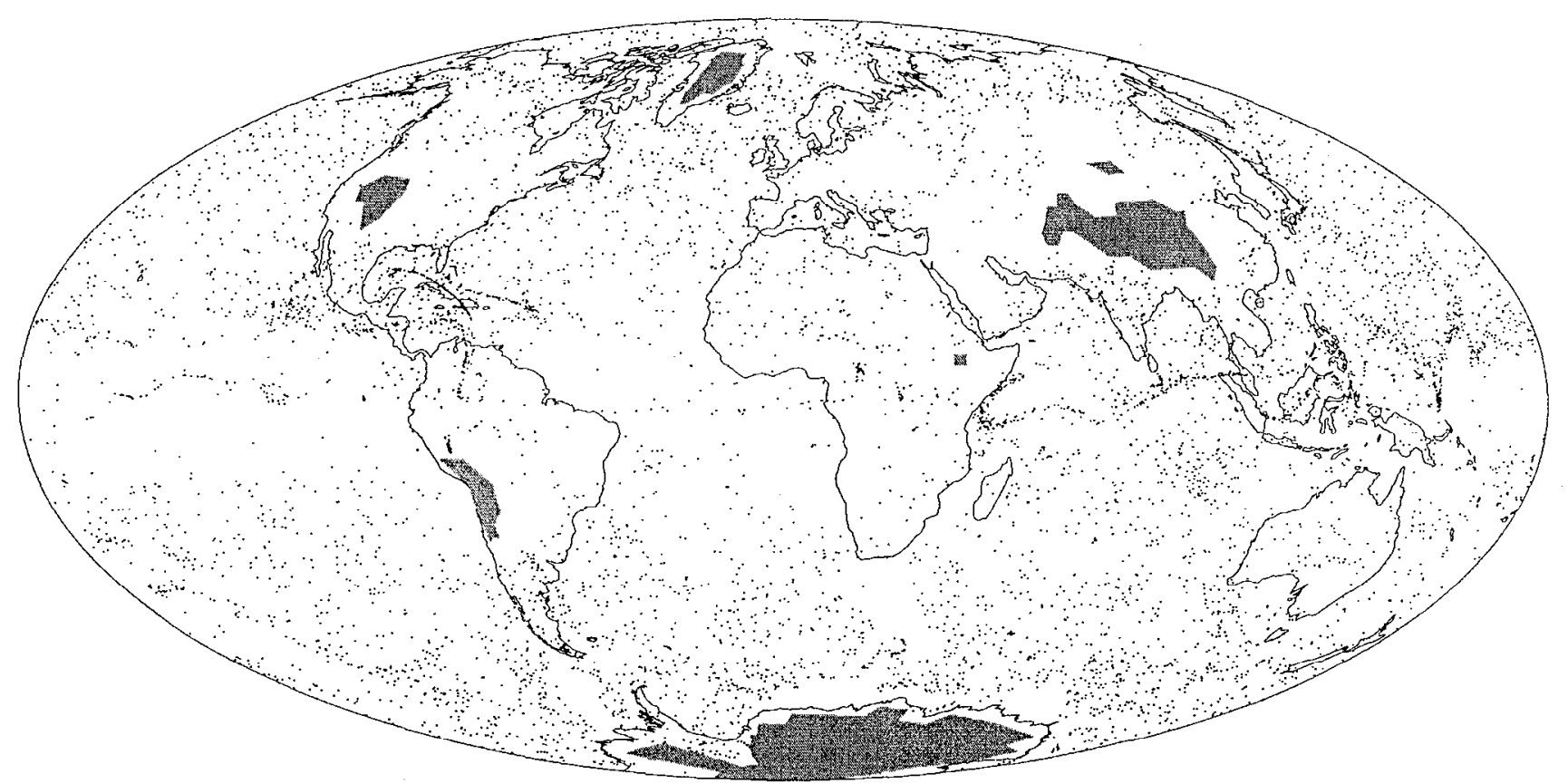

Figure 40. Location of balloons set for $850 \mathrm{mb} 15$ days after release as an initially uniform distribution. Terrain above $850 \mathrm{mb}$ is shaded in gray. 7862 balloons released, 7241 still aloft, 621 hit terrain. 


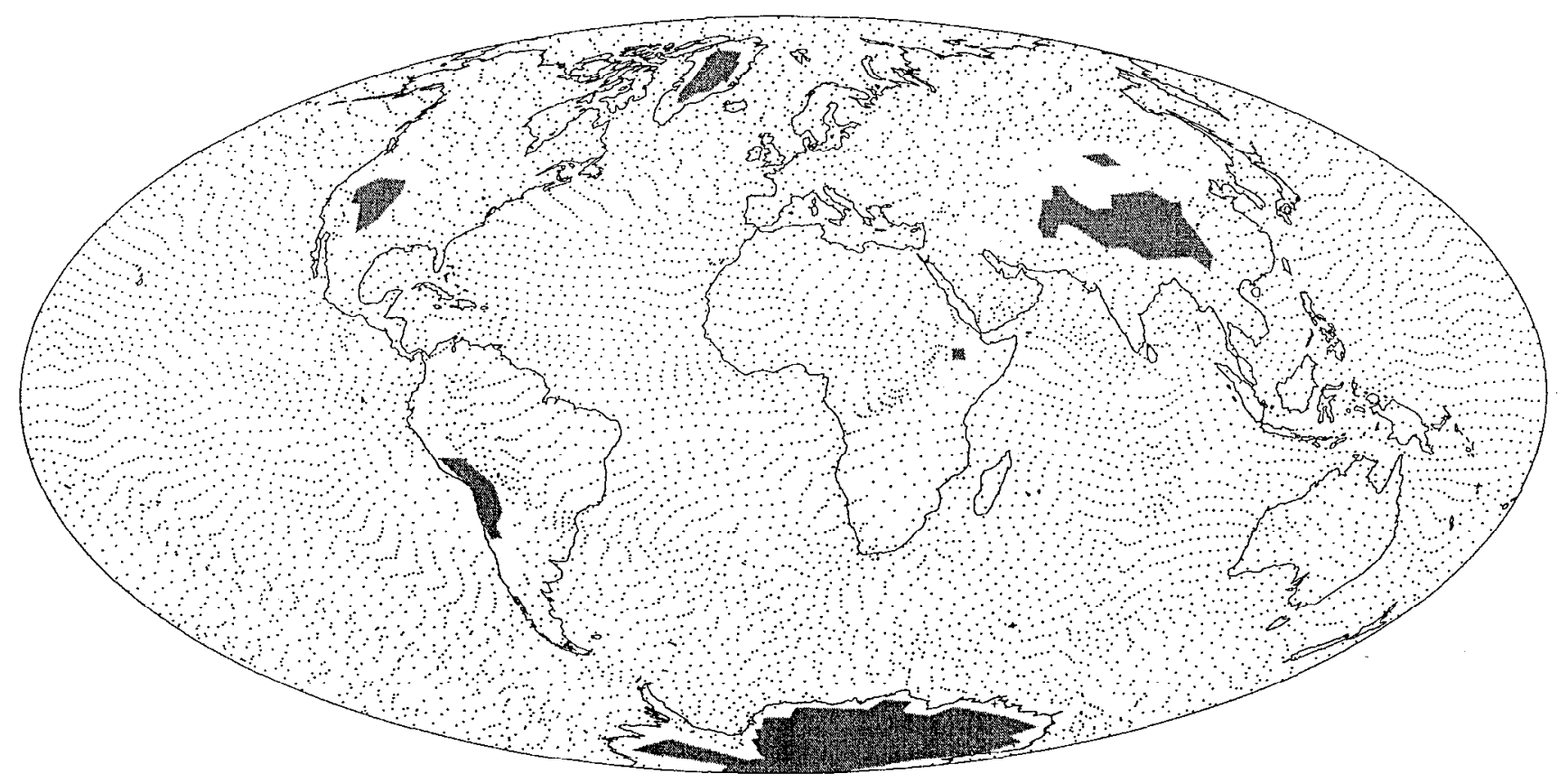

Figure 41. Location of balloons set for $850 \mathrm{mb} 1$ day after release as an initially uniform distribution. Terrain above $850 \mathrm{mb}$ is shaded in gray. 7862 balloons released, 7791 still aloft, 71 hit terrain.

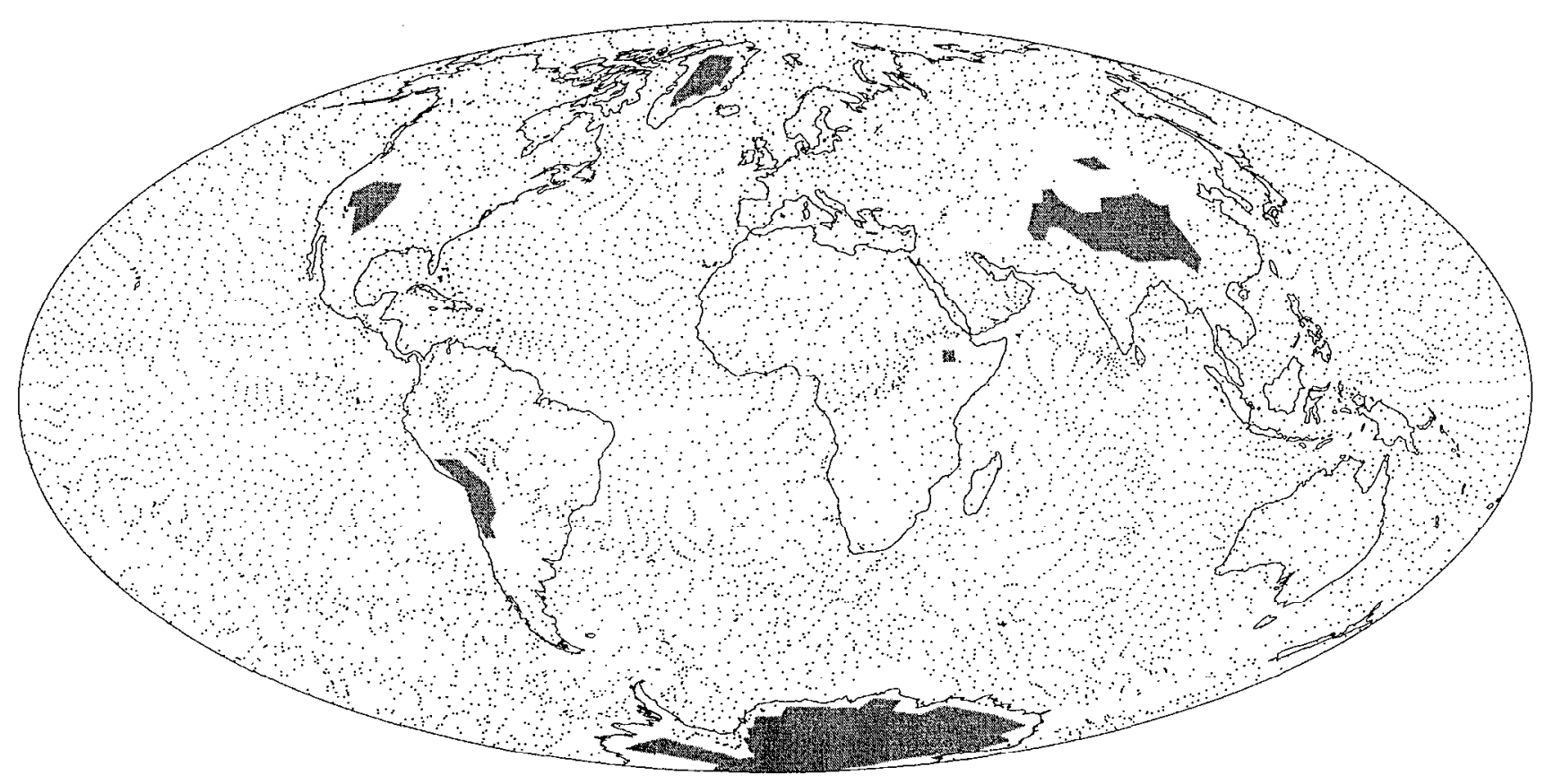

Figure 42. Location of balloons set for $850 \mathrm{mb} 2$ days after release as an initially uniform distribution. Terrain above $850 \mathrm{mb}$ is shaded gray. 7862 balloons released, 7729 still aloft, 133 hit terrain. 


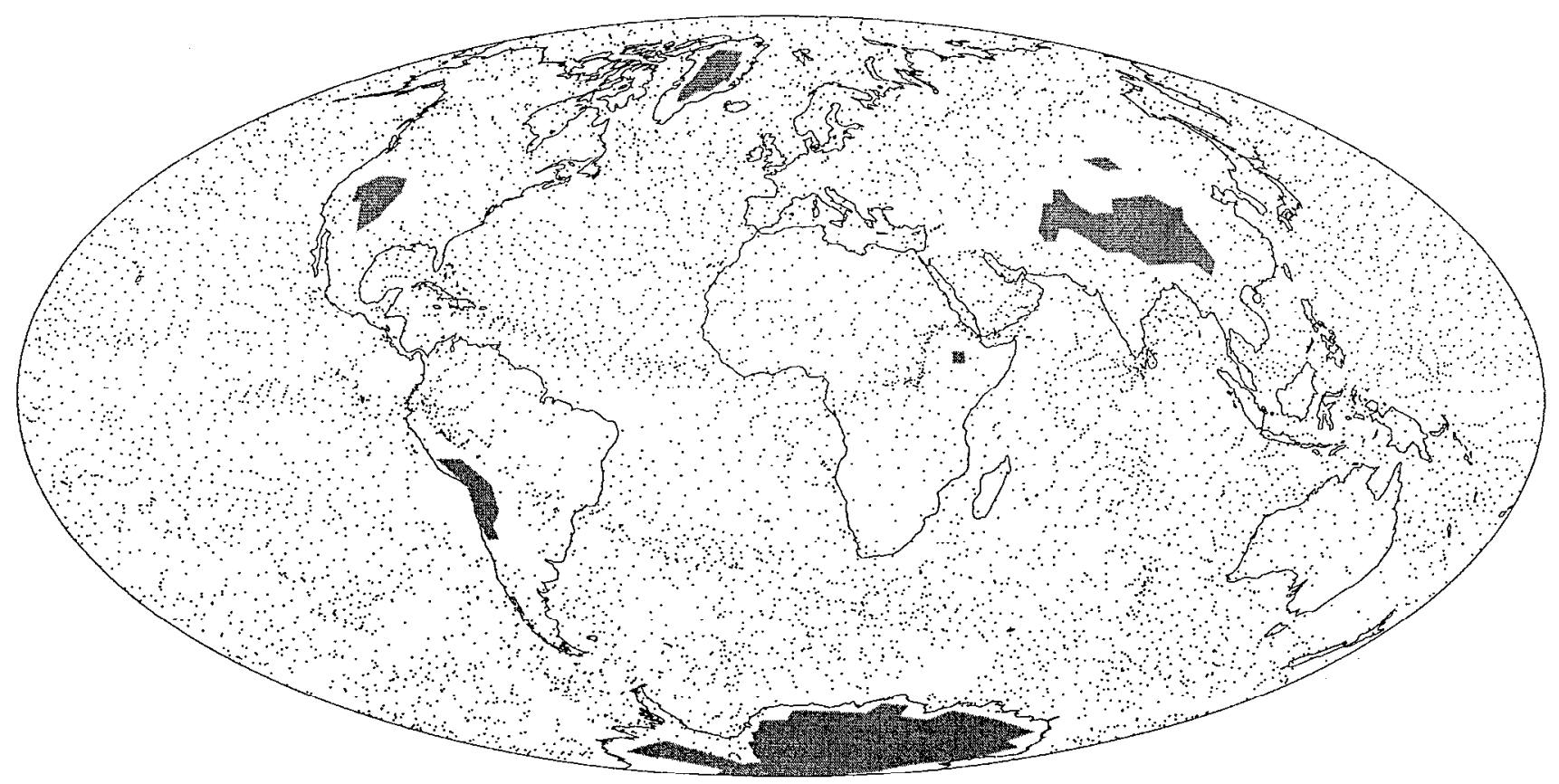

Figure 43. Location of balloons set for $850 \mathrm{mb} 3$ days after release as an initially uniform distribution. Terrain above $850 \mathrm{mb}$ is shaded gray. 7862 balloons released, 7676 still aloft, 186 hit terrain.

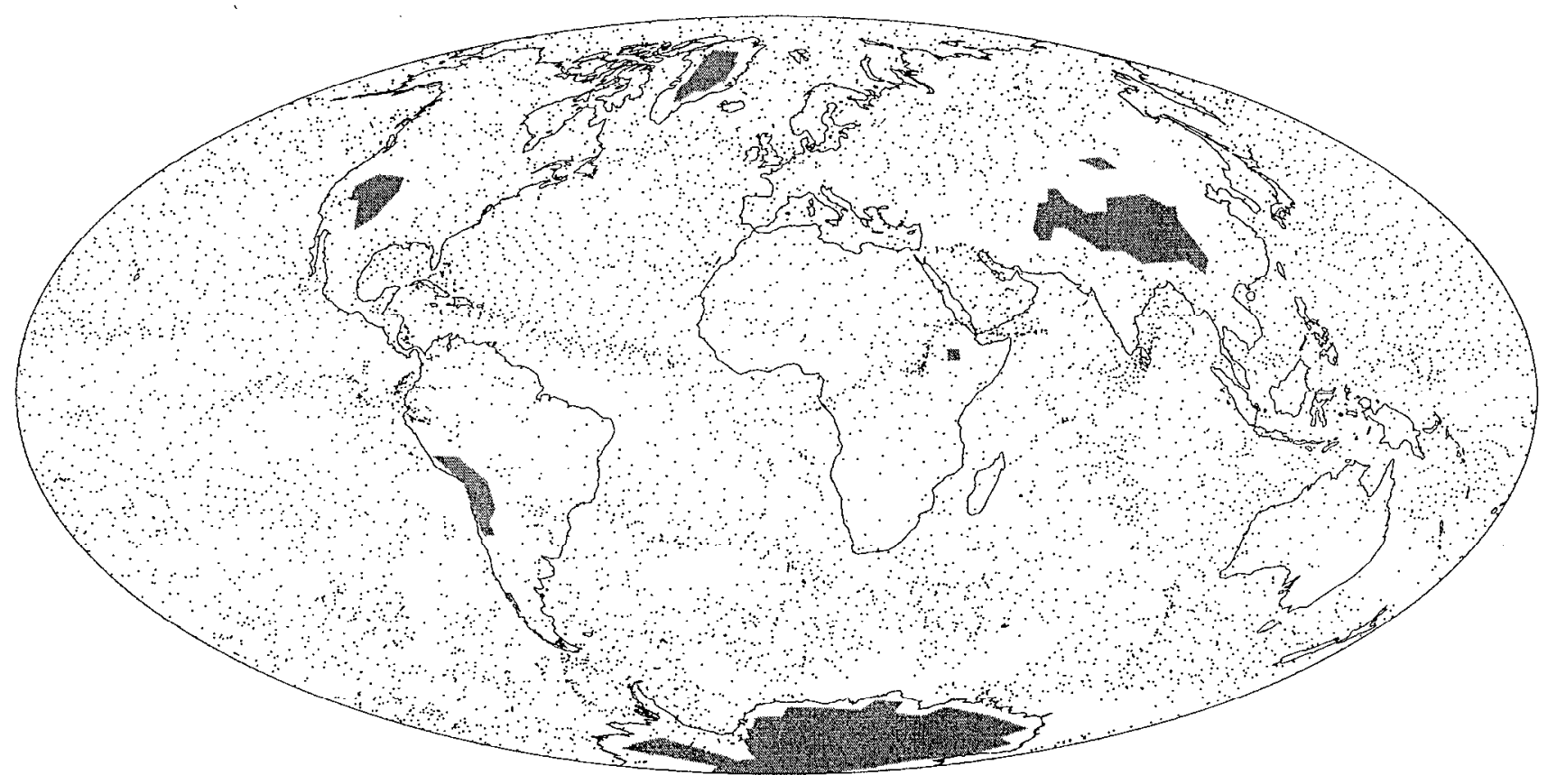

Figure 44. Location of balloons set for $850 \mathrm{mb} 4$ days after release as an initially uniform distribution. Terrain above $850 \mathrm{mb}$ is shaded gray. 7862 balloons released, 7651 still aloft, 211 hit terrain. 


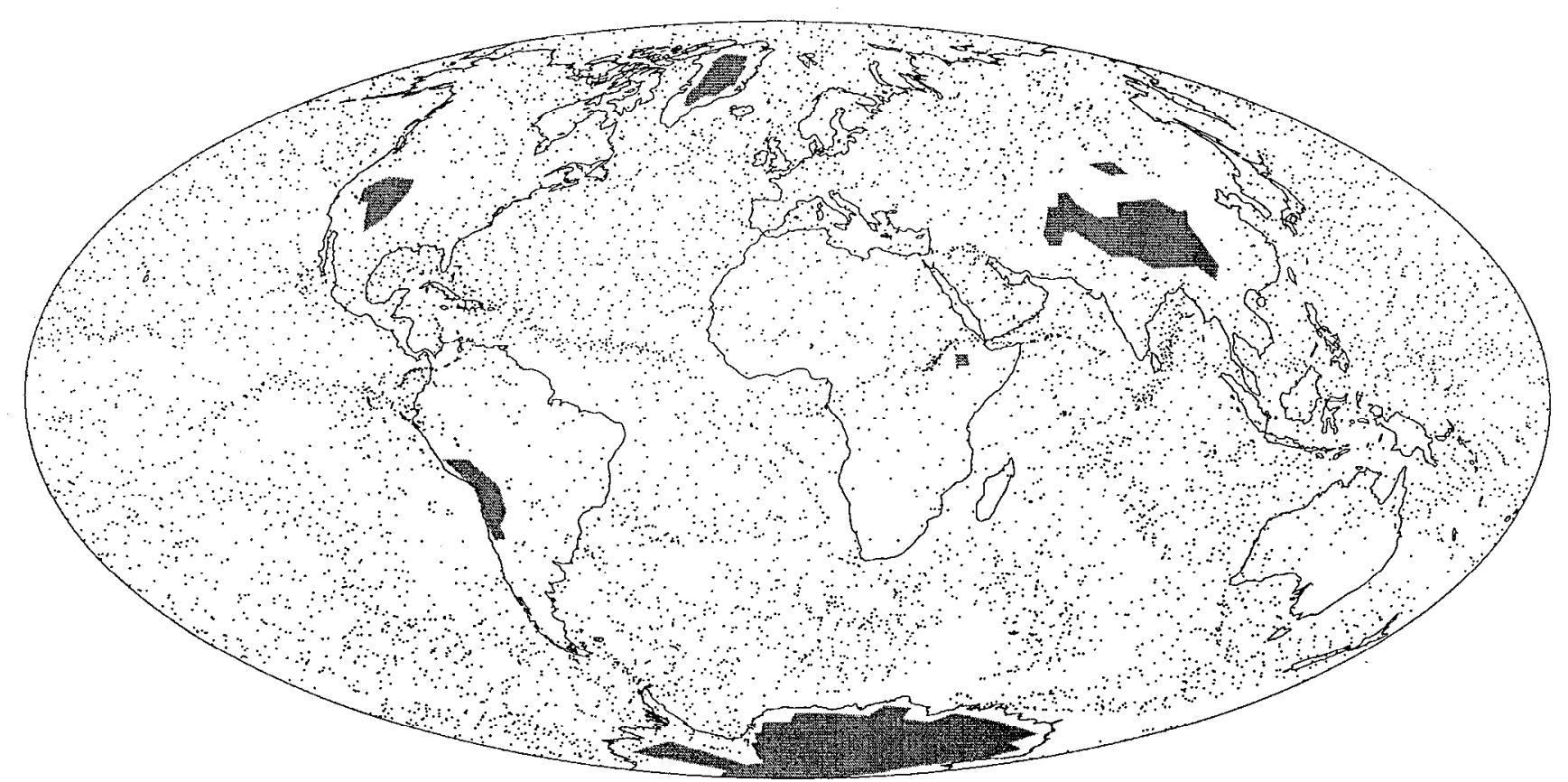

Figure 45. Location of balloons set for $850 \mathrm{mb} 5$ days after release as an initially uniform distribution. Terrain above $850 \mathrm{mb}$ is shaded in gray. 7862 balloons released, 7613 still aloft, 249 hit terrain.

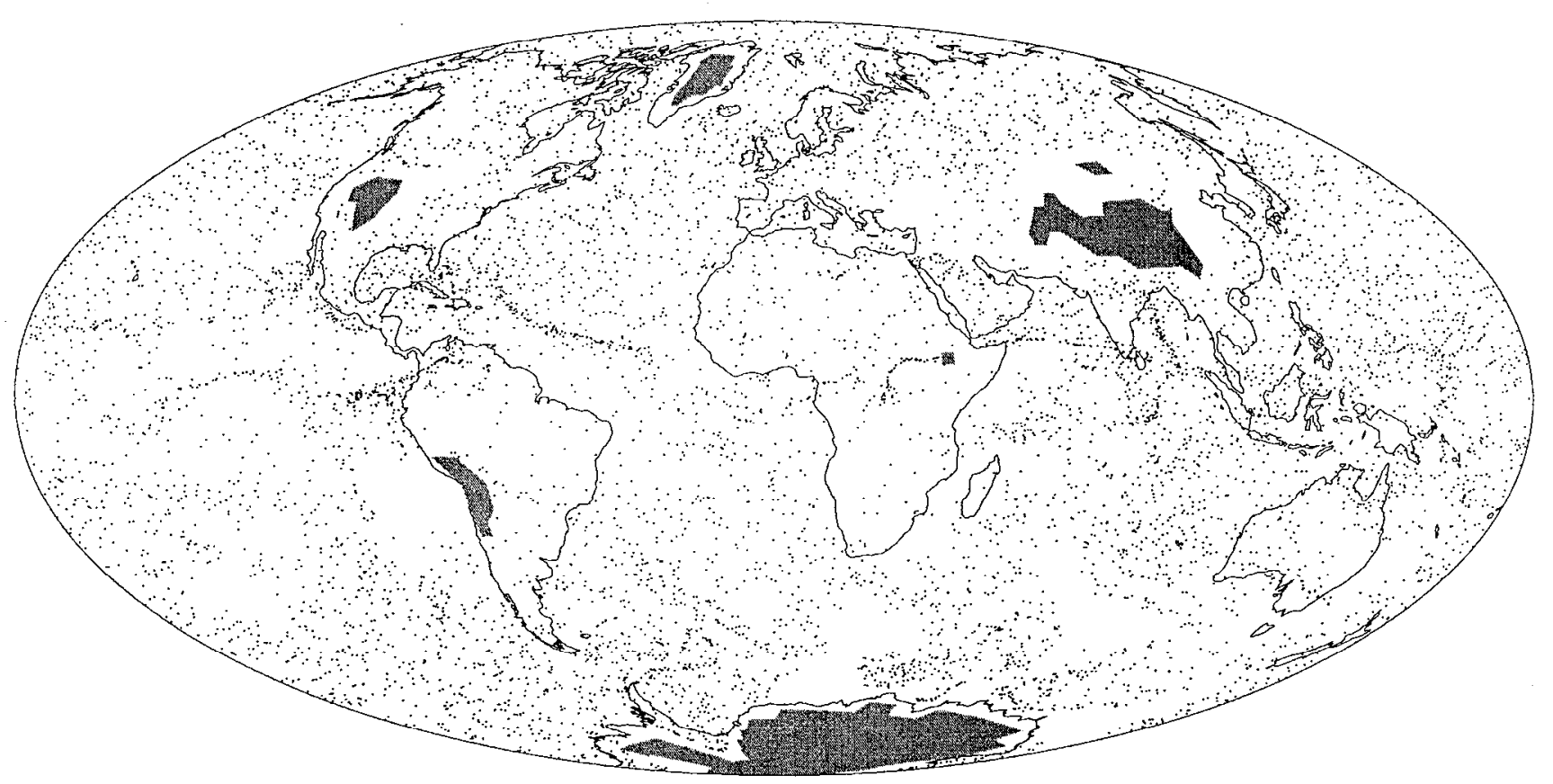

Figure 46. Location of balloons set for $850 \mathrm{mb} 7$ days after release as an initially uniform distribution. Terrain above $850 \mathrm{mb}$ is shaded in gray. 7862 balloons released, 7533 still aloft, 329 hit terrain. 


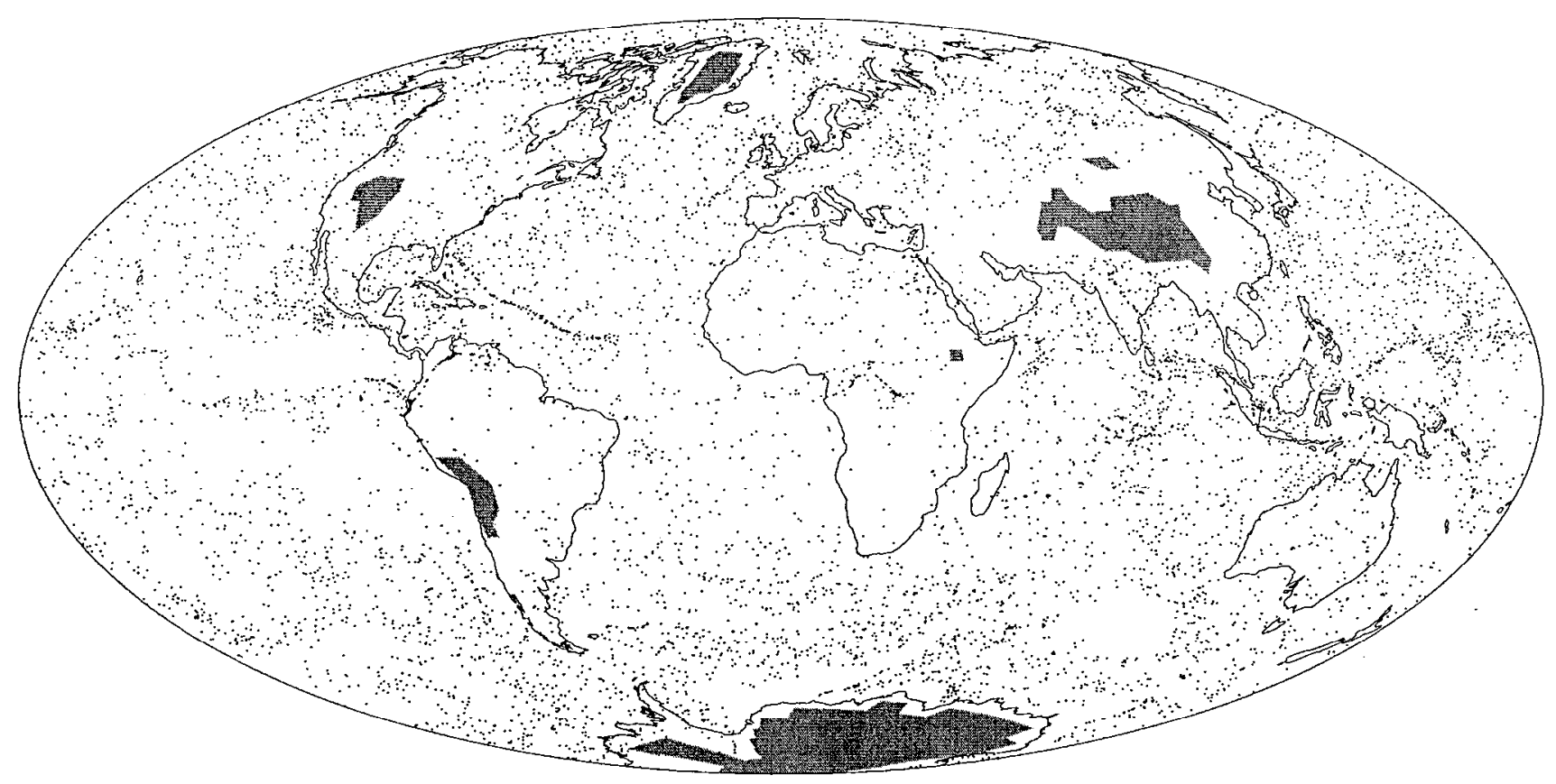

Figure 47.Location of balloons set for $850 \mathrm{mb} 10$ days after release as an initially uniform distribution. Terrain above $850 \mathrm{mb}$ is shaded in gray. 7862 balloons released, 7383 still aloft, 479 hit terrain.

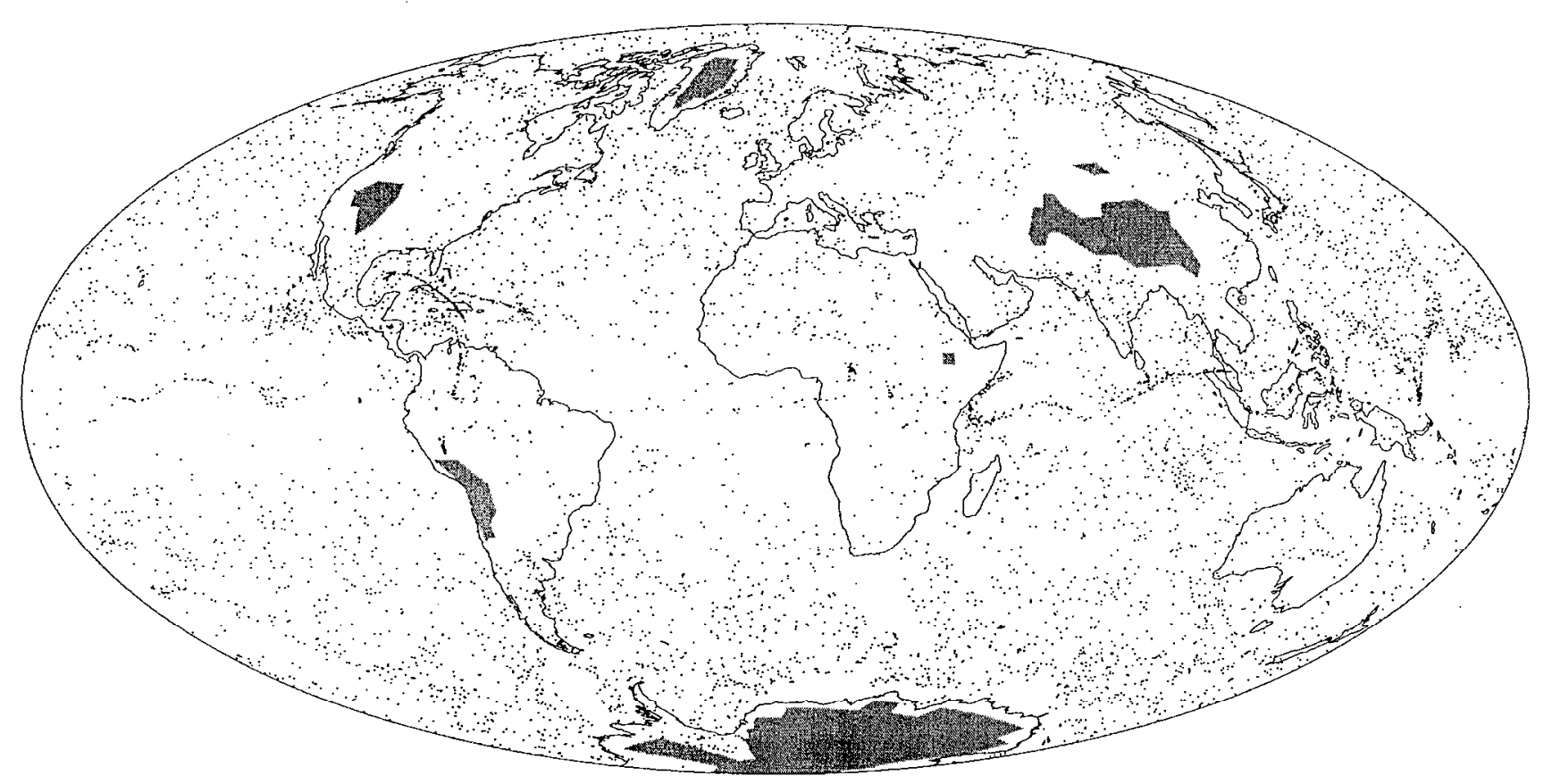

Figure 48. Location of balloons set for $850 \mathrm{mb} 15$ days after release as an initially uniform distribution. Terrain above $850 \mathrm{mb}$ is shaded in gray. 7862 balloons released, 7241 still aloft, 621 hit terrain. 
adequacy of a transponder network. The number of vertical layers per horizontal column with at least one balloon is plotted in Figures 49-54. In these plots warmer colors (yellow, orange; and red) mark areas with larger numbers of occupied layers, and cooler colors (blue, purple, and black) mark areas with fewer occupied layers. If we assume a vertical profile is defined when six or more layers provide wind and temperature data, we see that few areas have adequate transponders especially in the higher horizontal resolution cases (Figures 49, 51, and 53). Mid-latitudc columns generally have more occupied layers, but the predominance of blue and purple in the tropics confirms the earlier result that too few transponders remain there. Note, however, that regions of high topography, such as the south pole and the Himalayas, have only five to seven floating-levels above terrain; so, fewer occupied layers are required to define a vertical profile.

Major conclusions from the uniform distribution simulations include the following: Balloons quickly leave the tropics especially at low altitudes and near the tropopause. Low altitude transponders frequently run into terrain; any operational program would have to replace these balloons often. Predominantly zonal flow makes it possible to maintain an adequate transponder density in mid-latitudes and near the poles.

\section{B. Daily Release Scenario}

\section{CCM3/GRANTOUR}

The CCM3/GRANTOUR daily release simulation ran for 35 days. At the beginning of each day a balloon was released on each of the ten floating-level pressures from 298 sites. However, a few of the 298 sites were at altitudes above some floating-level pressures so not all levels had 298 release sites. The number of release sites for each level is included in Table 4 . For the floating-level pressures

where terrain was not a factor, 298 balloons were present on the first day, 596 on the second, etc. At larger floating-level pressures (lower altitudes) fewcr launch sites were active and balloons crashed into terrain; therefore, smaller numbers of balloons remained aloft. For example, at $925 \mathrm{mb} 272$ balloons were launched the first day, and 11 of these crashed, leaving 261. At the start of the second day 272 more were released, and 15 hit the ground during this day,

Table 4. Number of Balloons after 35 days for the CCM3/GRANTOUR Simulation

\begin{tabular}{rcccc}
\hline Level & $\begin{array}{c}\text { Release } \\
\text { Sites }\end{array}$ & Released & Crashed & Aloft \\
\hline $100-500$ & 298 & 10430 & 0 & 10430 \\
600 & 297 & 10395 & 206 & 10189 \\
700 & 295 & 10325 & 333 & 9992 \\
775 & 292 & 10220 & 623 & 9597 \\
850 & 288 & 10080 & 1322 & 8758 \\
925 & 272 & 9520 & 3297 & 6223 \\
\hline
\end{tabular}




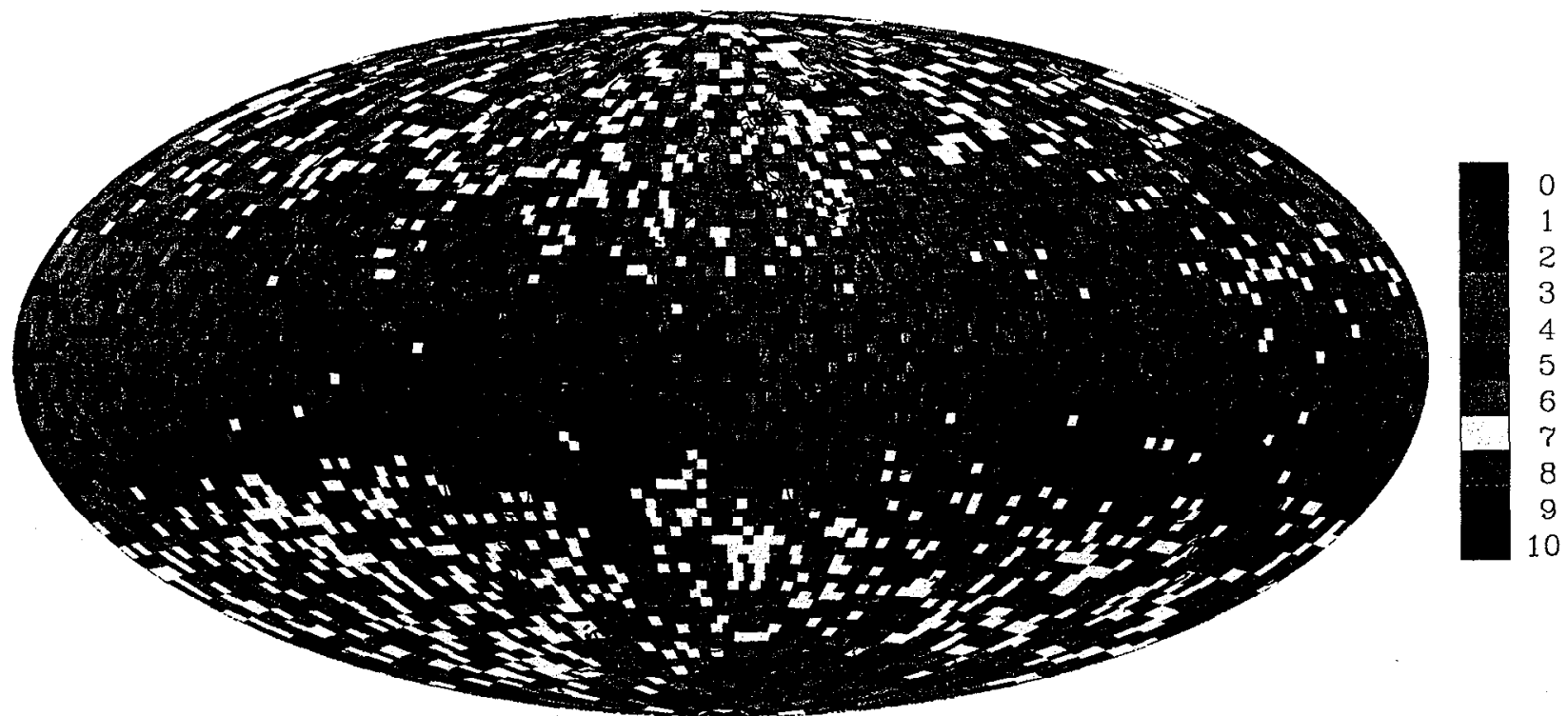

Figure 49. Number of vertical layers per horizontal column with at least 1 balloon for day 35 of the CCM3 wind data simulation starting with an initial uniform distribution. There are 80 equal area latitude bands and 8150 equal area columns of about $62,500 \mathrm{~km}^{2}$ or $250 \mathrm{~km}$ on a side.

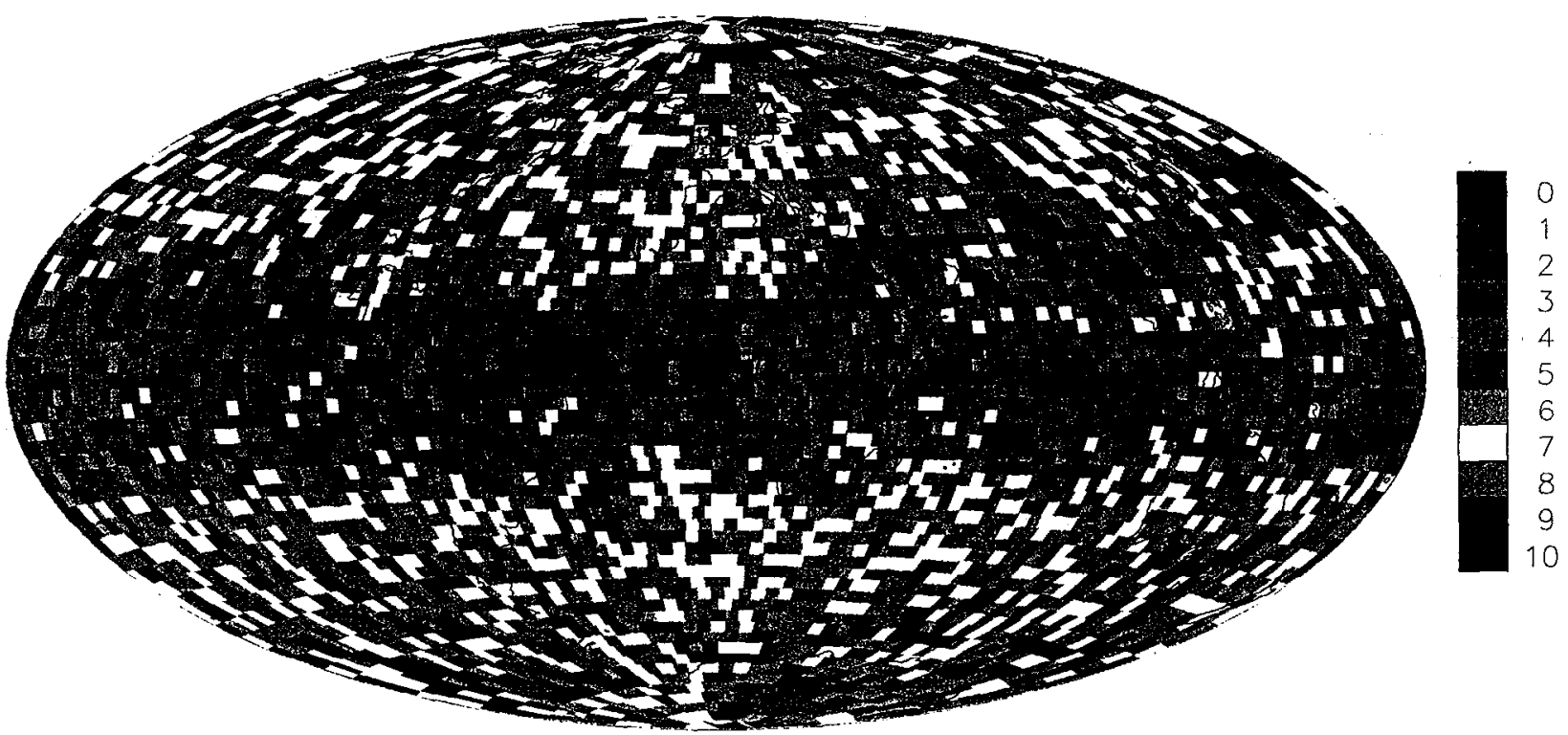

Figure 50. Number of vertical layers per horizontal column with at least 1 balloon for day 35 of the CCM3 wind data simulation starting with an initial uniform distribution. There are 64 equal area latitude bands and 5218 equal area columns of about $98,000 \mathrm{~km}^{2}$ or $313 \mathrm{~km}$ on a side. 


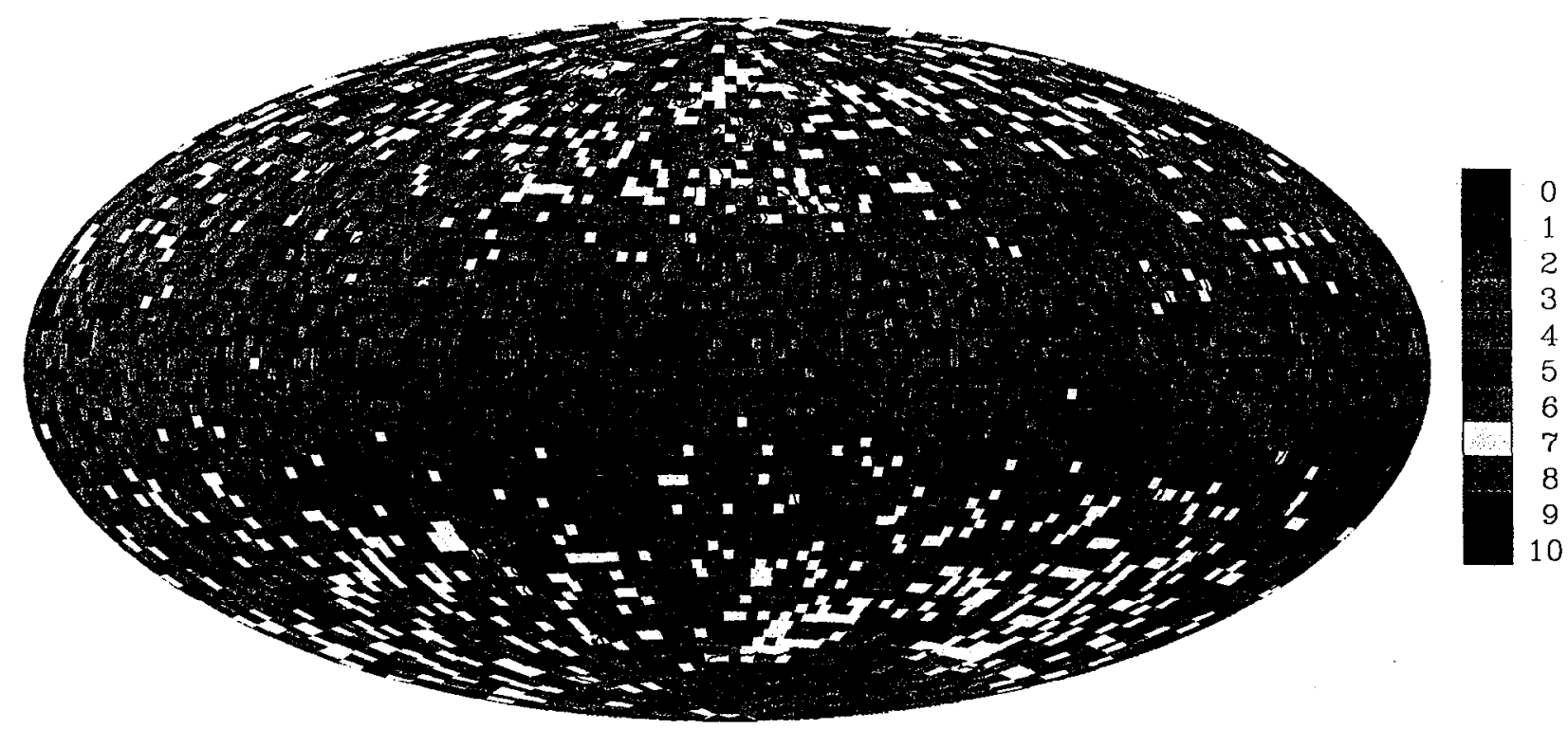

Figure 51. Number of vertical layers per horizontal column with at least 1 balloon for day 35 of the NOGAPS wind data simulation starting with an initial uniform distribution. There are 80 equal area latitude bands and 8150 equal area columns of about $62,500 \mathrm{~km}^{2}$ or $250 \mathrm{~km}$ on a side.

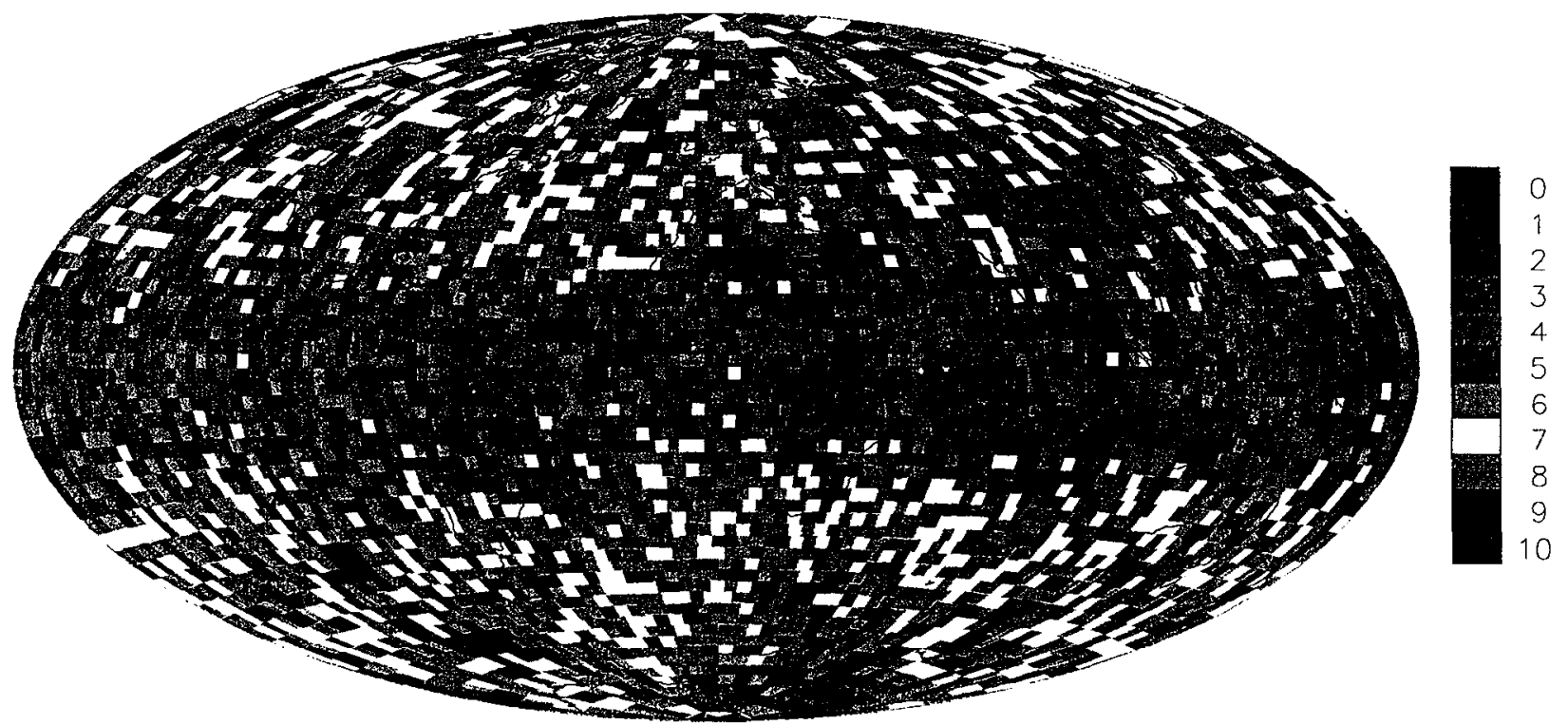

Figure 52. Number of vertical layers per horizontal column with at least 1 balloon for day 35 of the NOGAPS wind data simulation starting with an initial uniform distribution. There are 64 equal area latitude bands and 5218 equal area columns of about $98,000 \mathrm{~km}^{2}$ or $313 \mathrm{~km}$ on a side. 


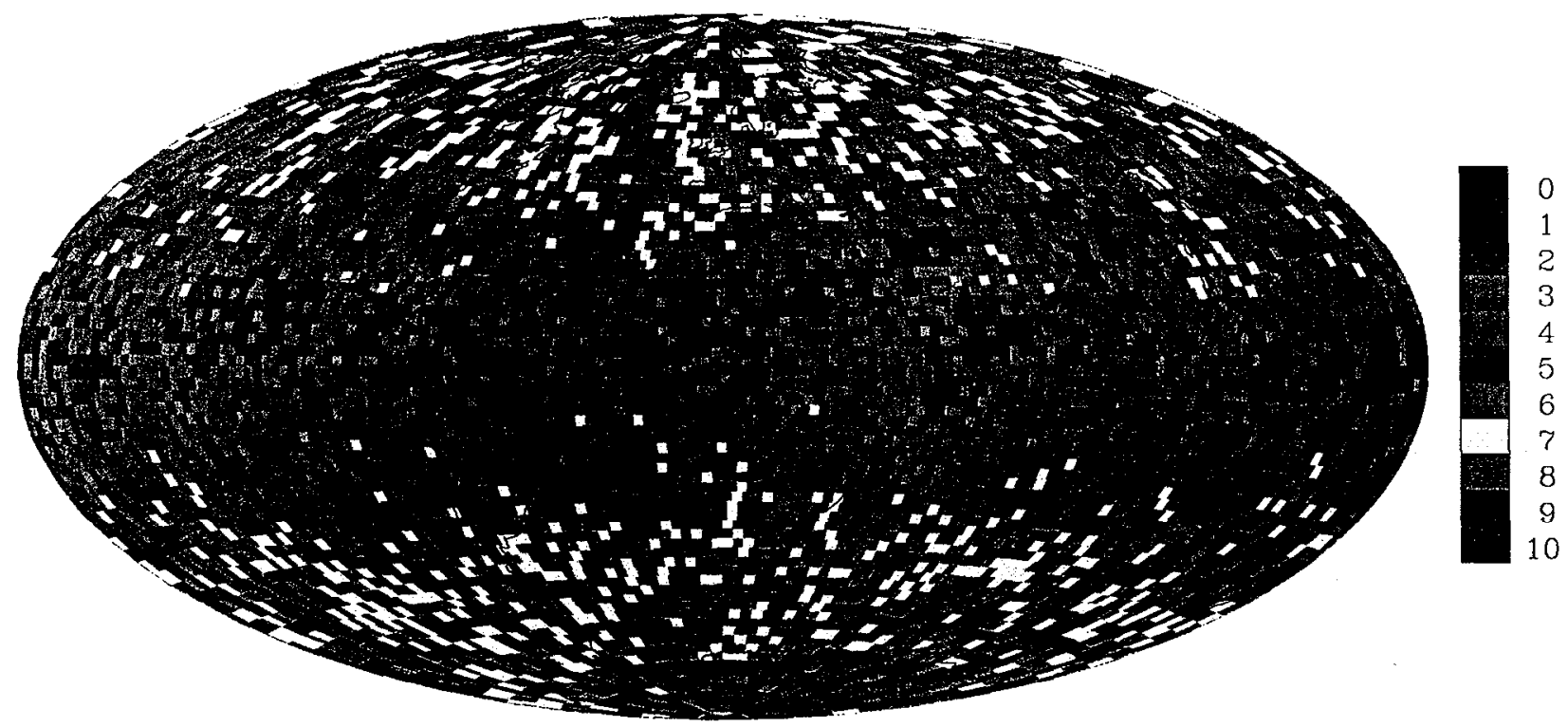

Figure 53. Number of vertical layers per horizontal column with at least 1 balloon for day 47 of the NOGAPS wind data simulation starting with an initial uniform distribution. There are 80 equal area latitude bands and 8150 equal area columns of about $62,500 \mathrm{~km}^{2}$ or $250 \mathrm{~km}$ on a side.

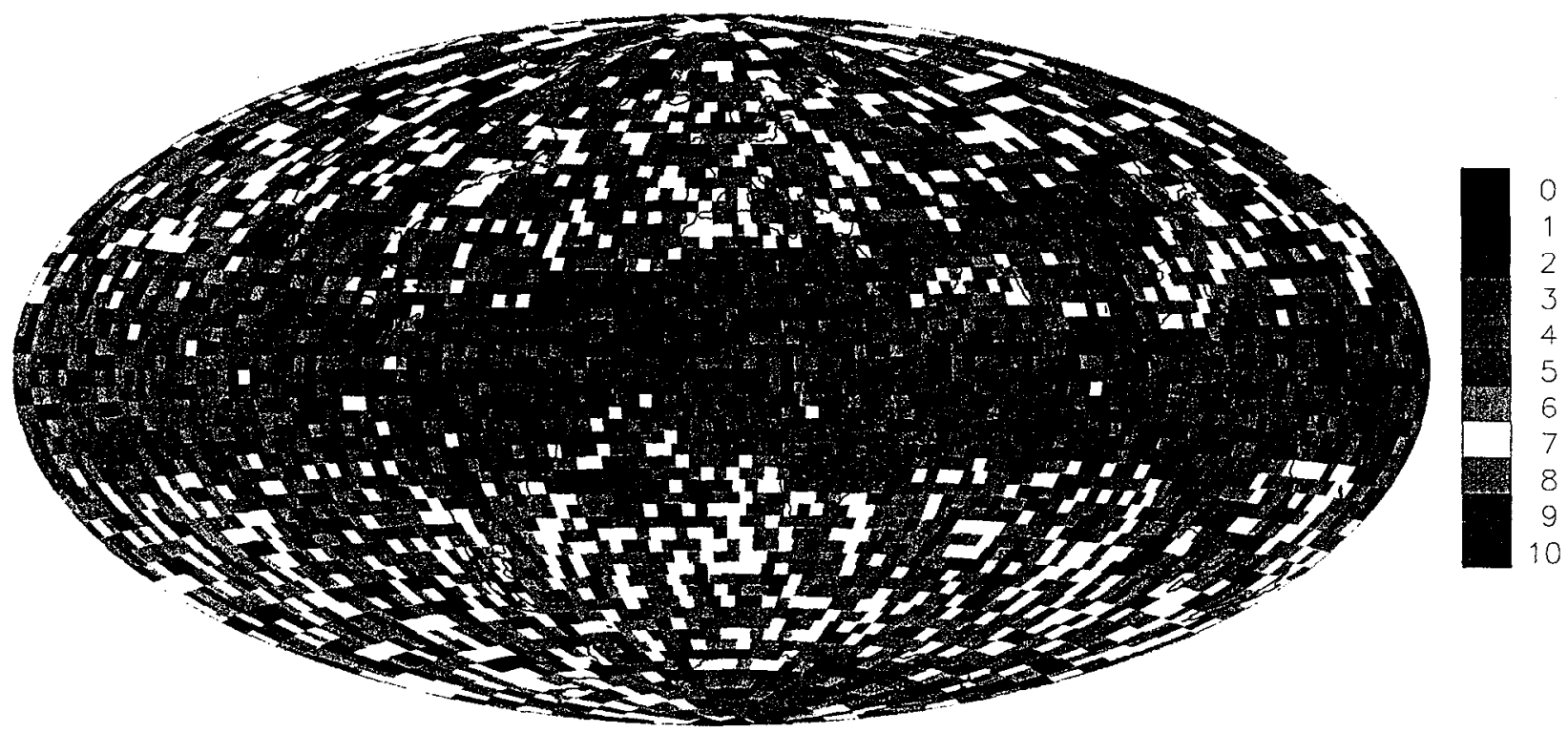

Figure 54. Number of vertical layers per horizontal column with at least 1 balloon for day 47 of the NOGAPS wind data simulation starting with an initial uniform distribution. There are 64 equal area latitude bands and 5218 equal area columns of about $98,000 \mathrm{~km}^{2}$ or $313 \mathrm{~km}$ on a side. 
leaving 518. On the third day, 272 more were launched, and 32 crashed, leaving 758 aloft after three days. On the $35^{\text {th }}$ day the last 272 balloons were released, 135 balloons crashed, and 6223 were still aloft. In the daily release simulation 65 per cent of the released balloons were still aloft at the end of the run compared with 46 per cent in the uniform distribution run. More balloons are left aloft in the daily release scenario because their average age is smaller and they have less time to crash into the mountains.

Locations of the active transponders after 35 days are shown in Figures 55-64. Comparing these plots with the uniform distribution nun (Figures 3-12) reveals a very noticeable improvement in global coverage. Much of the improvement is due to continual release of balloons in regions where airflow divergence removes transponders. In addition, somc improvement is due to a larger number of active balloons (10430 vs. 8192 for layers above terrain). Finally, for levels close to the surface $(925$ and $850 \mathrm{mb})$, a larger fraction of the released transponders is still active at the end of the $35^{\text {th }}$ day.

Many characteristics we pointed out in the discussion of the uniform release are present in the daily release simulation. These repeated features include convergence of balloons in several tropical areas such as central India and the Carribean, northern Arabian, and South China Seas, ribbons of balloons in the tropics and mid-latitudes, especially in the southern hemisphere, and large areas downwind of the mountains almost completely without transponders.

Nevertheless, the depleted areas are smaller and not as intense as in the initial uniform distribution case.

Global coverage is worst for the layers closest to the surface (Figure 55, $925 \mathrm{mb}$ ) and to the tropopause (Figure 63, $200 \mathrm{mb}$ ). The global distribution of transponders in the rest of the atmosphere is very good. At $925 \mathrm{mb}$, wind speeds are smaller and the flow less zonal so balloons are not transported around the globe as rapidly as at higher altitudes. In the tropics especially, transponders remain close to their release points and gather in specific areas or along convergence lines. This leads to under sampling in some areas and surplus transponders in others. More and perhaps a different selection of release points would help rectify this defect.

The failure to keep sufficient transponders in the tropical tropopause region is potentially more serious. As we pointed out in the uniform distribution section, transport out of this region is rapid; after only one week most of the balloons that started here are gone. The only obvious strategy to counteract this problem is more frequent releases from more sites, perhaps using shorter lifetime balloons to prevent swamping mid-latitudes with transponders. Another possibility would be launching higher level balloons and allowing them to lose buoyancy and sink through this part or the atmosphere, but just designing small transponder carrying balloons to reach such high altitudes is already a formidable problem. 


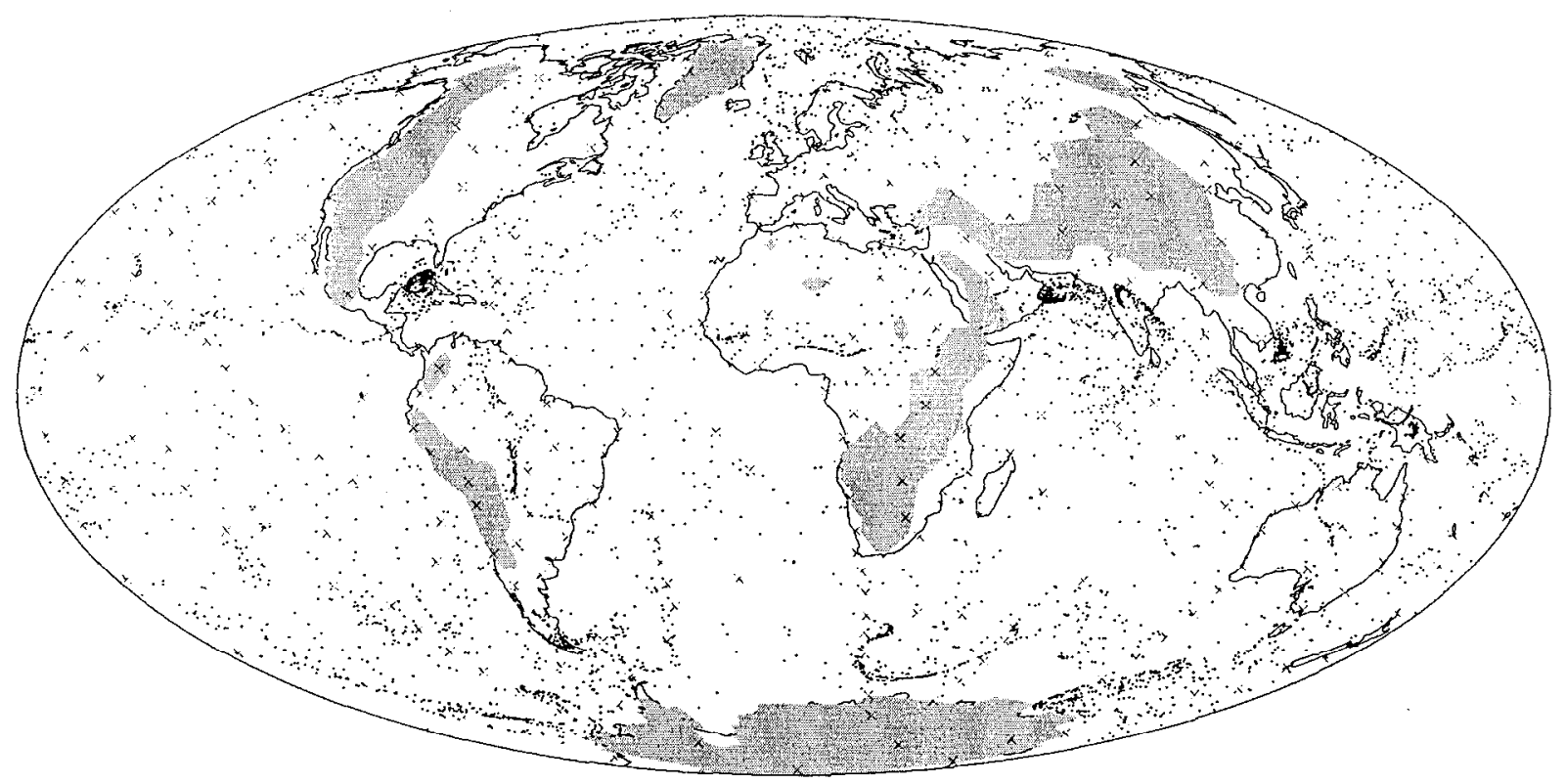

Figure 55. Location of balloons set for $925 \mathrm{mb}$ after 35 days of daily releases from 298 launch sites indicated by $\times$. Terrain above $925 \mathrm{mb}$ is shaded in gray. 9520 balloons released, 6223 still aloft, 3297 hit terrain.

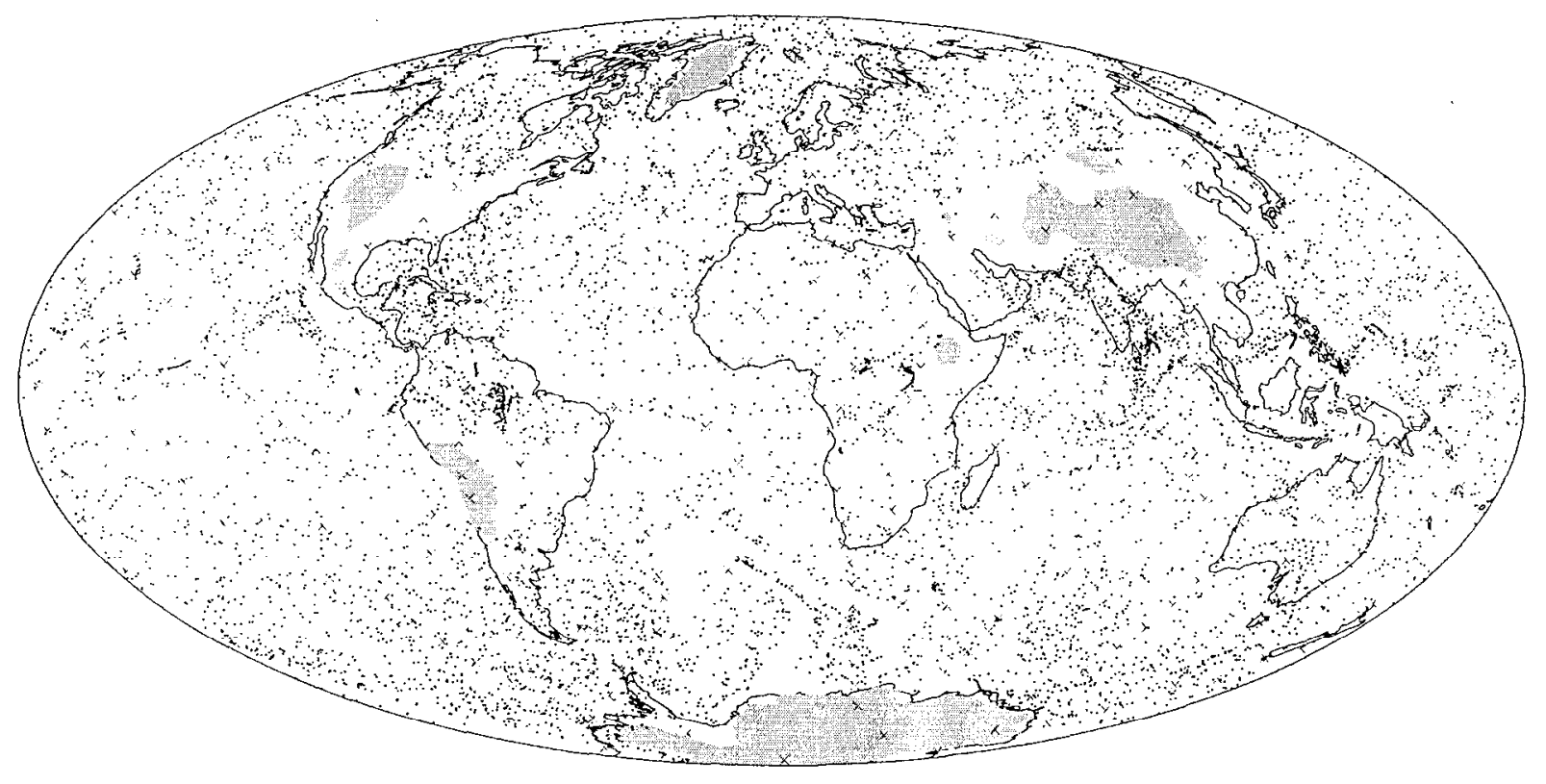

Figure 56. Location of balloons set for $850 \mathrm{mb}$ after 35 days of daily releases from 298 launch sites indicated by $\times$. Terrain above $850 \mathrm{mb}$ is shaded in gray. 10080 balloons released, 8758 still aloft, 1322 hit terrain. 


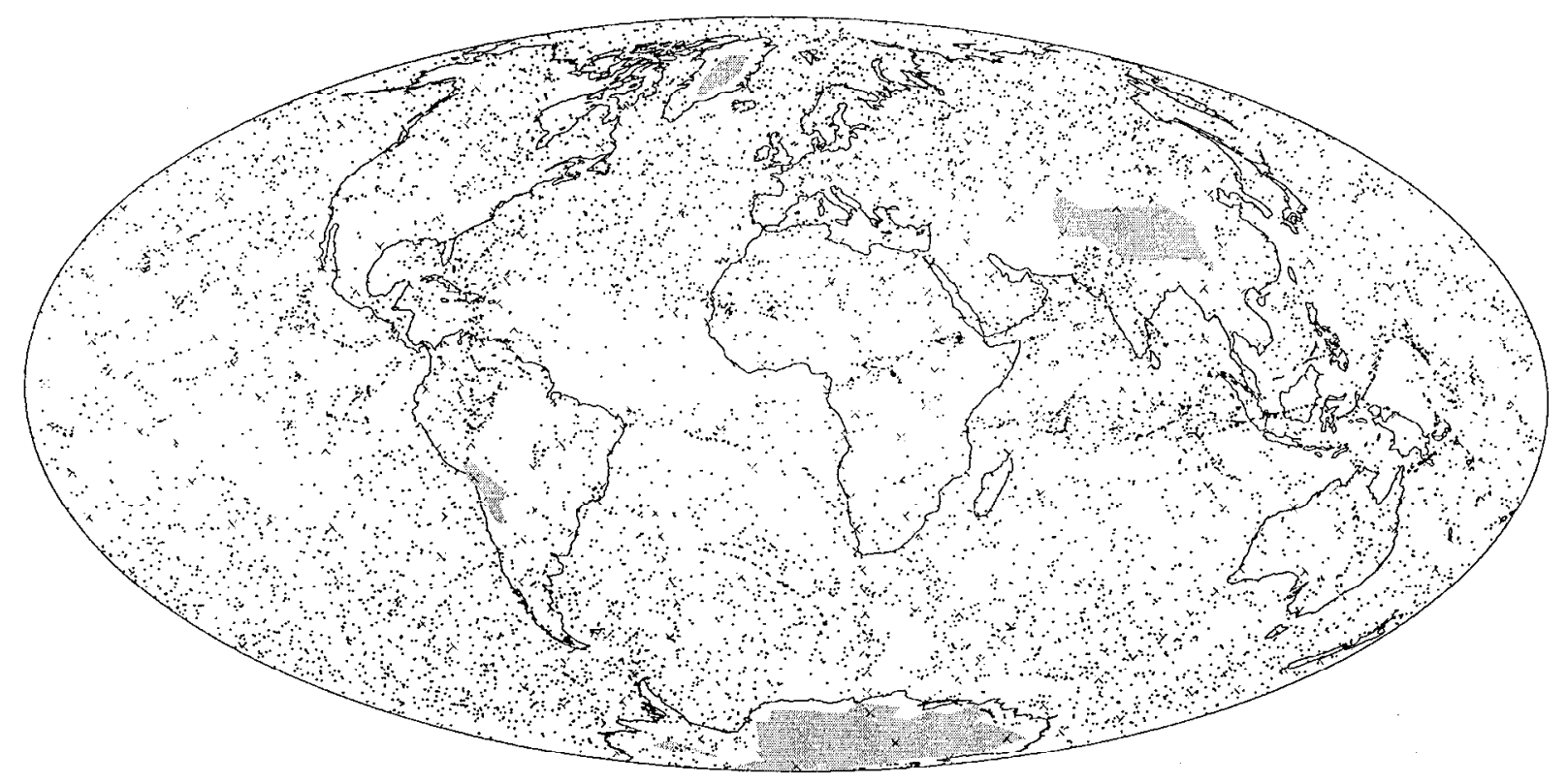

Figure 57. Location of balloons set for $775 \mathrm{mb}$ after 35 days of daily releases from 298 launch sites indicated by $\times$. Terrain above $775 \mathrm{mb}$ is shaded in gray. 10220 balloons released, 9597 still aloft, 623 hit terrain.

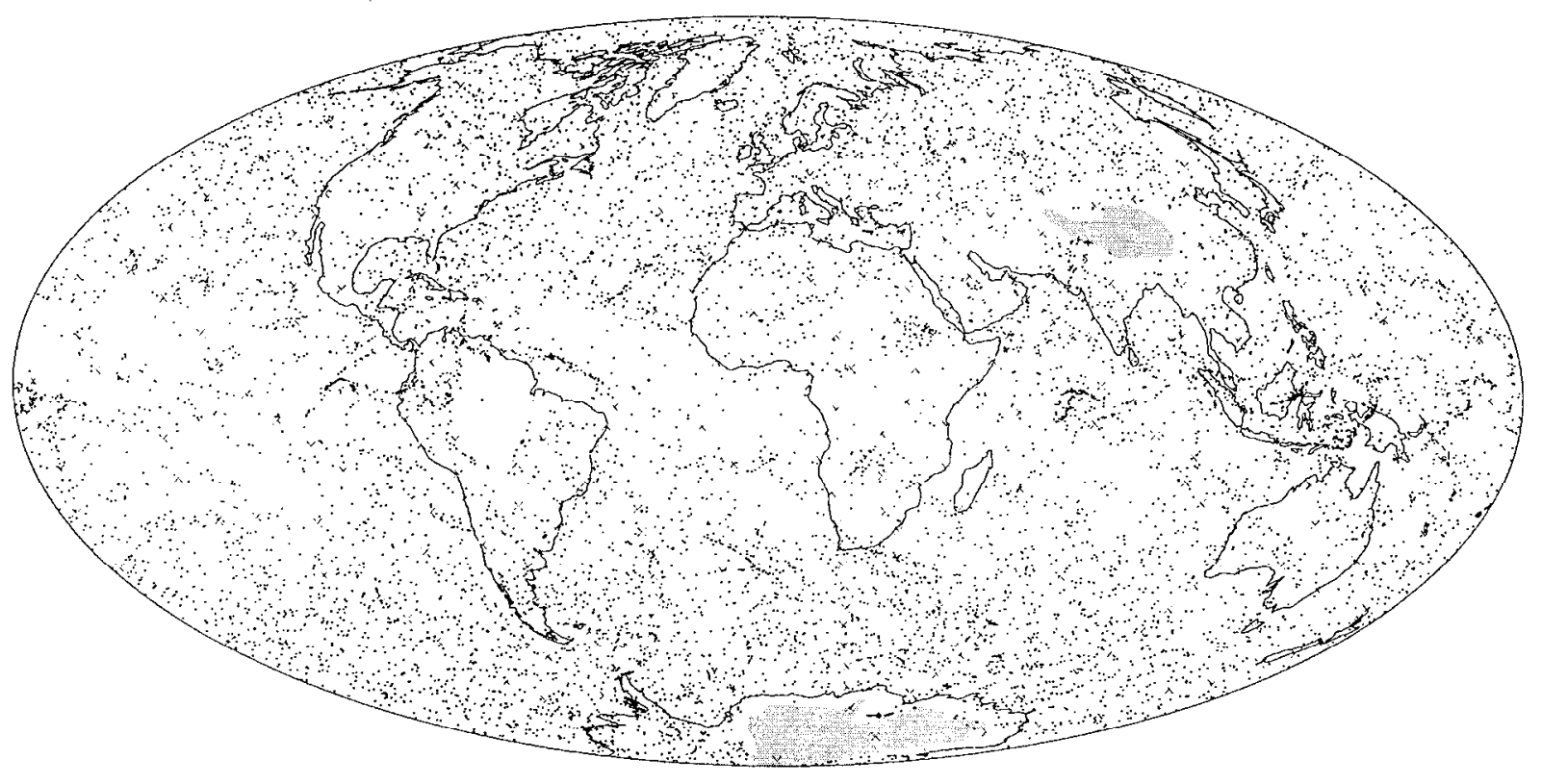

Figure 58. Location of balloons set for $700 \mathrm{mb}$ after 35 days of daily releases from 298 launch sites indicated by $\times$. Terrain above $700 \mathrm{mb}$ is shaded in gray. 10325 balloons released, 9992 still aloft, 333 hit terrain. 


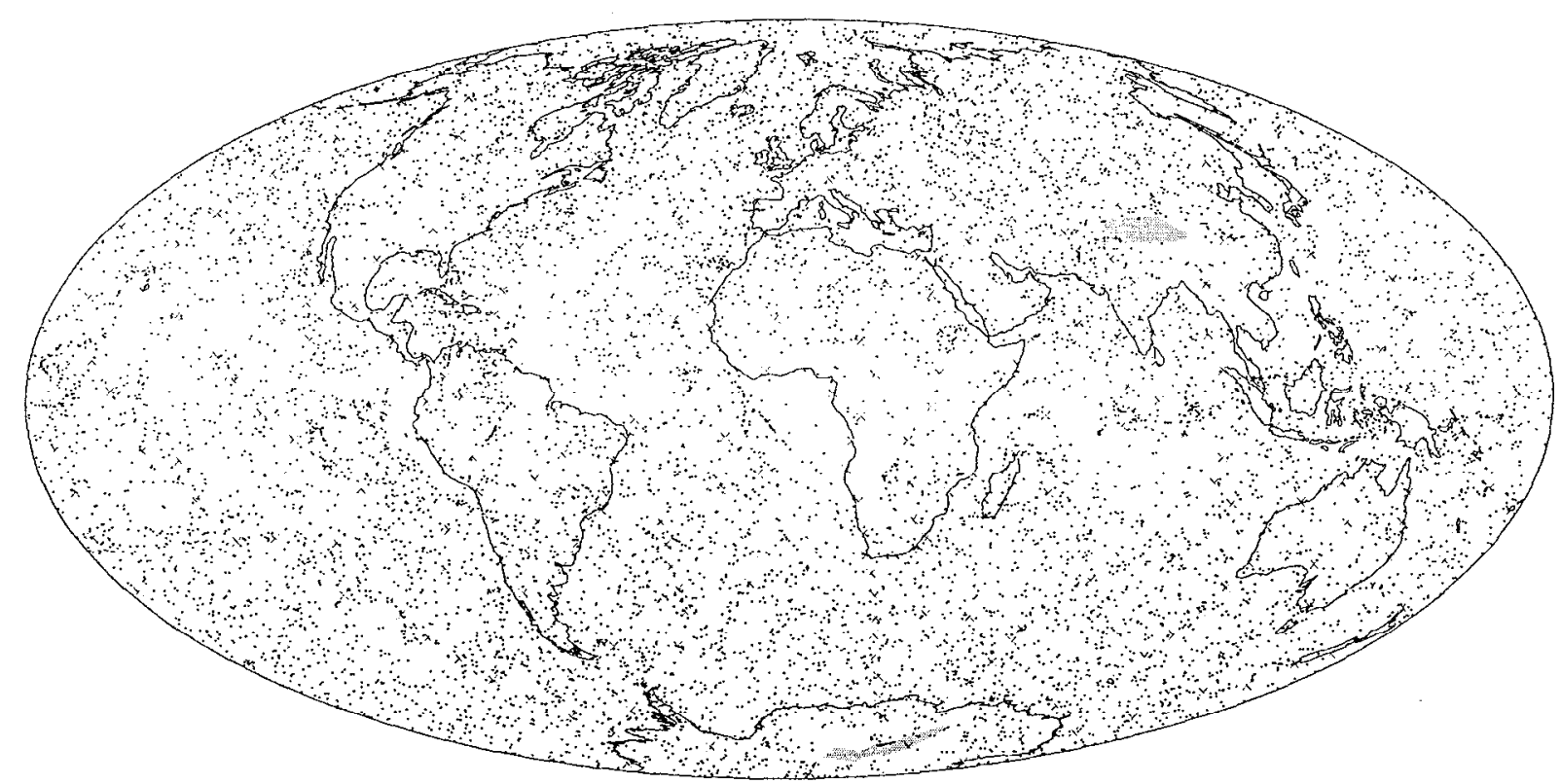

Figure 59. Location of balloons set for $600 \mathrm{mb}$ after 35 days of daily releases from 298 launch sites indicated by $\times$. Terrain above $600 \mathrm{mb}$ is shaded in gray. 10395 balloons released, 10189 still aloft, 206 hit terrain.

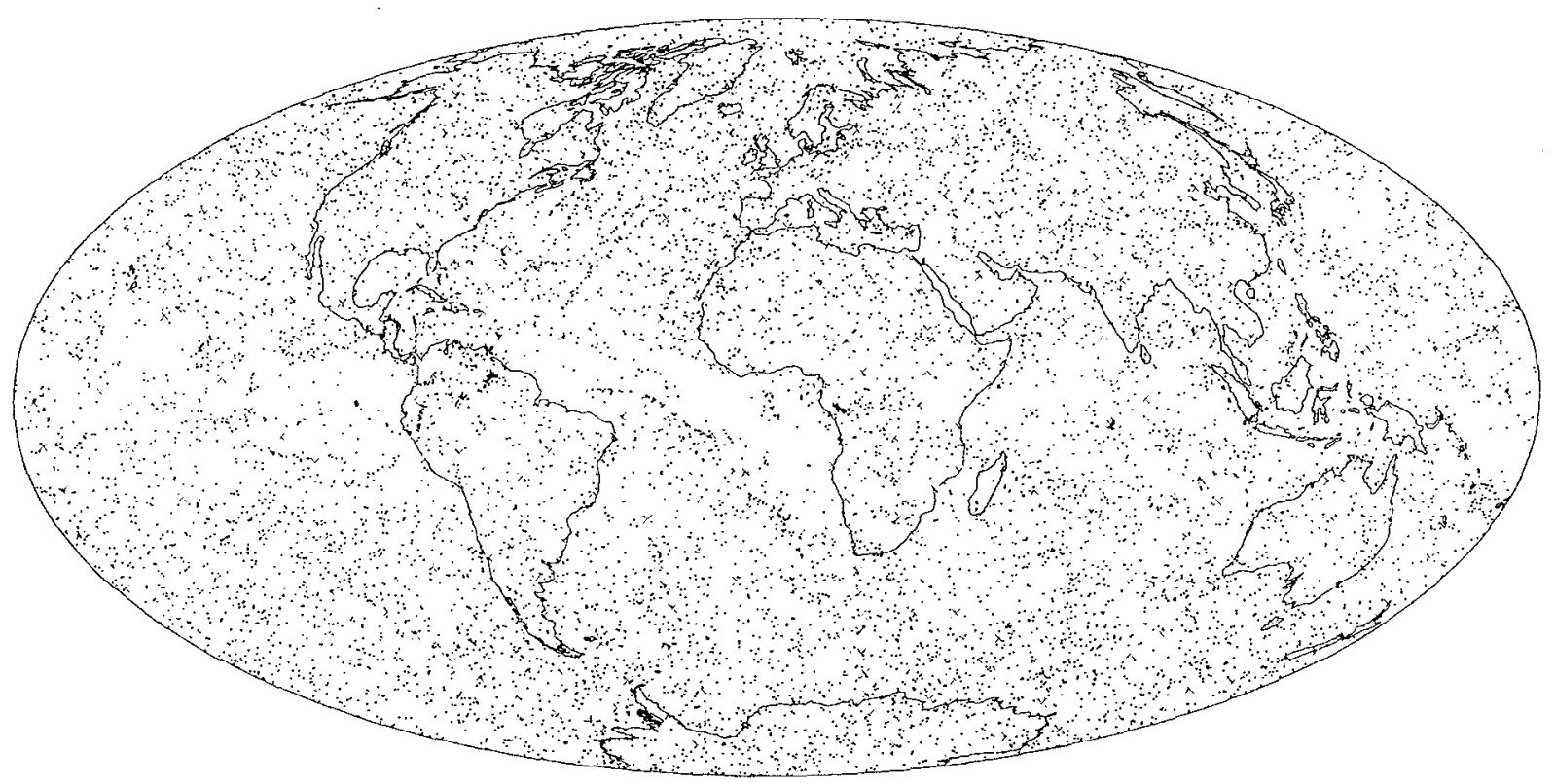

Figure 60. Location of balloons set for $500 \mathrm{mb}$ after 35 days of daily releases from 298 launch sites indicated by $\times .10430$ balloons released and aloft. 


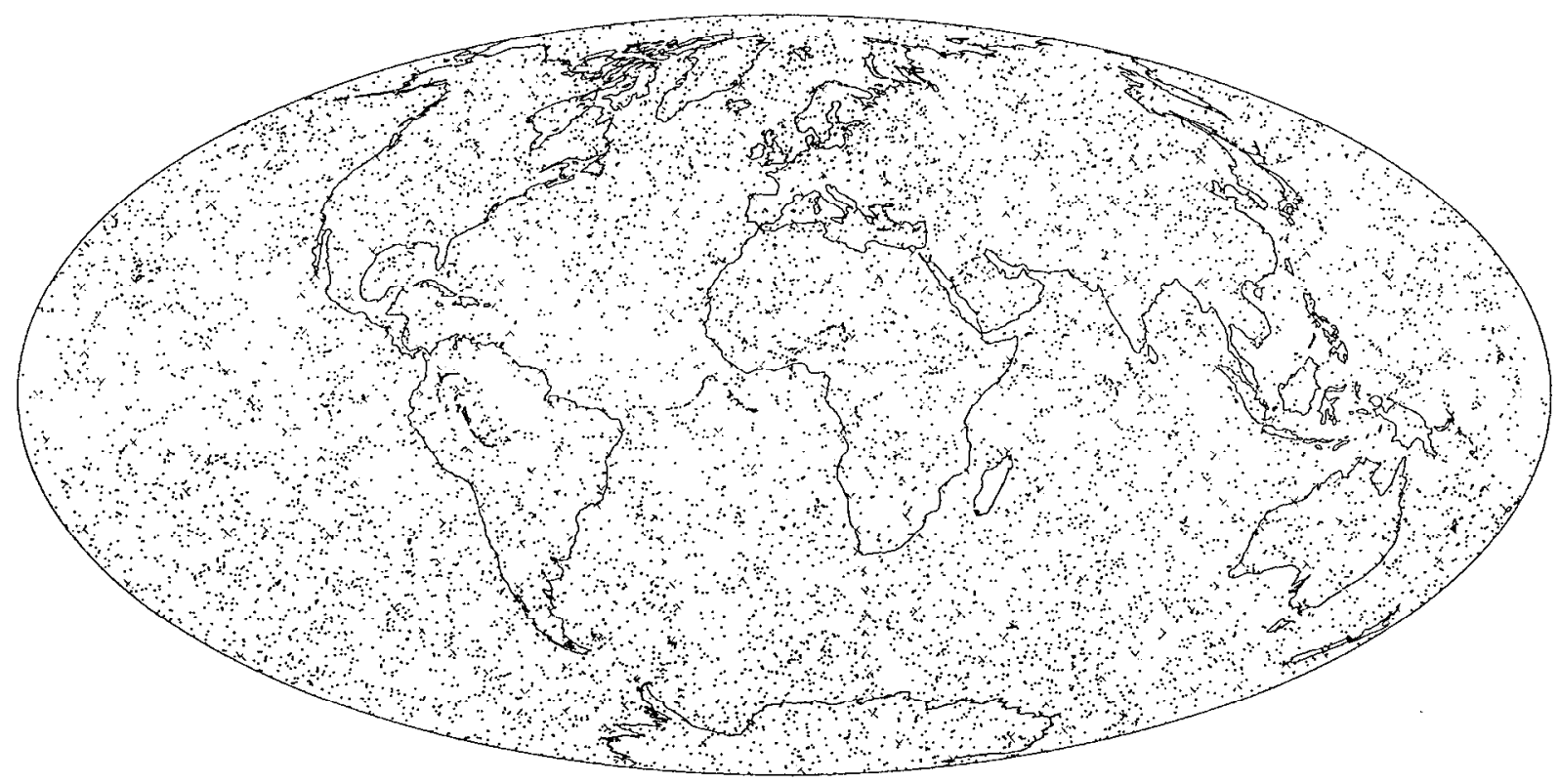

Figure 61. Location of balloons set for $400 \mathrm{mb}$ after 35 days of daily releases from 298 launch sites indicated by $\times .10430$ balloons released and aloft.

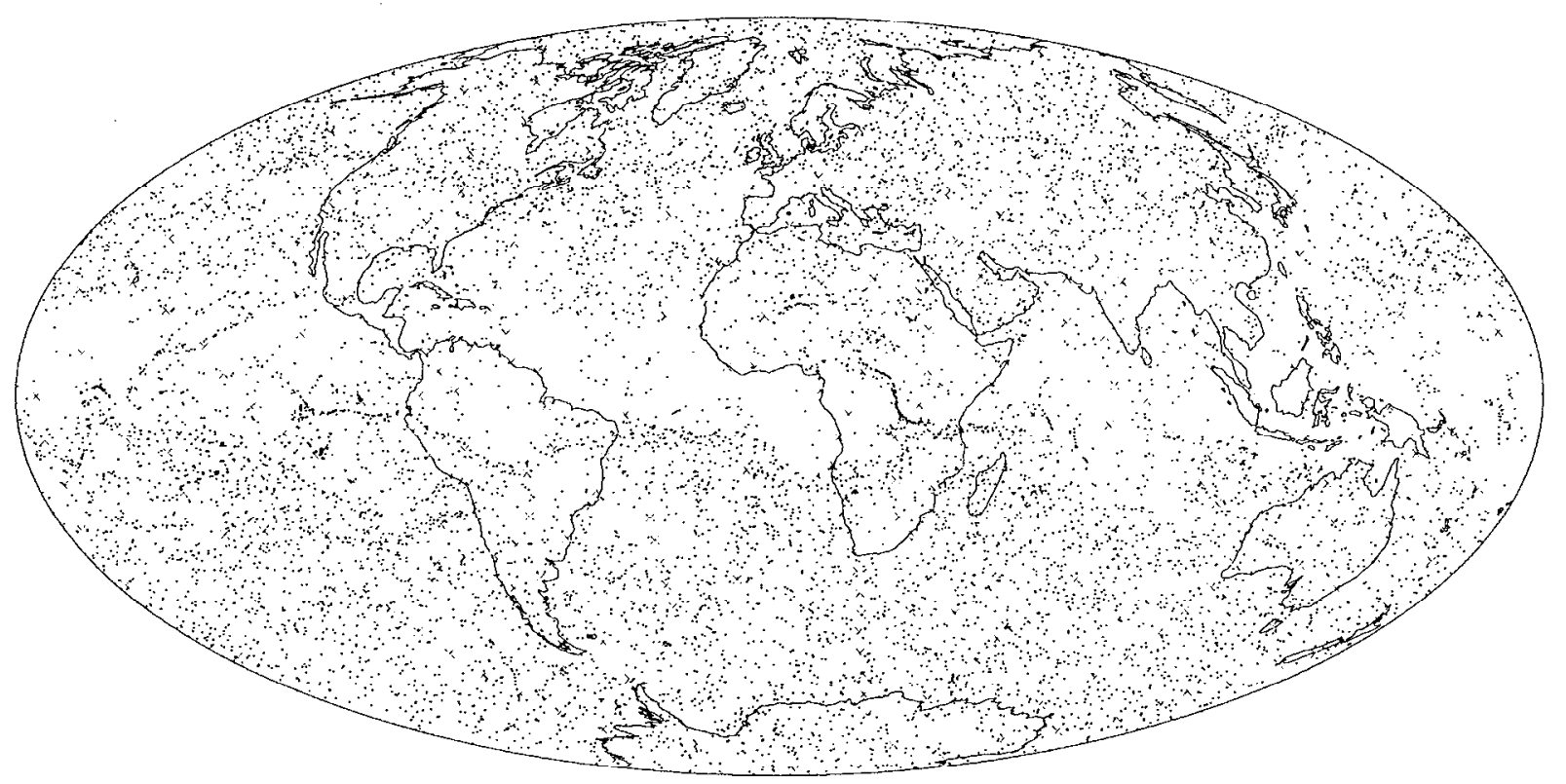

Figure 62. Location of balloons set for $300 \mathrm{mb}$ after 35 days of daily releases from 298 launch sites indicated by $\times .10430$ balloons released and aloft. 


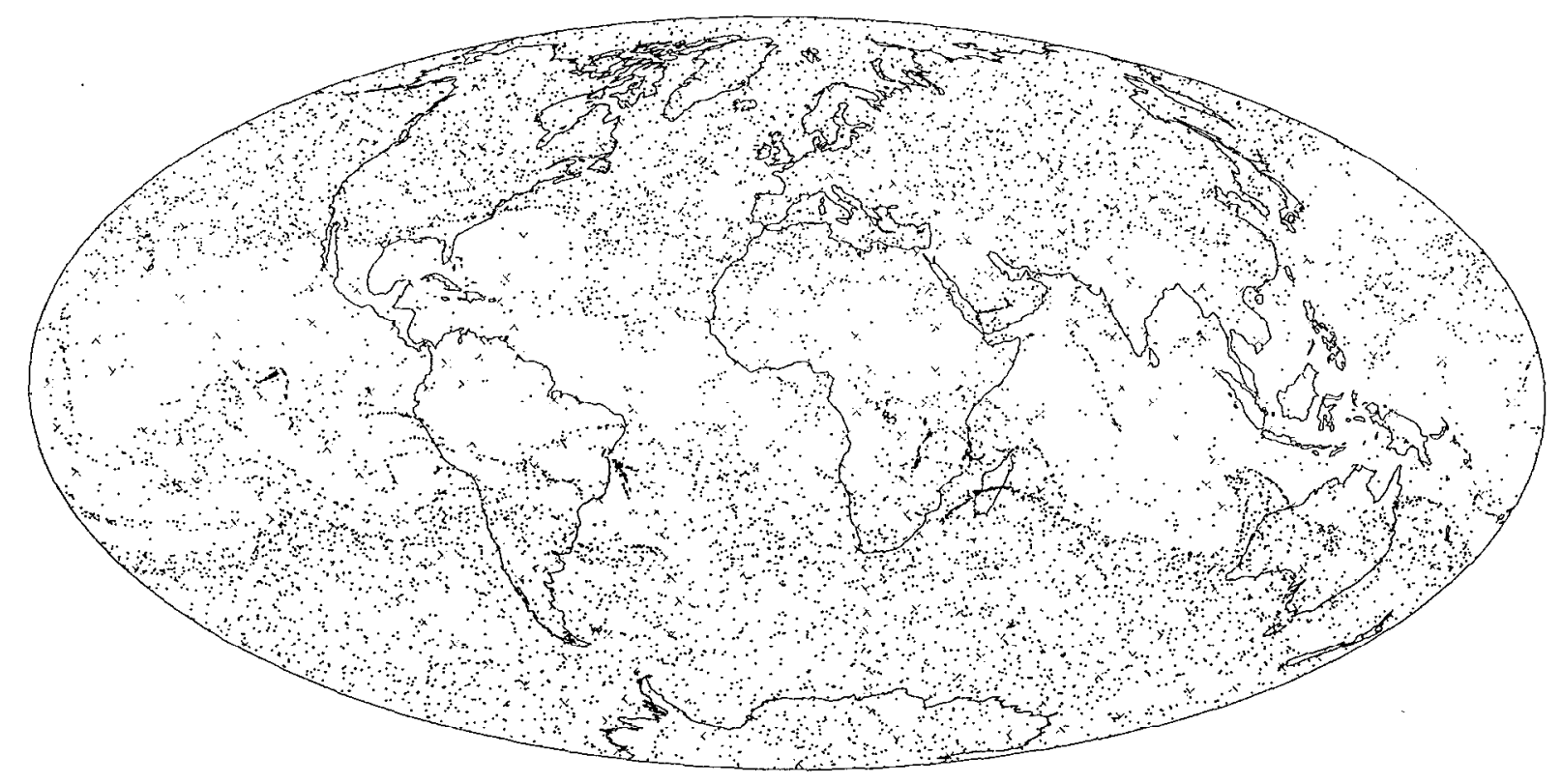

Figure 63. Location of balloons set for $200 \mathrm{mb}$ after 35 days of daily releases from 298 launch sites indicated by $\times .10430$ balloons released and aloft.

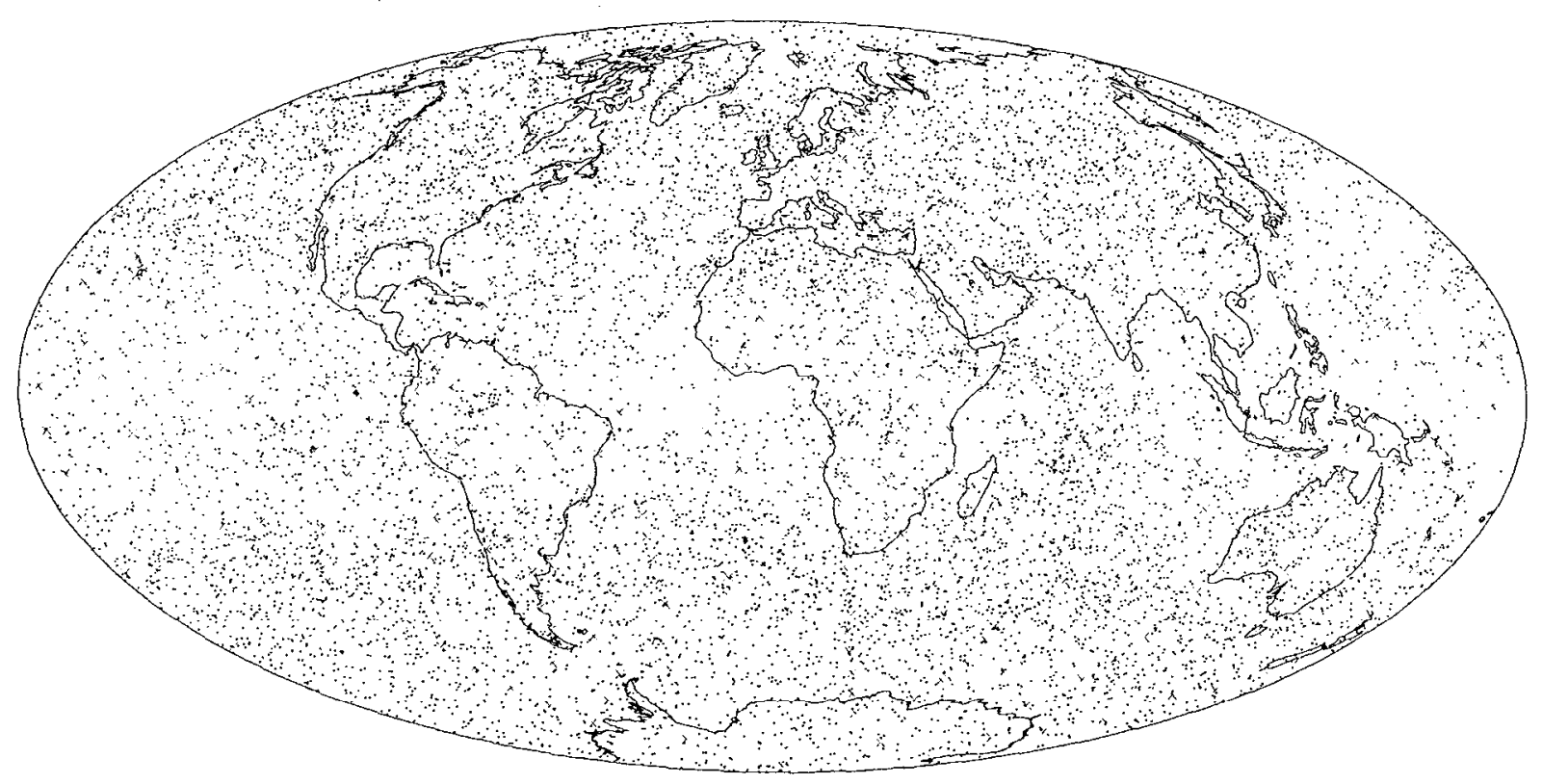

Figure 64. Location of balloons set for $100 \mathrm{mb}$ after 35 days of daily releases from 298 launch sites indicated by $\times .10430$ balloons released and aloft. 


\section{NOGAPS/GRANTOUR}

The NOGAPS/GRANTOUR simulation with daily balloon releases from 298 sites was run for 47 days. The higher spatial resolution of NOGAPS provides a better terrain distribution and a different number of active release sites for the lower floating-pressure levels. Table 5 gives the number of active release sites at each level and the fate of balloons after 35 and 47 days. Comparing Table 5 with Table 4 again shows that the higher resolution topography in the NOGAPS /GRANTOUR simulation results in a more rapid loss of balloons by terrain collisions.

The NOGAPS/GRANTOUR balloon locations after 35 days for the daily release scenario are plotted in Figures 65-74 and after 47 days in Figures 75-84. No significant differences exist between the CCM3 and NOGAPS simulations. The greater attrition of transponders by terrain in the NOGAPS simulation produces somewhat degraded coverage near the surface compared to CCM3 results. Nevertheless, the main problems remain. At low levels balloons are depleted from large portions of the tropics while they cluster into groups and bands in other areas. The tropical tropopause suffers a serious shortage of transponders, although not quite as severe as in the CCM3 case. In the middle levels of the atmosphere and above the tropopause, on the other hand, the transponders are distributed acceptably.

The best transponder distributions occur at the end of the NOGAPS/GRANTOUR simulation, i.e., after 47 days with daily releases from 298 sites. Better distributions after 47 days than after 35 days are mainly a result of the larger number of balloons aloft. However, the NOGAPS/GRANTOUR distribution at $925 \mathrm{mb}$ after 47 days with only 5677 balloons aloft is considerably better than the CCM3/GRANTOUR distribution after 35 days with 6223 active balloons.

Table 5. Number of Balloons after 35 and 47 days for the NOGAPS/GRANTOUR Simulation

\begin{tabular}{rrrrrrrr}
\hline & \multirow{2}{*}{$\begin{array}{c}\text { Release } \\
\text { Levels }\end{array}$} & Sites & \multicolumn{3}{c}{ Day 35 } & \multicolumn{3}{c}{ Day 47 } \\
\cline { 3 - 7 } $100-500$ & 298 & 10430 & 0 & 10430 & 14006 & 0 & 14006 \\
600 & 298 & 10430 & 284 & 10146 & 14006 & 495 & 13511 \\
700 & 295 & 10325 & 797 & 9528 & 13865 & 1210 & 12655 \\
875 & 290 & 10150 & 1306 & 8844 & 13630 & 2070 & 11560 \\
850 & 282 & 9870 & 2596 & 7274 & 13254 & 3863 & 9391 \\
925 & 267 & 9345 & 4469 & 4876 & 12549 & 6872 & 5677 \\
\hline
\end{tabular}




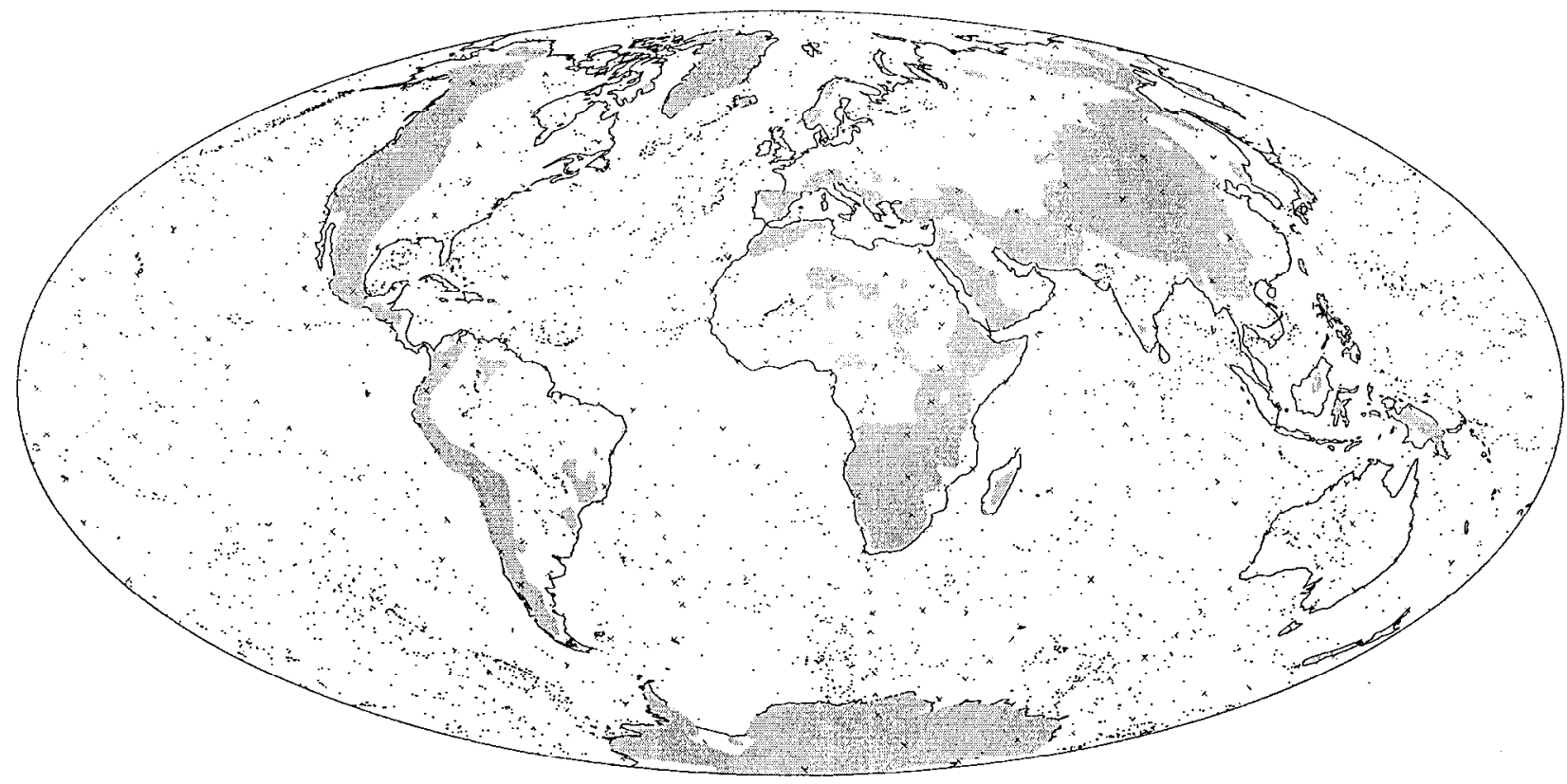

Figure 65. Location of balloons set for $925 \mathrm{mb}$ after 35 days of daily releases from 298 launch sites indicated by $\times$. Terrain above $925 \mathrm{mb}$ is shaded in gray. 9345 balloons released, 4876 still aloft, 4469 hit terrain.

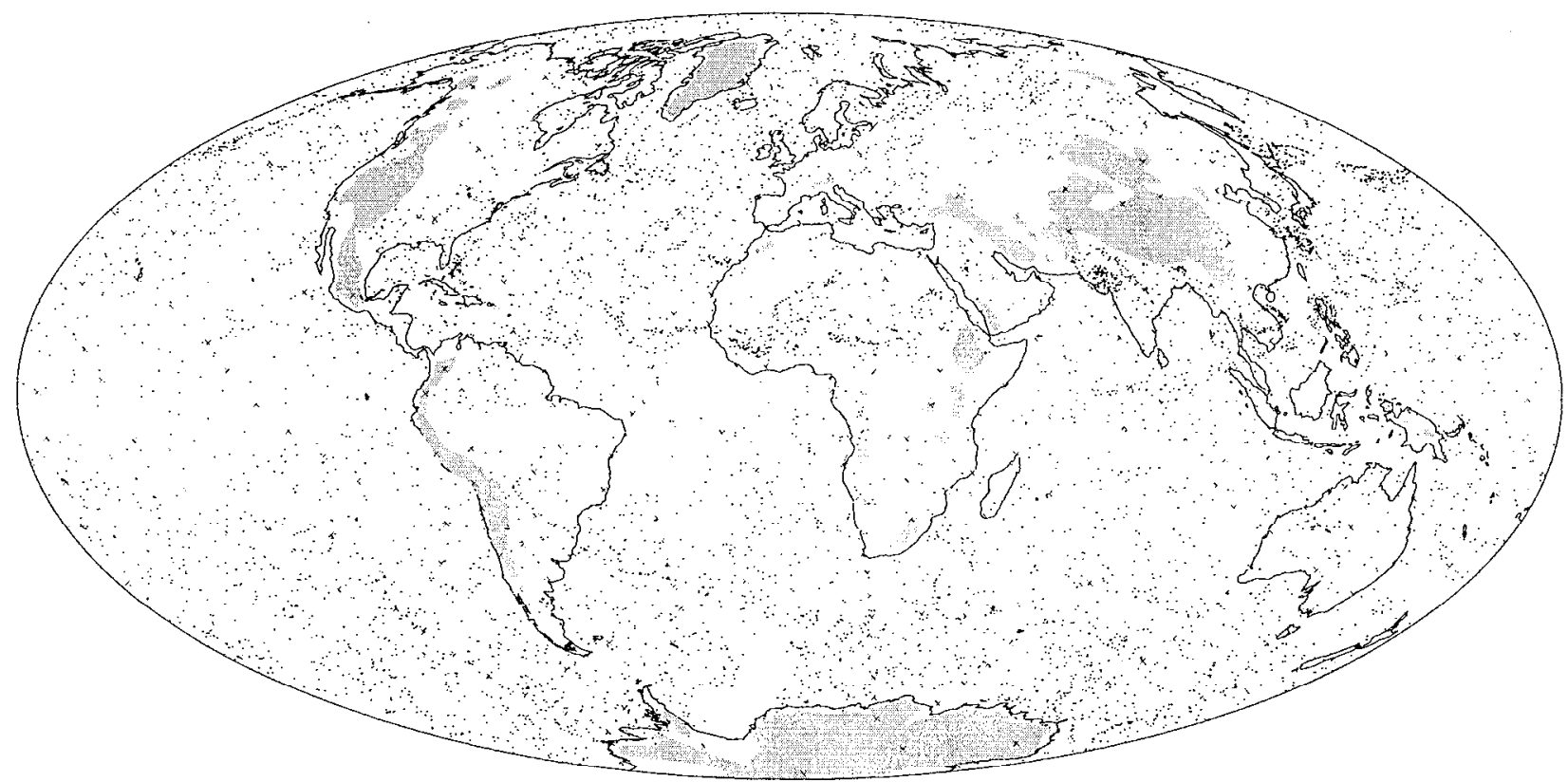

Figure 66. Location of balloons set for $850 \mathrm{mb}$ after 35 days of daily releases from 298 launch sites indicated by $\times$. Terrain above $850 \mathrm{mb}$ is shaded in gray. 9870 balloons released, 7274 still aloft, 2596 hit terrain. 


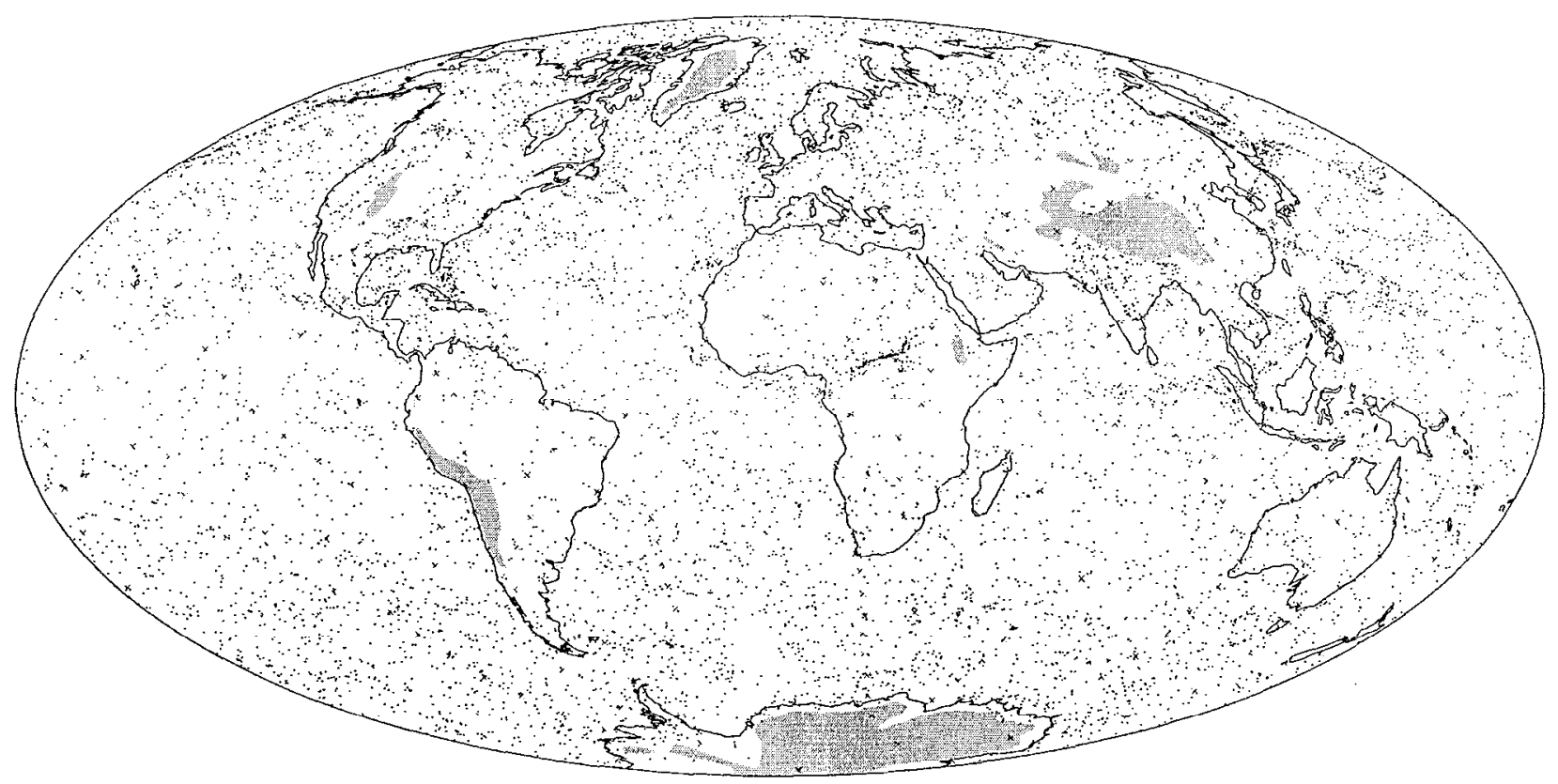

Figure 67. Location of balloons set for $775 \mathrm{mb}$ after 35 days of daily releases from 298 launch sites indicated by $\times$. Terrain above $775 \mathrm{mb}$ is shaded in gray. 10150 balloons released, 8844 still aloft, 1306 hit terrain.

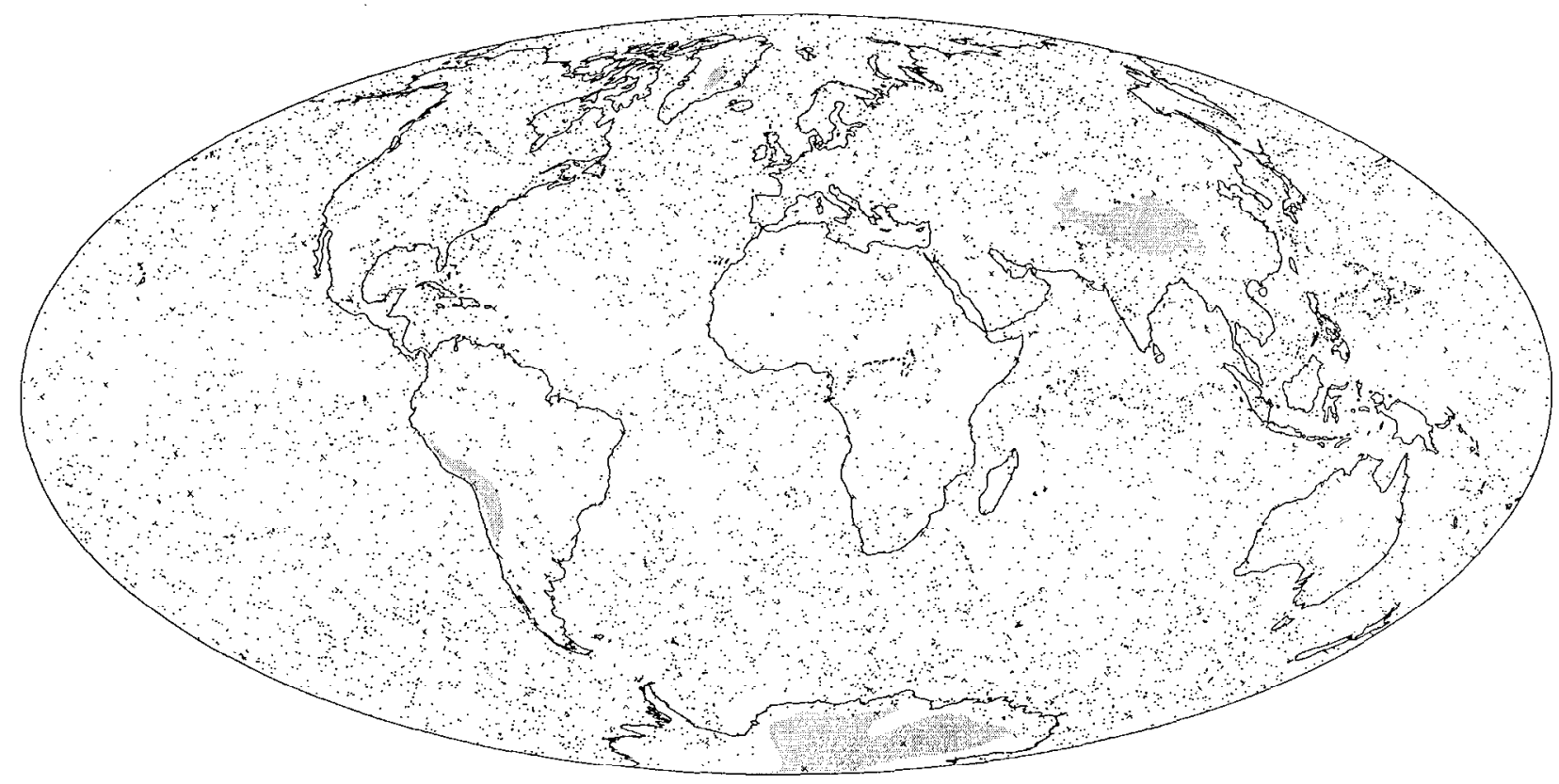

Figure 68. Location of balloons set for $700 \mathrm{mb}$ after 35 days of daily releases from 298 launch sites indicated by $x$. Terrain above $700 \mathrm{mb}$ is shaded in gray. 10325 balloons released, 9528 still aloft, 797 hit terrain. 


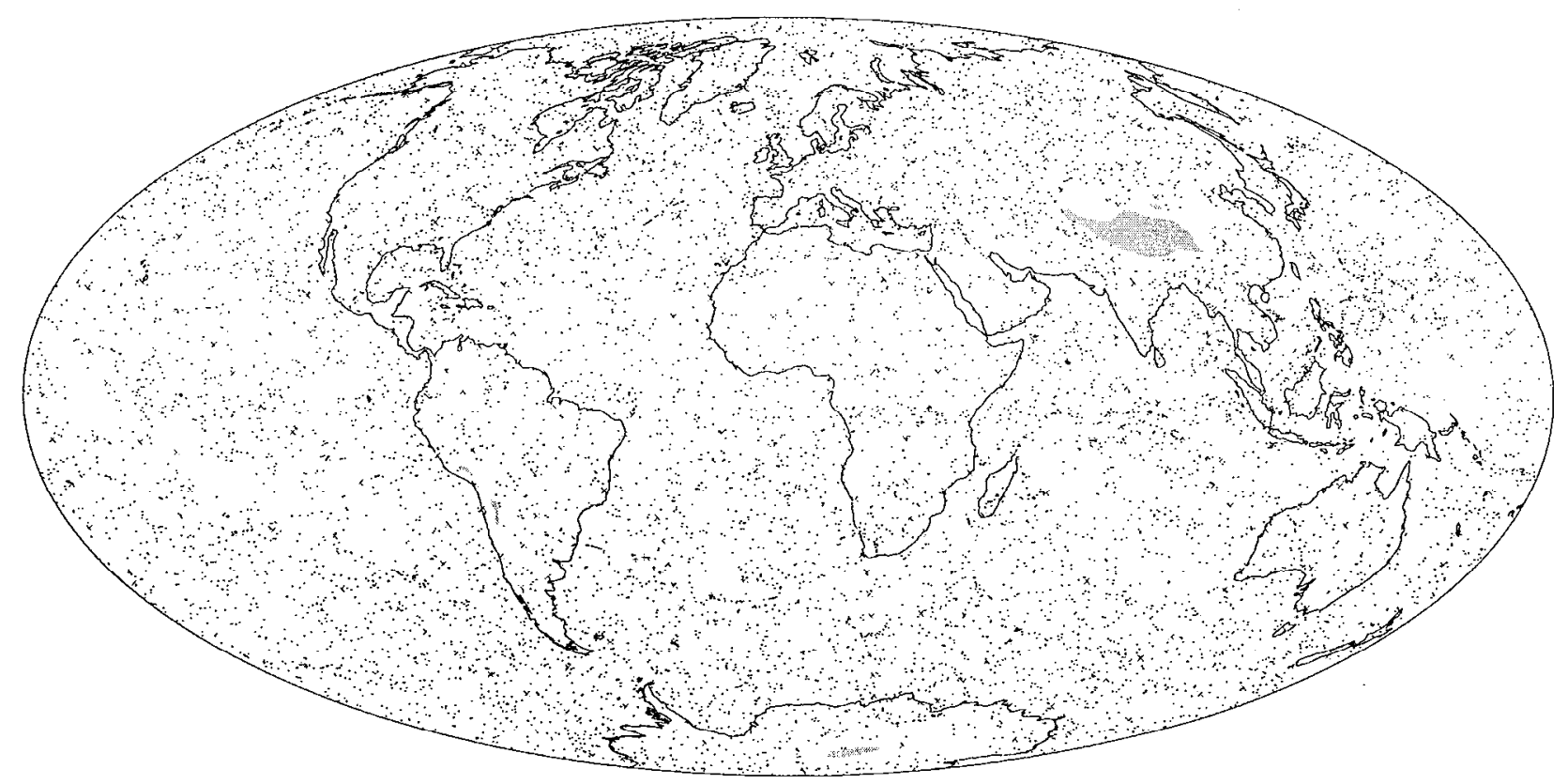

Figure 69. Location of balloons set for $600 \mathrm{mb}$ after 35 days of daily releases from 298 launch sites indicated by $x$. Terrain above $600 \mathrm{mb}$ is shaded in gray. 10430 balloons released, 10146 still aloft, 284 hit terrain.

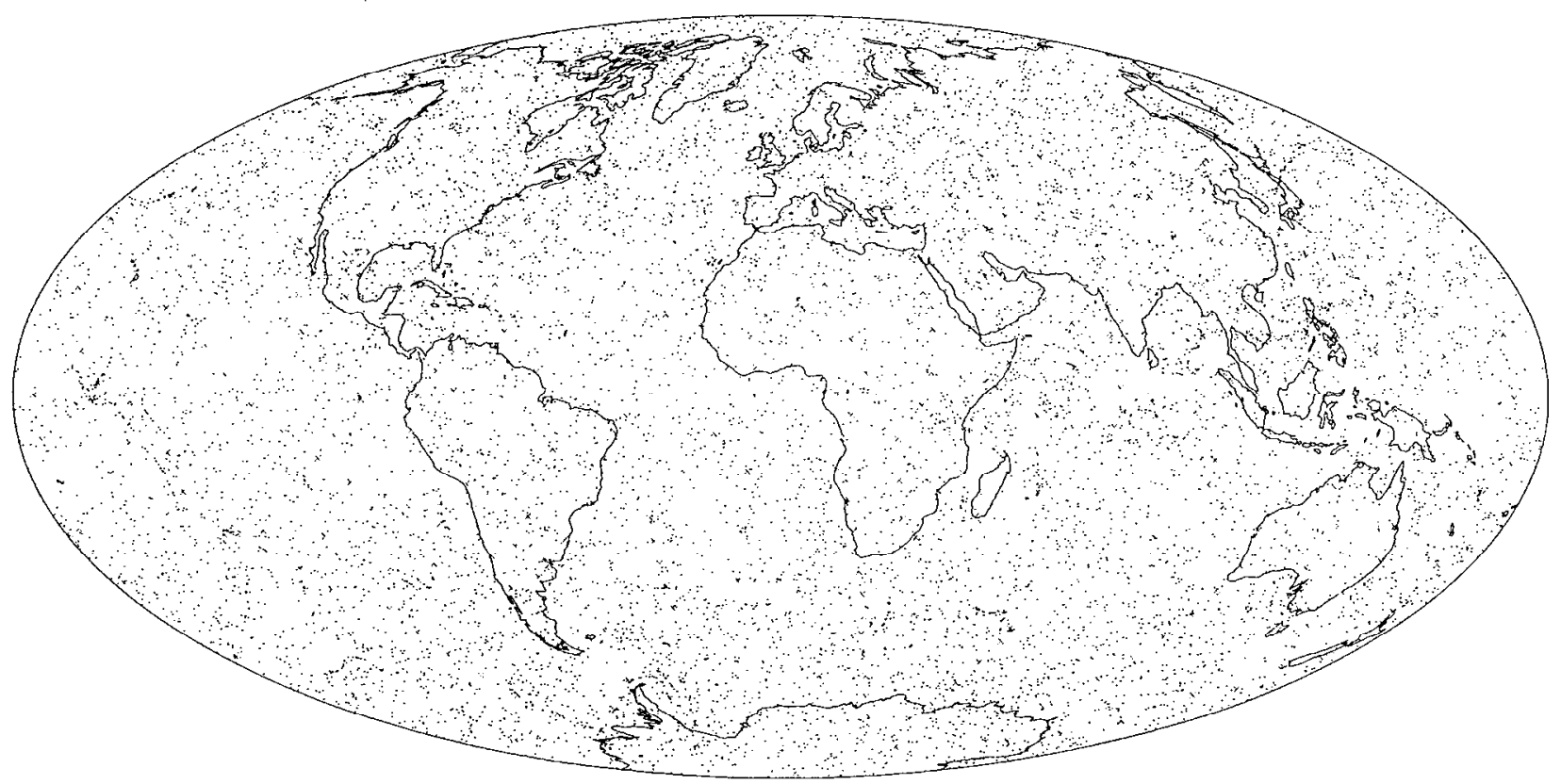

Figure 70. Location of balloons set for $500 \mathrm{mb}$ after 35 days of daily releases from 298 launch sites indicated by $\times .10430$ balloons released and still aloft. 


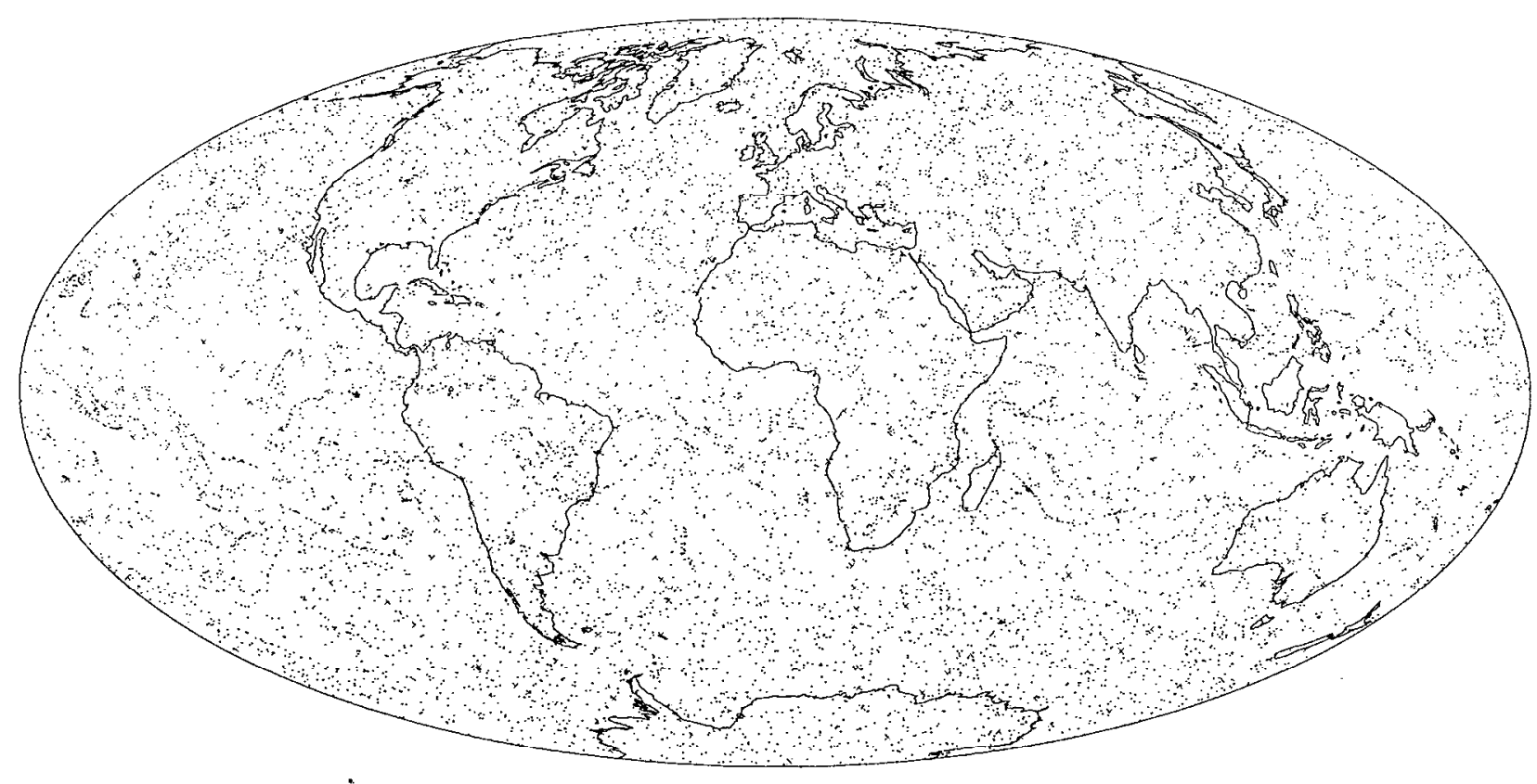

Figure 71. Location of balloons set for $400 \mathrm{mb}$ after 35 days of daily releases from 298 launch sites indicated by $\times .10430$ balloons released and still aloft.

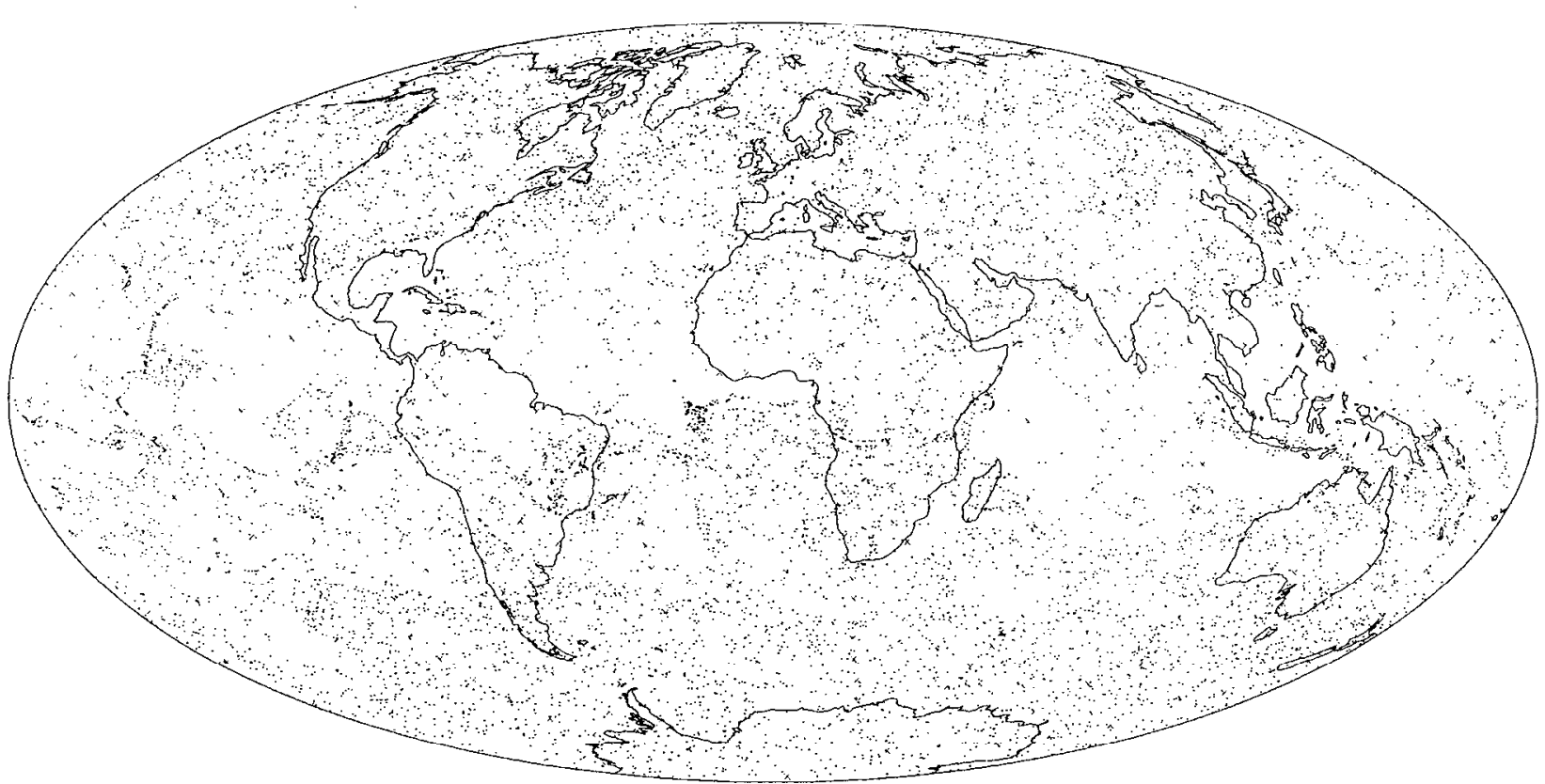

Figure 72. Location of balloons set for $300 \mathrm{mb}$ after 35 days of daily releases from 298 launch sites indicated by $\times .10430$ balloons released and still aloft. 


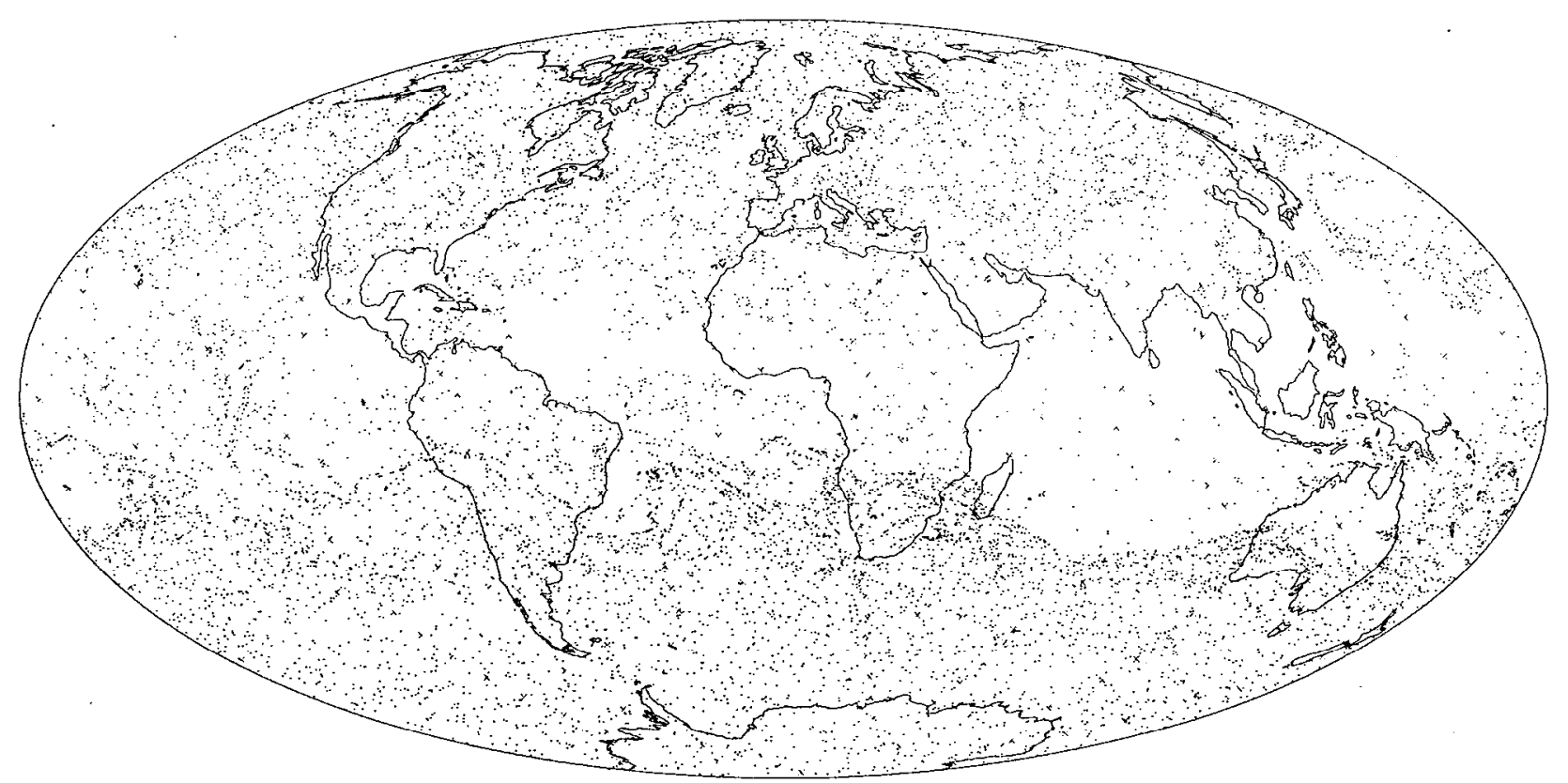

Figure 73. Location of balloons set for $200 \mathrm{mb}$ after 35 days of daily releases from 298 launch sites indicated by $\times .10430$ balloons released and still aloft.

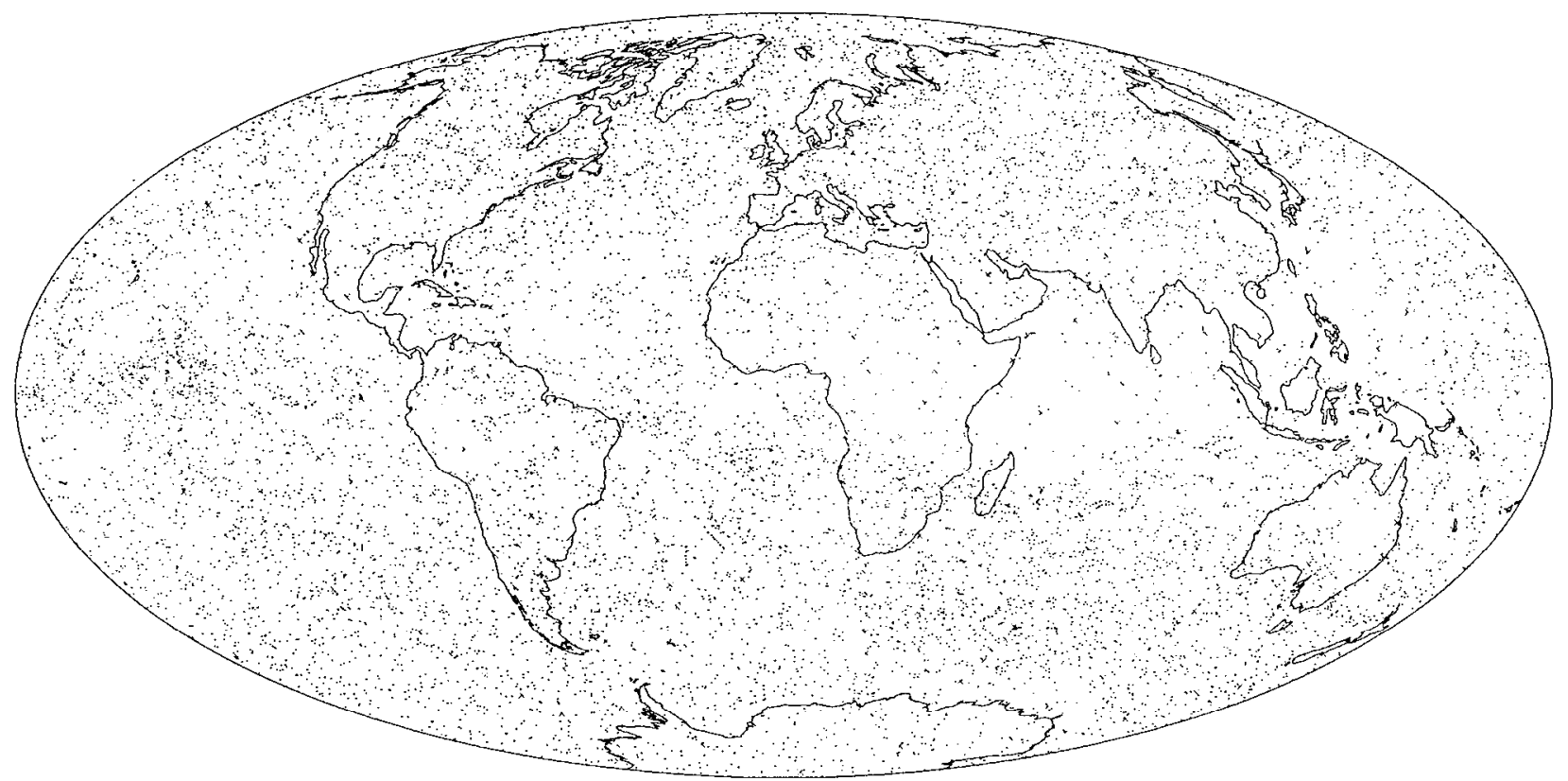

Figure 74. Location of balloons set for $100 \mathrm{mb}$ after 35 days of daily releases from 298 launch sites indicated by $\times .10430$ balloons released and still aloft. 


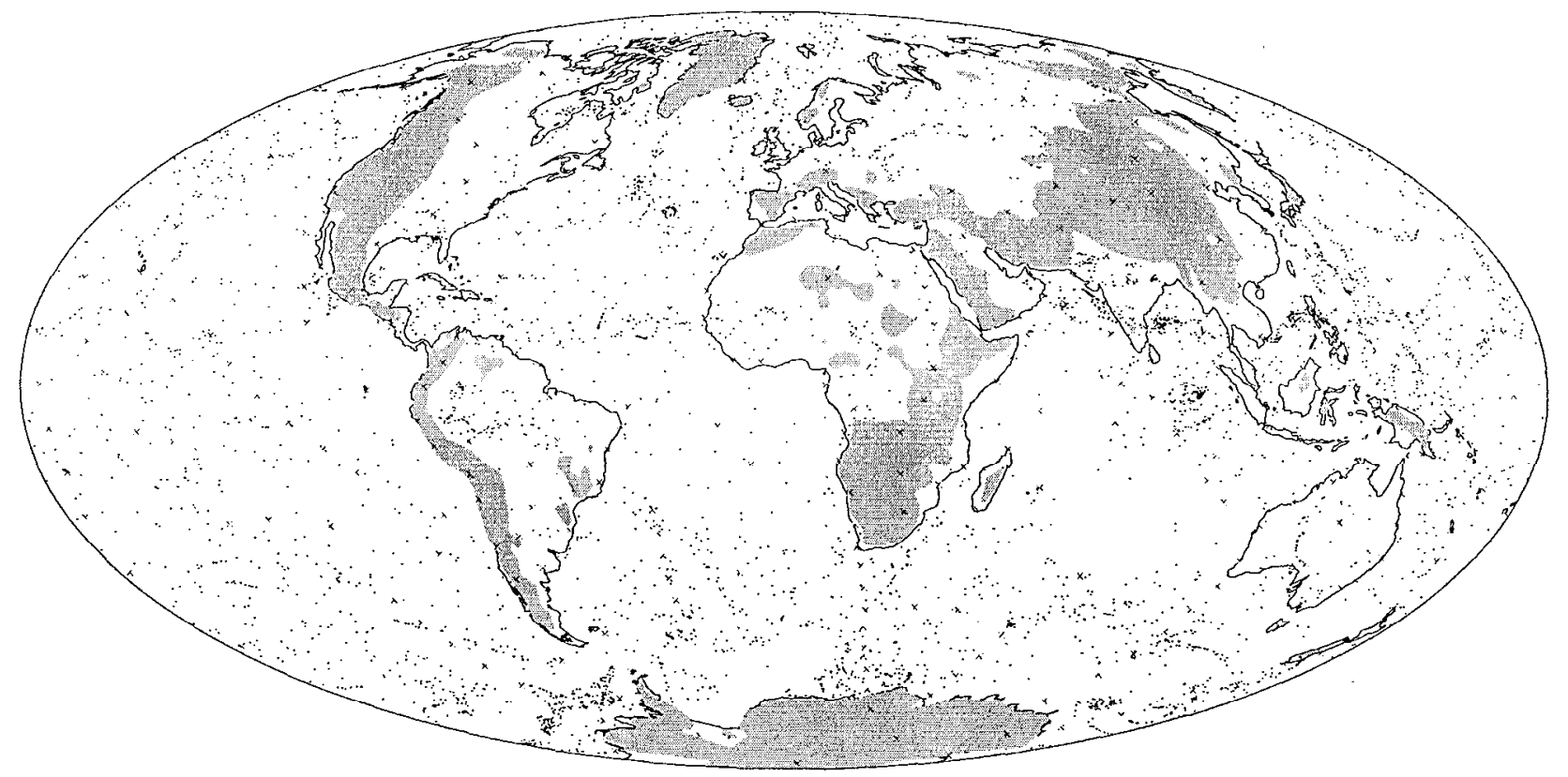

Figure 75. Location of balloons set for $925 \mathrm{mb}$ after 47 days of daily releases from 298 launch sites indicated by $\times$. Terrain above $925 \mathrm{mb}$ is shaded in gray. 12549 balloons released, 5677 still aloft, and 6872 hit terrain.

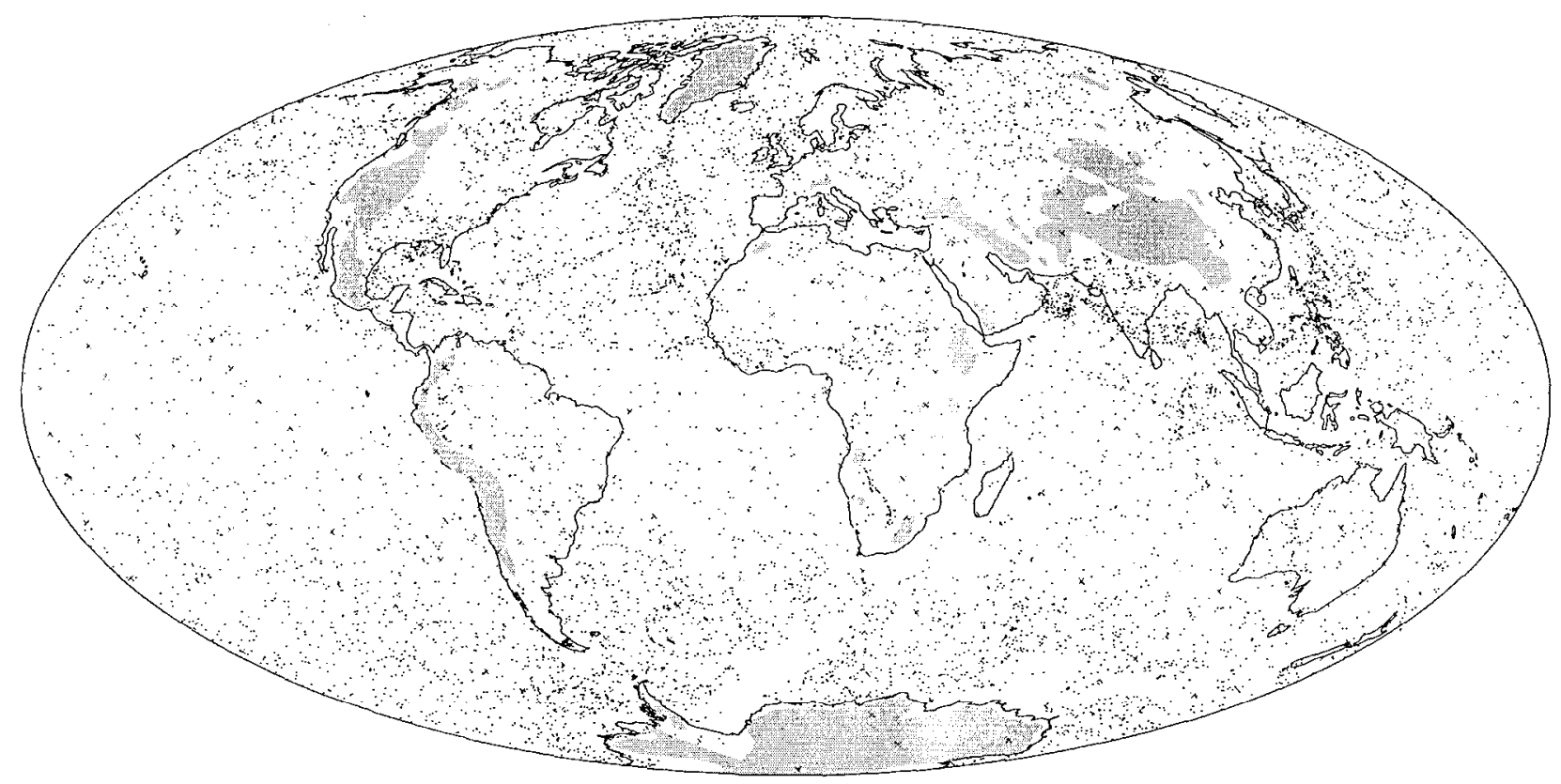

Figure 76. Location of balloons set for $850 \mathrm{mb}$ after 47 days of daily releases from 298 launch sites indicated by $\times$. Terrain above $850 \mathrm{mb}$ is shaded in gray. 13254 balloons released, 9391 still aloft, 3863 hit terrain. 


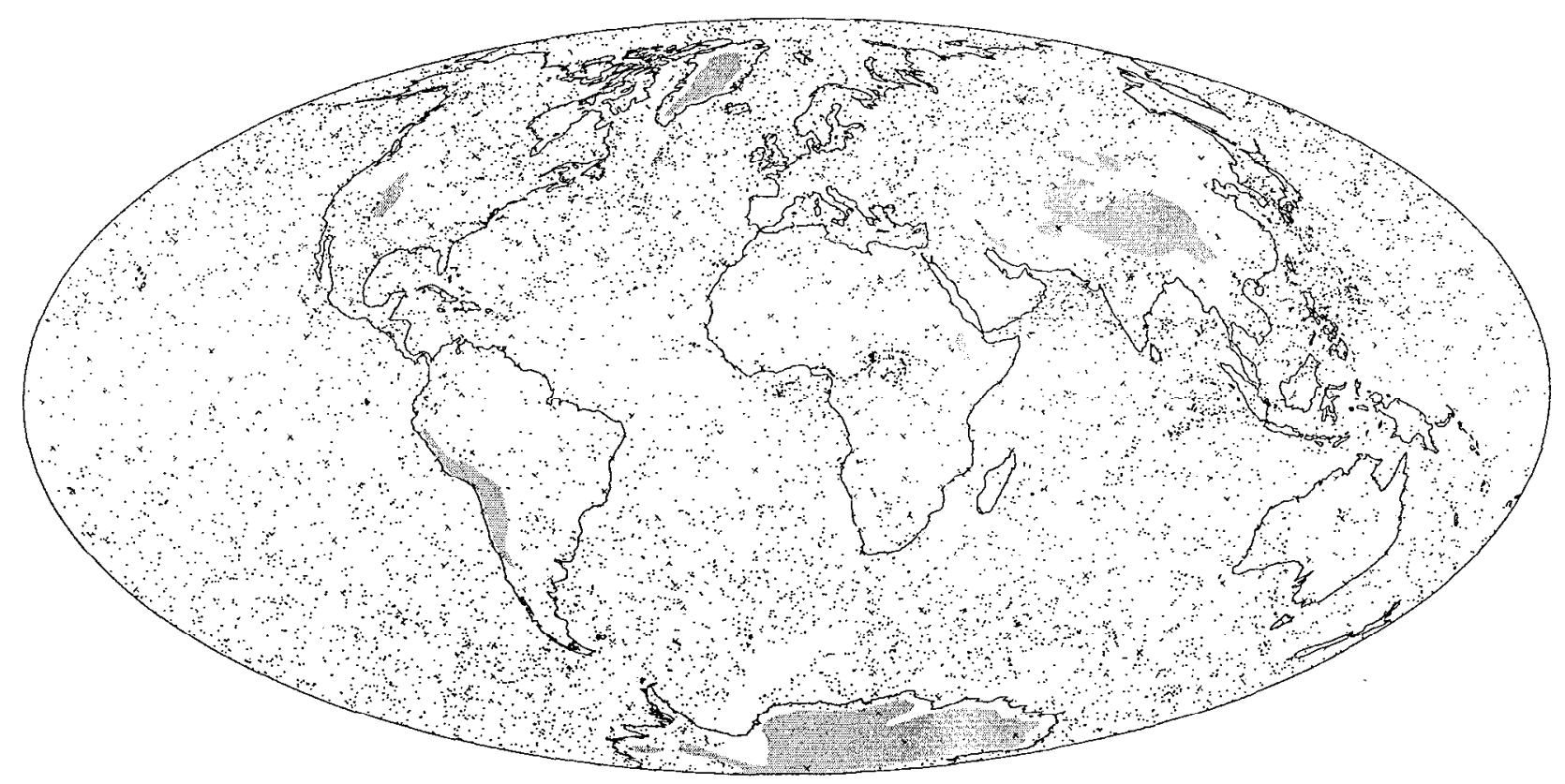

Figure 77. Location of balloons set for $775 \mathrm{mb}$ after 47 days of daily releases from 298 launch sites indicated by $\times$. Terrain above $775 \mathrm{mb}$ is shaded in gray. 13630 balloons released, 11560 still aloft, 2070 hit terrain.

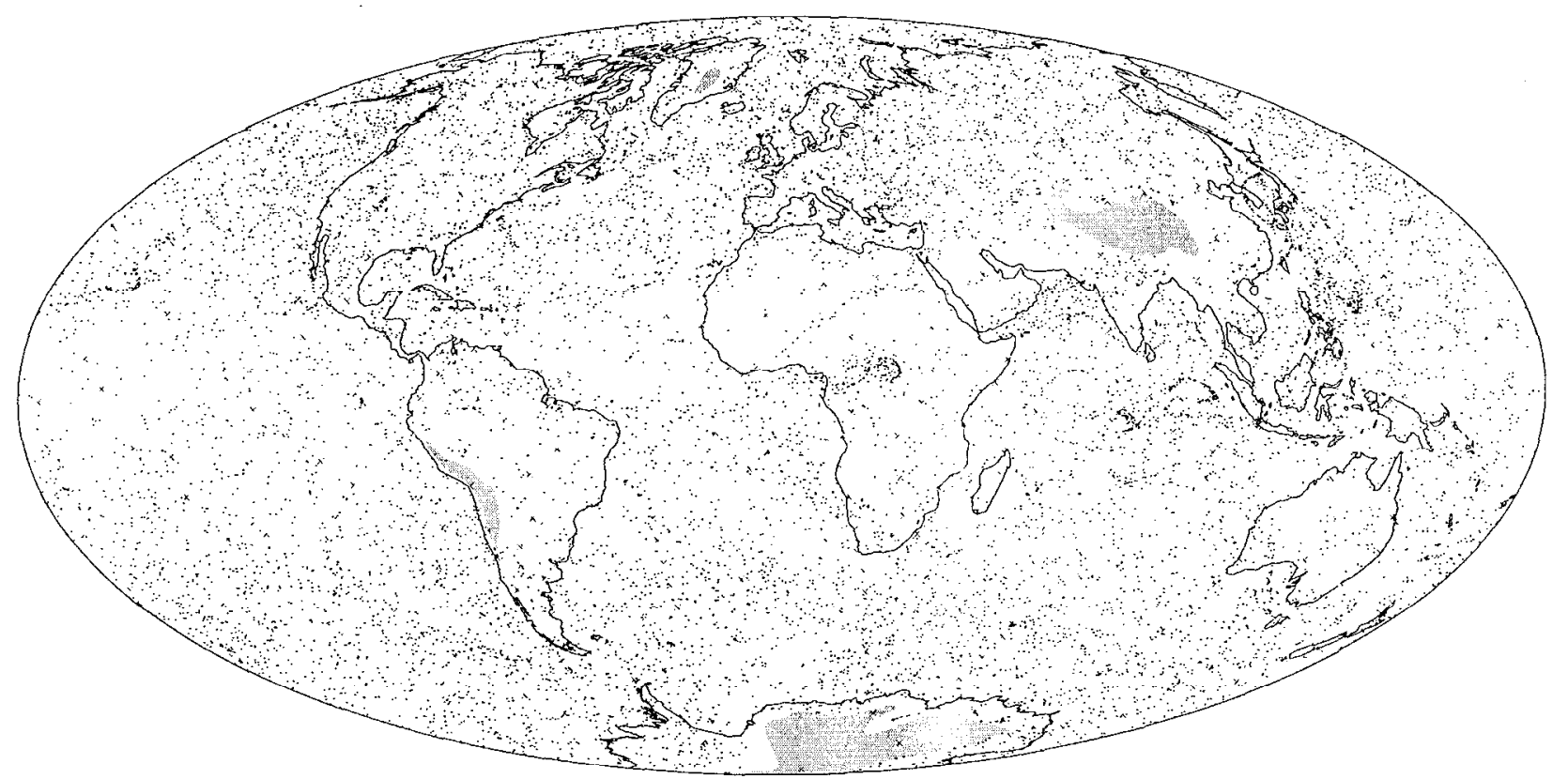

Figure 78. Location of balloons set for $700 \mathrm{mb}$ after 47 days of daily releases from 298 launch sites indicated by $\times$. Terrain above $700 \mathrm{mb}$ is shaded in gray. 13865 balloons released, 12655 still aloft, 1210 hit terrain. 


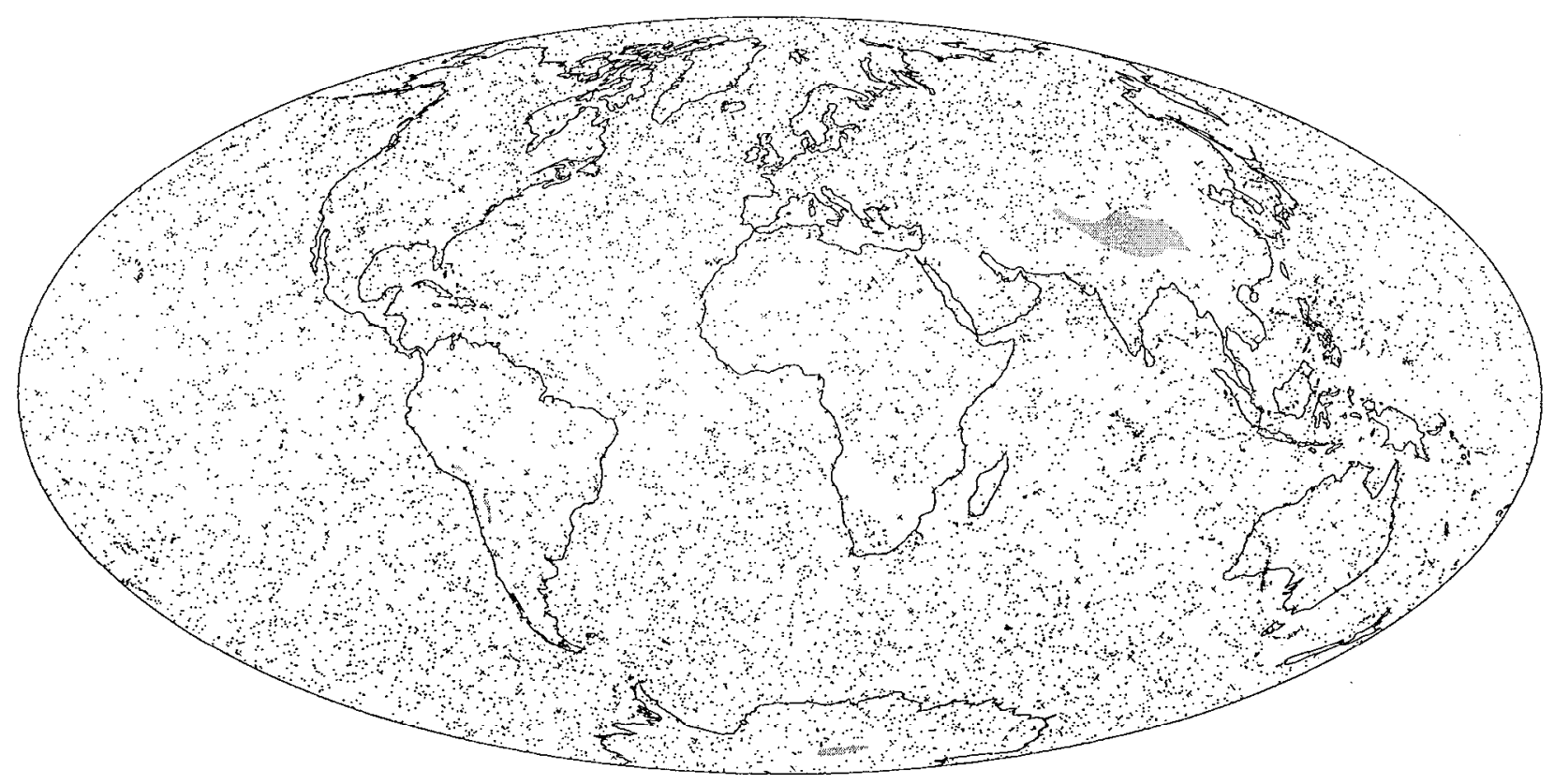

Figure 79. Location of balloons set for $600 \mathrm{mb}$ after 47 days of daily releases from 298 launch sites indicated by $\times$. Terrain above $600 \mathrm{mb}$ is shaded in gray. 14006 balloons released, 13511 still aloft, 495 hit terrain.

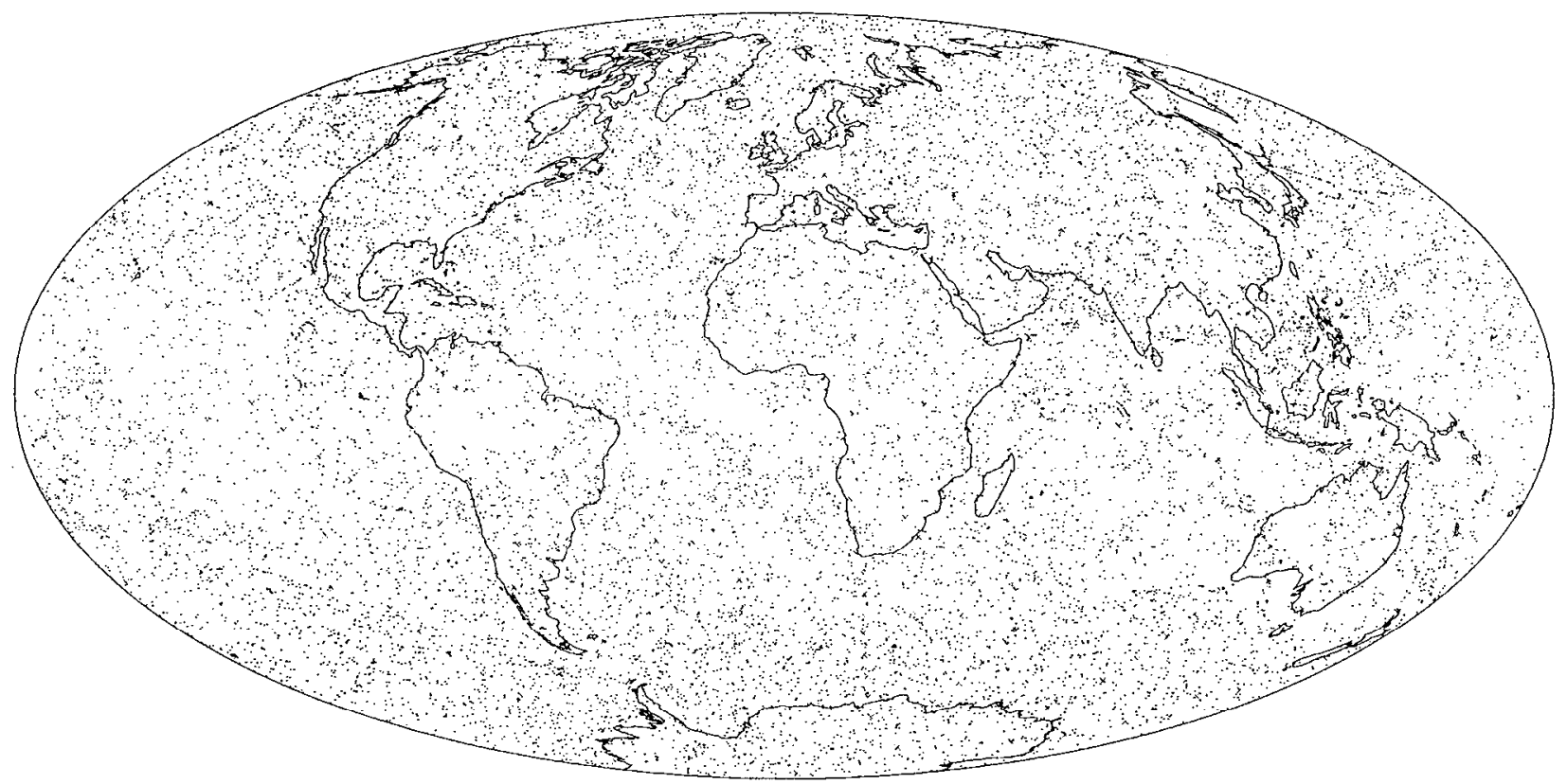

Figure 80. Location of balloons set for $500 \mathrm{mb}$ after 47 days of daily releases from 298 launch sites indicated by $\times .14006$ balloons released and still aloft. 


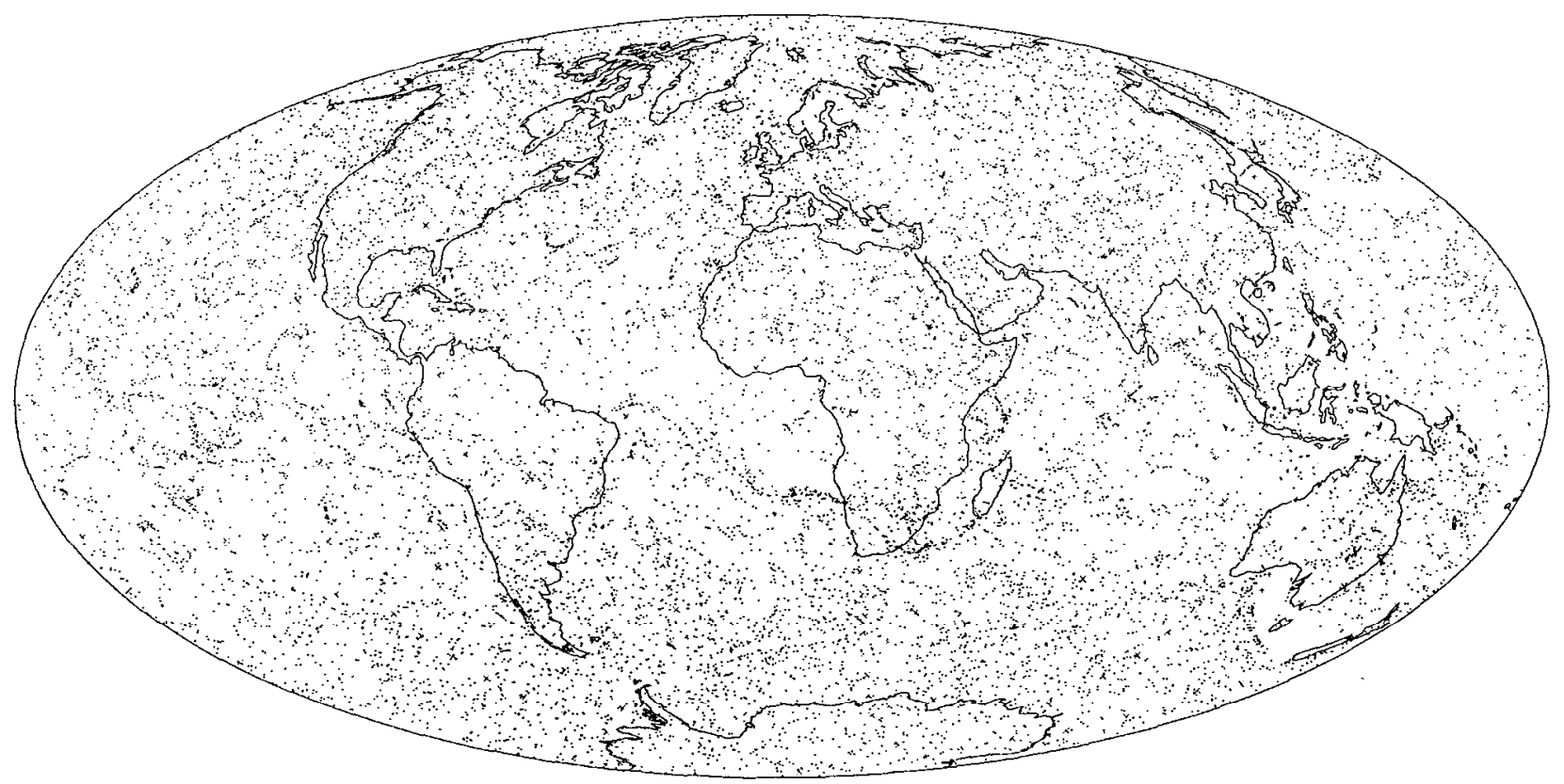

Figure 81. Location of balloons set for $400 \mathrm{mb}$ after 47 days of daily releases from 298 launch sites indicated by $\times .14006$ balloons released and still aloft.

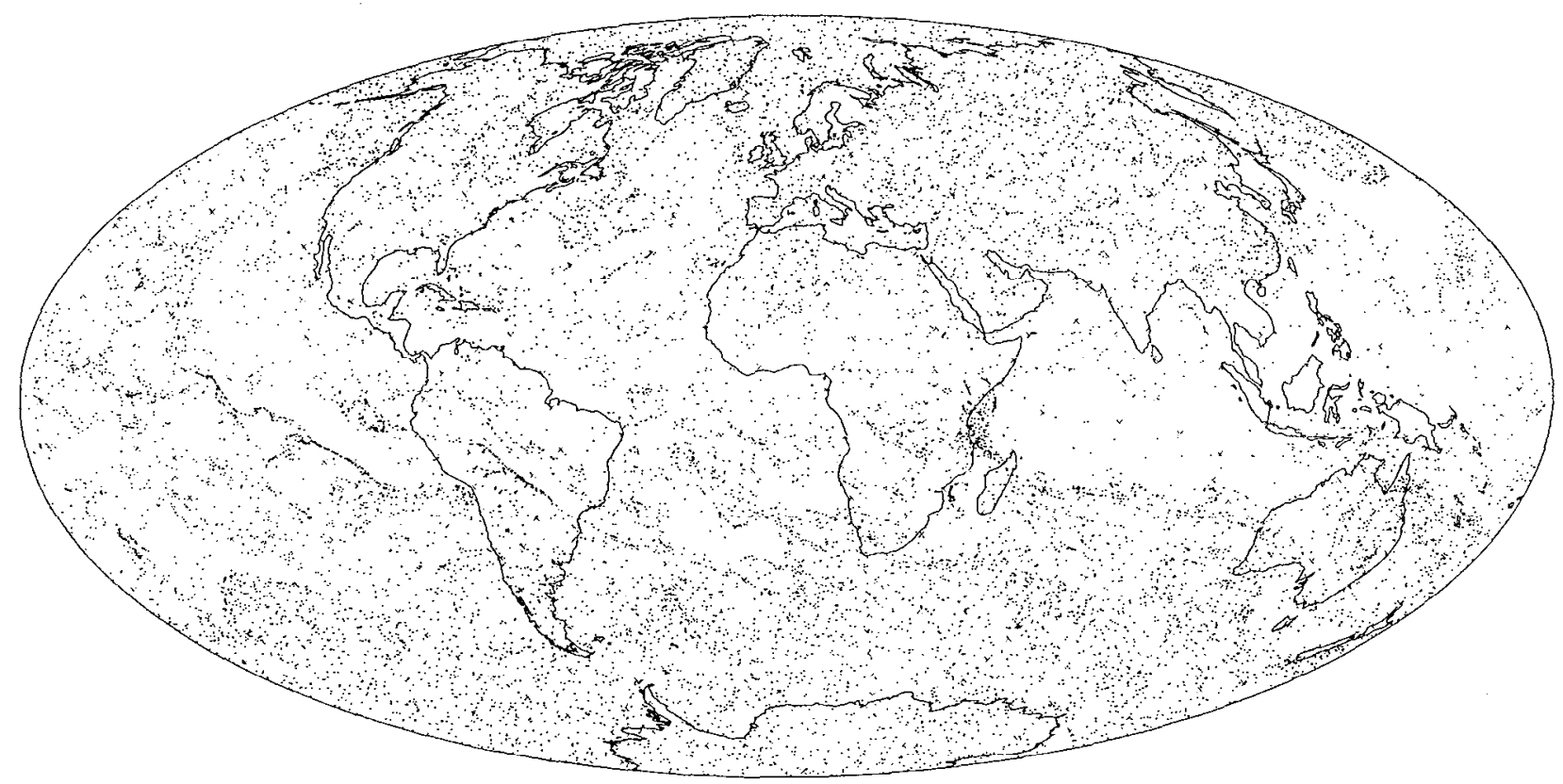

Figure 82. Location of balloons set for $300 \mathrm{mb}$ after 47 days of daily releases from 298 launch sites indicated by $\times .14006$ balloons released and still aloft. 


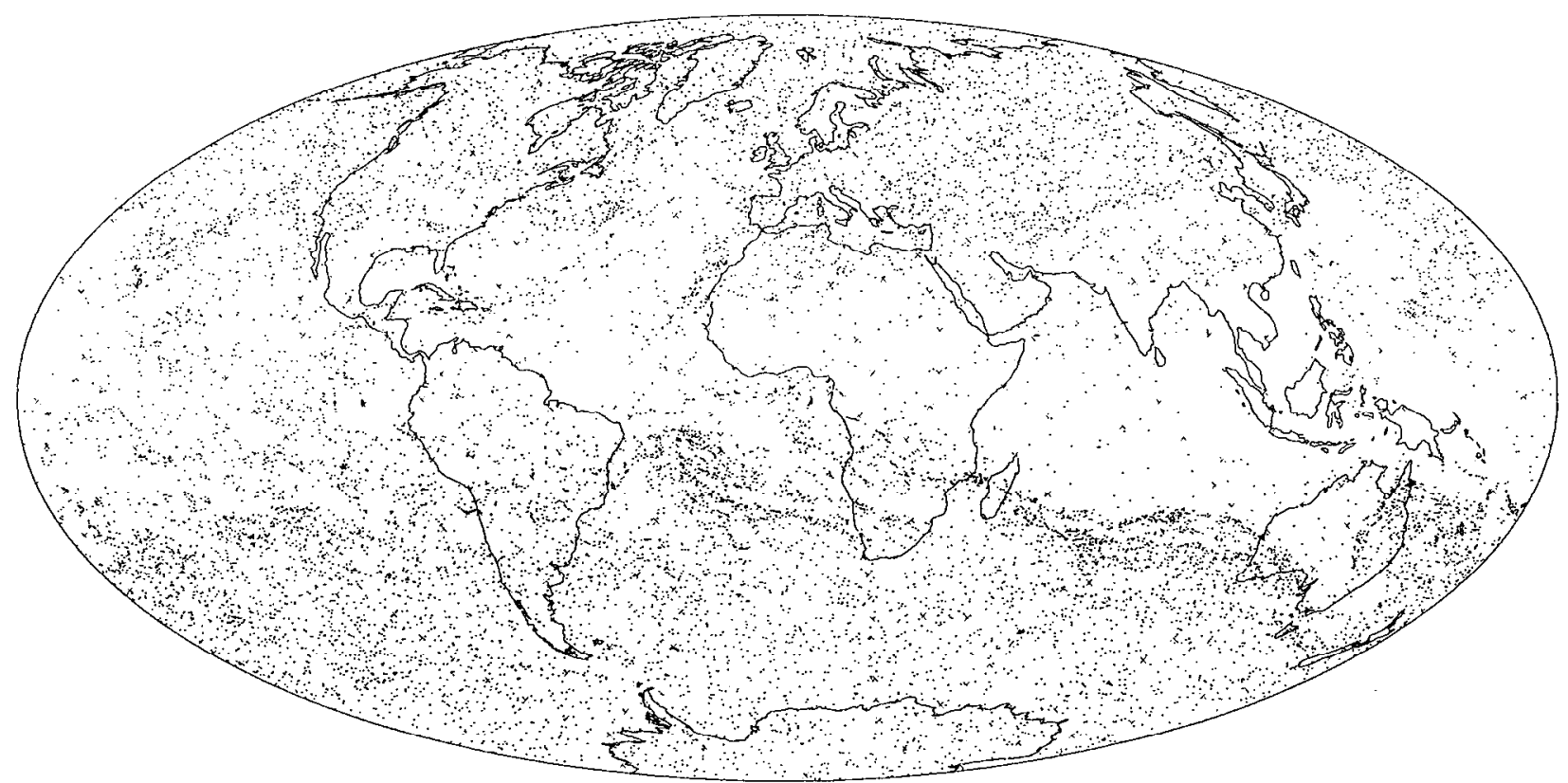

Figure 83. Location of balloons set for $200 \mathrm{mb}$ after 47 days of daily releases from 298 launch sites indicated by $\times .14006$ balloons released and still aloft.

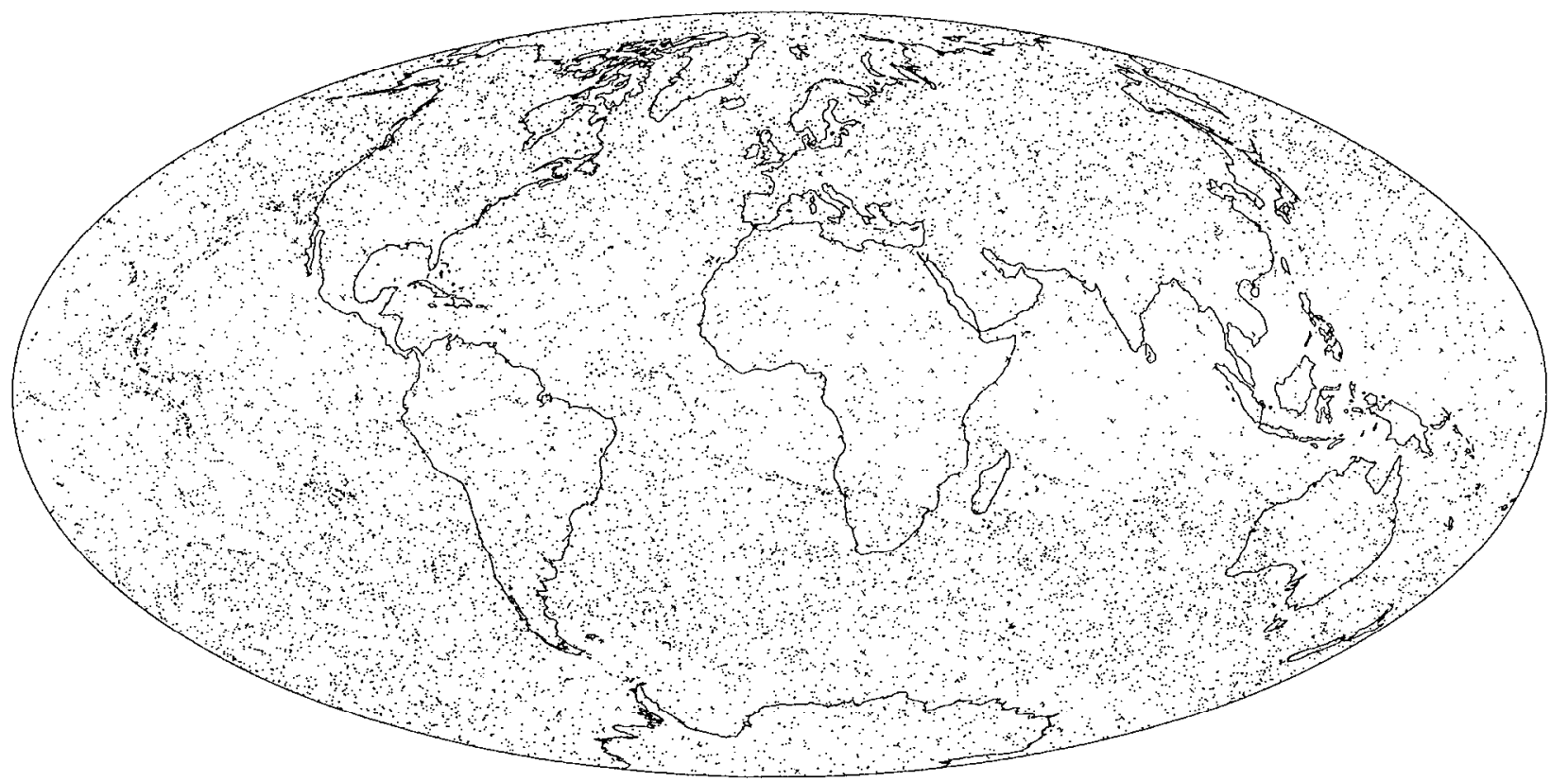

Figure 84. Location of balloons set for $100 \mathrm{mb}$ after 47 days of daily releases from 298 launch sites indicated by $\times .14006$ balloons released and still aloft. 


\section{Vertical Sounding Coverage}

For the daily release scenario, the feasibility of providing vertical profiles of wind and temperature to current NWP's can again be addressed by considering the number of vertical layers in columns with the NWP's horizontal resolution that contain at least one balloon. This information is plotted in Figures 85-86 for the CCM3/GRANTOUR simulation after 35 days and in Figures 87-90 for the NOGAPS/GRANTOUR simulations after 35 and 47 days.

Comparison of these plots for the daily release scenario to the corresponding Figures 49-54 for the initially uniform distribution revels a significant improvement. The fraction of the globe in warmer colors (red, orange, and yellow), where there is adequate coverage, is larger and the fraction in cooler colors (blue, purple, and black), where the data is too sparse to define a vertical sounding, is much smaller for the daily release scenario. Much of this improvement is due to a larger number of active transponders. However, comparison of Figures 85 with 87 and 86 with 88 shows that the NOGAPS/GRANTOUR simulation after 35 days gives better sounding coverage than the CCM3/GRANTOUR simulation even though CCM3/GRANTOUR has more active transponders.

For the NOGAPS/GRANTOUR simulation after 47 days and the horizontal sounding resolution grid with 64 latitude bands (Figure 90), many columns in the mid-latitudes have at least one transponder in each of the ten levels. Few columns have more than three levels with no transponders. Many of these are in regions of high mountains (Antarctica, Himalayas); the rest are in the tropics.

In summary, the daily release simulations produce global balloon distributions adequate to provide wind and temperature data for NWP's. The simulations with 298 release sites indicate that sufficient levels have at least one transponder to construct vertical temperature and wind profiles over the entire globe except the tropics. The shortage of transponders in the tropics is noted at all levels in both the uniform initial and daily release scenarios, but is worst near the tropopause and at the lowest levels. It needs to be addressed, probably by releasing more balloons in this region.

\section{CONCLUSIONS}

The feasibility of providing adequate wind and temperature data for initialization, data assimilation, and validation of NWP's has been demonstrated by transport simulations of an array of small balloon-bourne transponders. Horizontal distributions over the globe are very good in midlatitudes and polar regions and in the mid-troposphere. Problem areas are the tropical tropopause, where balloons leave very rapidly and gather in bands at the edge of the Hadley circulation, and low tropical elevations, where balloon distributions become non-uniform due to well-known convergence/divergence patterns. In addition, loss of balloons via surface collisions leads to sparseness at low elevations. The low elevation problems are readily addressed by 


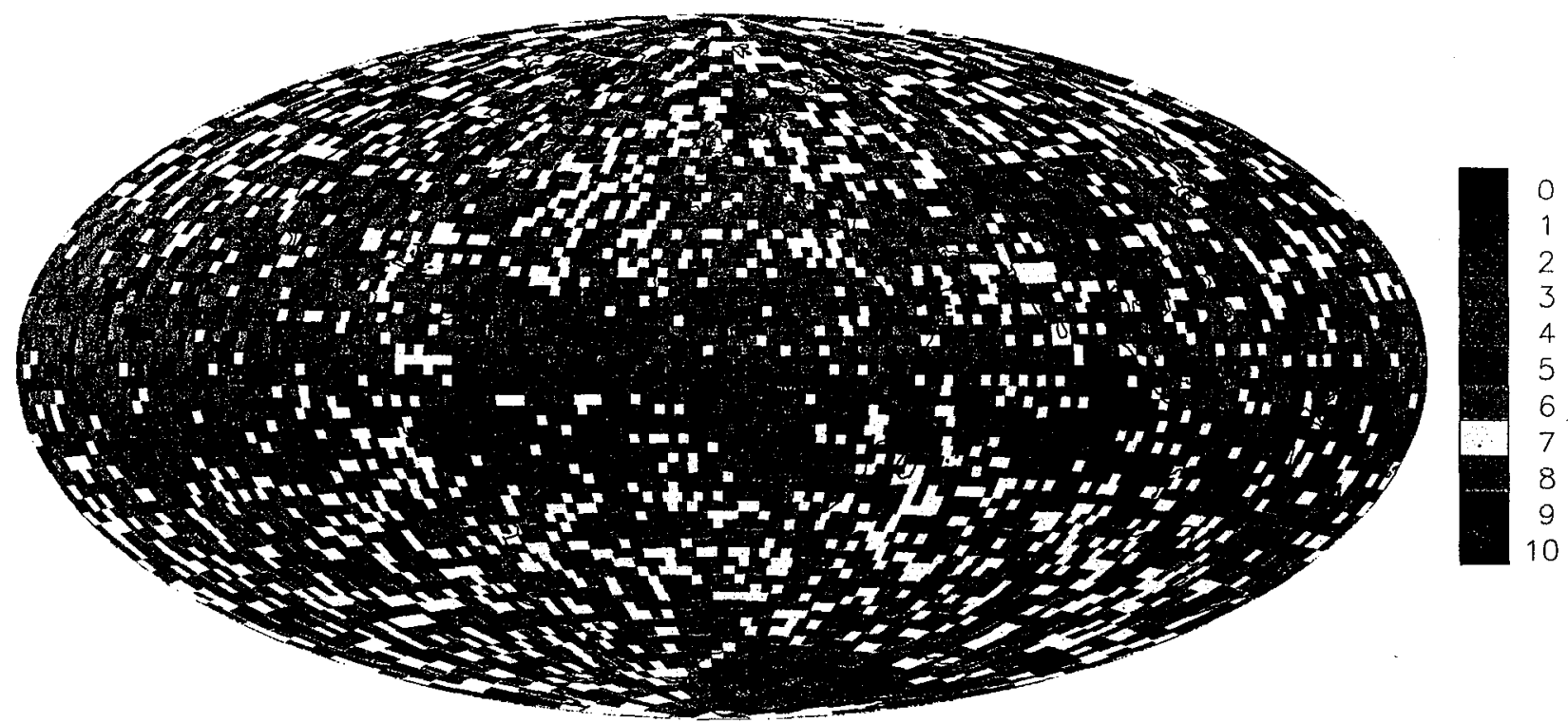

Figure 85. Number of vertical layers per horizontal column with at least 1 balloon for day 35 of the CCM3 wind data simulation for daily release from 298 sites. There are 80 equal area latitude bands and 8150 equal area columns of about $62,500 \mathrm{~km}^{2}$ or $250 \mathrm{~km}$ on a side.

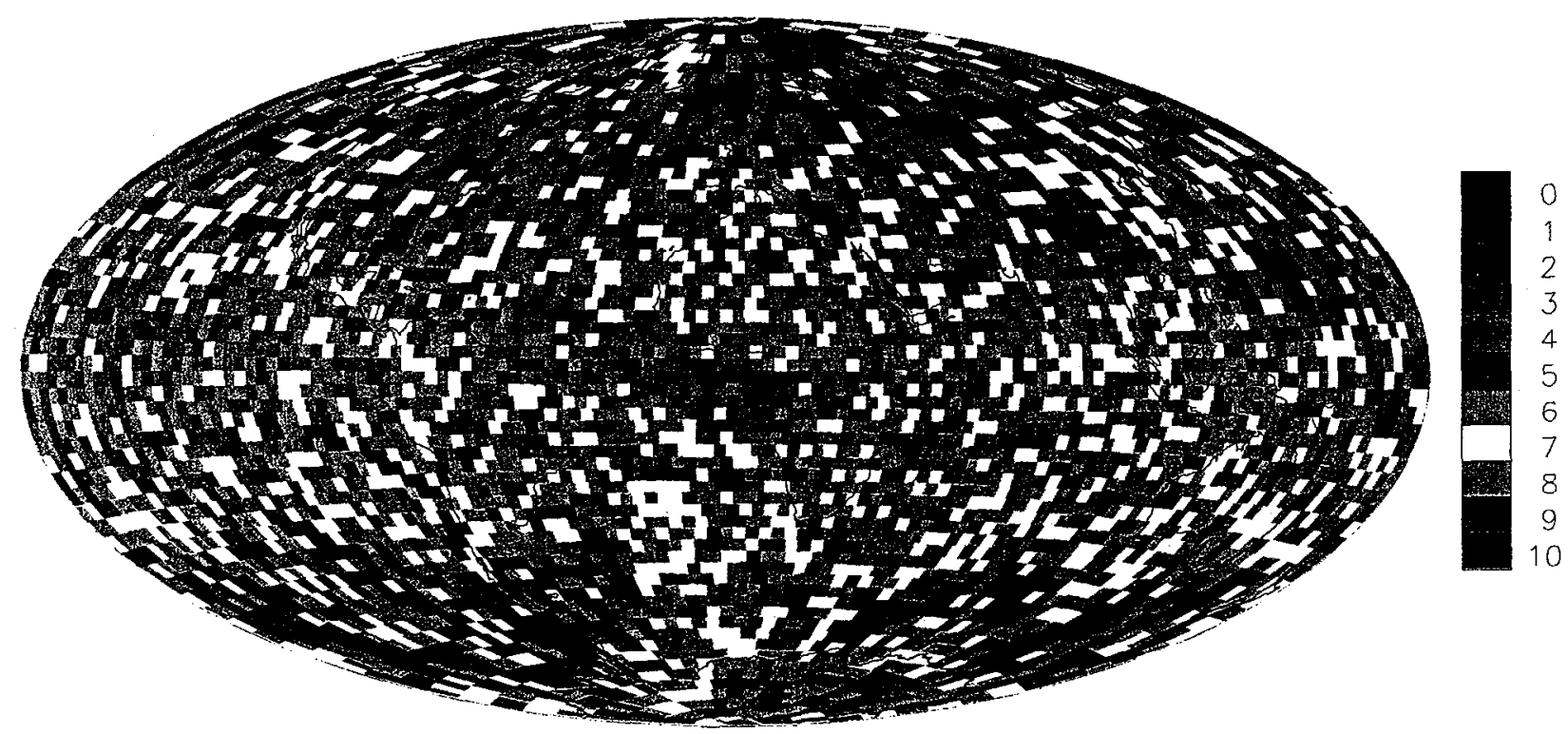

Figure 86. Number of vertical layers per horizontal column with at least 1 balloon for day 35 of the CCM3 wind data simulation for daily release from 298 sites. There are 64 equal area latitude bands and 5218 equal area columns of about $98,000 \mathrm{~km}^{2}$ or $313 \mathrm{~km}$ on a side. 


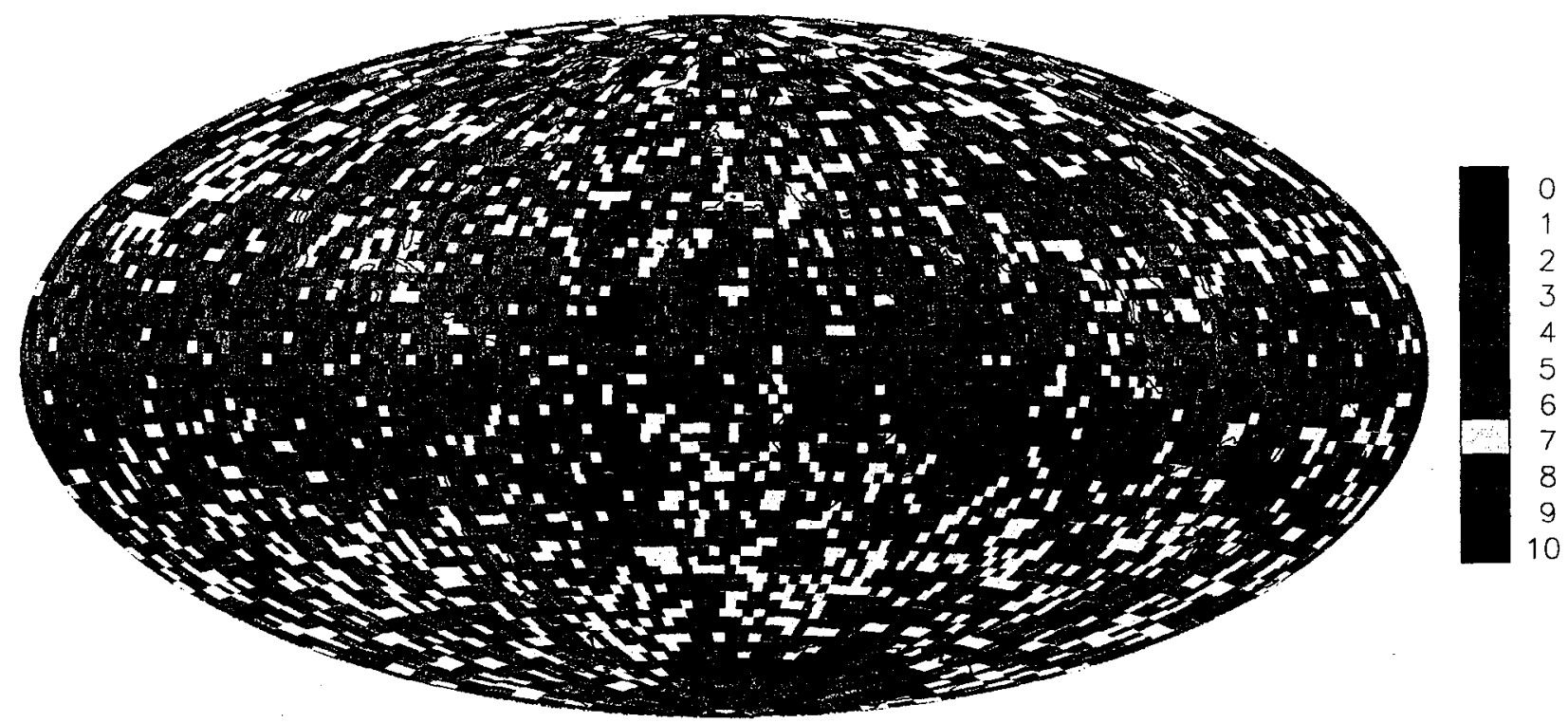

Figure 87. Number of vertical layers per horizontal column with at least 1 balloon for day 35 of the NOGAPS wind data simulation with daily releases from 298 sites. There are 80 equal area latitude bands and 8150 equal area columns of about $62,500 \mathrm{~km}^{2}$ or $250 \mathrm{~km}$ on a side.

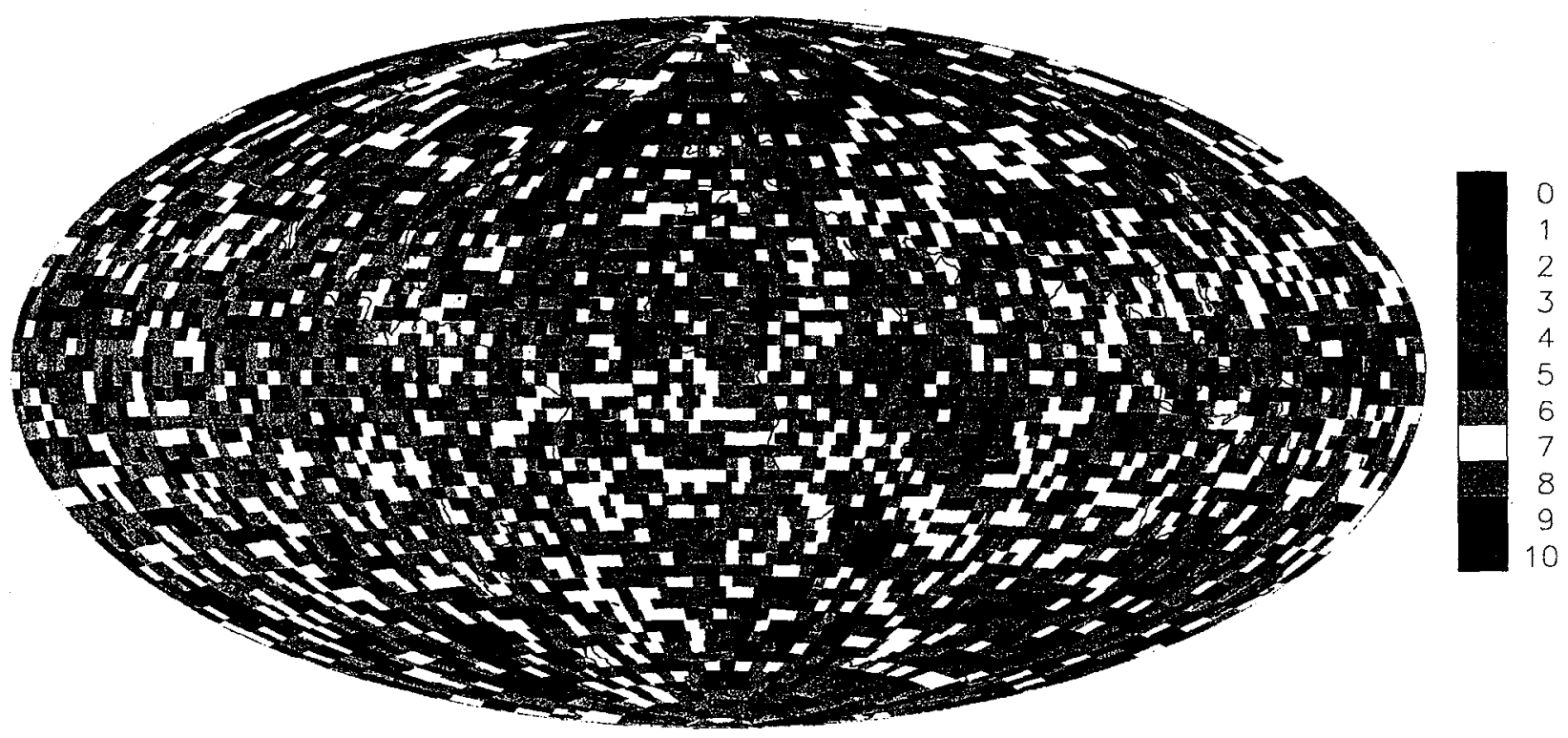

Figure 88. Number of vertical layers per horizontal column with at least 1 halloon for day 35 of the NOGAPS wind data simulation with daily releases from 298 sites. There are 64 equal area latitude bands and 5218 equal area columns of about $98,000 \mathrm{~km}^{2}$ or $313 \mathrm{~km}$ on a side. 


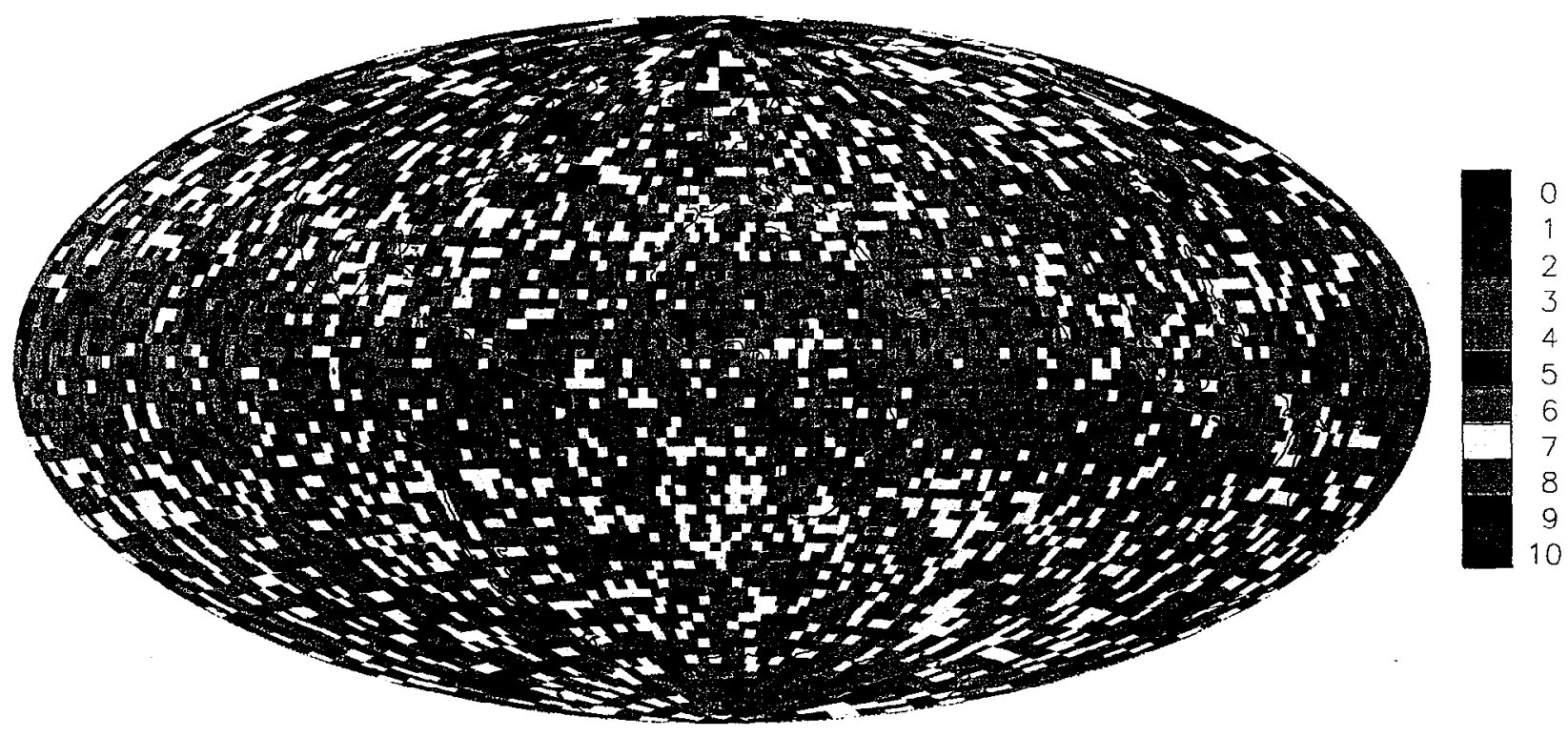

Figure 89. Number of vertical layers per horizontal column with at least 1 balloon for day 47 of the NOGAPS wind data simulation with daily releases from 298 sites. There are 80 equal area latitude bands and 8150 equal area columns of about $62,500 \mathrm{~km}^{2}$ or $250 \mathrm{~km}$ on a side.

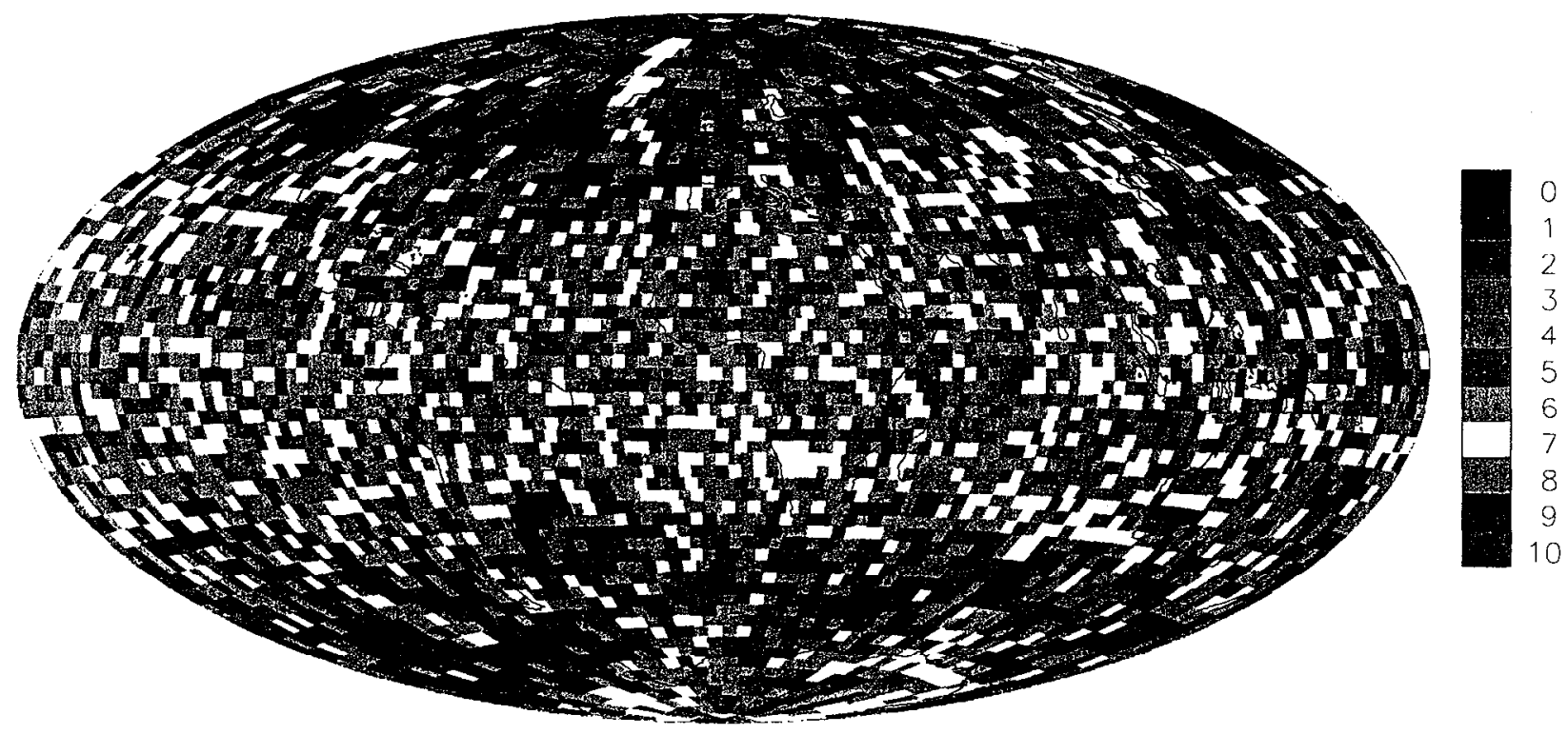

Figure 90. Number of vertical layers per horizontal column with at least 1 balloon for day 47 of the NOGAPS wind data simulation with daily releases from 298 sites. There are 64 equal area latitude bands and 5218 equal area columns of about $98,000 \mathrm{~km}^{2}$ or $313 \mathrm{~km}$ on a side. 
launching additional balloons, but the rapid divergence of balloons from the tropical tropopause is not easily neutralized.

While the initial results reported herein are promising, several additional effects need to be studied further. These include simulation of a full annual cycle to remove seasonal bias, optimization of the sequential launch scenario, more realistic representation of balloon vertical motion including changes in balloon density by heating/cooling and water loading, higher density of release sites, addition of vertical floating-pressure or neutral buoyancy levels, incorporation of diffusion in the horizontal velocity, and inclusion of more balloon loss processes.

The only balloon loss mechanism included in this study is terrain collision, but balloons also fail for other reasons including defects in manufacture, skin deterioration, and crashes with airplanes and birds. Also, a balloon's buoyancy changes with time as air and helium (or other lighter-than-air gas) diffuse through its skin; therefore, the assumption that a balloon maintains its floating-level pressure for a long time is unrealistic. In addition, a balloon's surface absorbs and emits thermal radiation, so its temperature will change. At night, water vapor will very likely condense on balloons, greatly reducing their lift and perhaps causing them to hit the ground. Finally, as balloons move through clouds, they accrete liquid water and/or ice, and that reduces or destroys their buoyancy. Such balloons could easily be dragged to the ground, especially where water loading and downdrafts are correlated. 


\section{REFERENCES}

Atherton, C. A., S. Grotch, D. D. Parrish, J. E. Penner, and J. J. Walton, 1996, The role of anthropogenic emissions of $\mathrm{NO}_{\mathrm{x}}$ on tropospheric ozone over the North Atlantic Ocean: A three dimensional, global model study, Atmos. Environ., 30, 1739-1750.

Atherton, C. S., J. E. Penner, C. Price, and J. J. Walton, 1995, Climate change and its effect on tropospheric ozone, in Global Environmental Change: Proceedings of the NATO Workshop on Atmospheric Ozone as a Climate Gas, (W.-C. Wang, ed.), Springer-Verlag, 65-85.

Chuang, C. C., J. E. Penner, K. E. Taylor, and J. J. Walton, 1994, Climate effects of anthropogenic sulfate: Simulations from a coupled chemistry/climate model, Proceedings of Conference on Atmospheric Chemistry, January 23-28, 1994, Nashville, Tennessee, 170-174.

Grossman, A. S. and C. R. Molenkamp, 1999a: Atmospheric test models and numerical experiments for the simulation of the global distributions of weather data transponders. LLNL Report UCRL-ID-135526.

Grossman, A. S. and C. R. Molenkamp, 1999b: Atmospheric test models and numerical experiments for the simulation of the global distributions of weather data transponders, II. Vertical Transponder Motions Considerations. LLNL Report UCRL-ID-135526 Pt. 2.

Hogan, T. F. and T. E. Rosmond, 1991: The description of the U. S. Navy operational global atmospheric prediction system's spectral forecast model. Mon. Wea. Rev., 119, 17861815 .

Kiehl, J. T., J. J. Hack, G. B. Bonan, B. Y. Boville, B. P. Briegleg, D. L. Williamson, and P. J. Rasch, 1996: Description of the NCAR Community Climate Model (CCM3). NCAR Tech Note. NCAR/TN-420+STR.

Penner, J. E., C. S. Atherton, J. Dignon, S. J. Ghan, J. J. Walton and S. Hameed, 1991, Tropospheric nitrogen: A three-dimensional study of sources, distribution, and deposition, J. Geophys. Res. 96, 959-990.

Penner, J. E., C. S. Atherton, and T. Graedel, 1994, Global emissions and models of photochemically active compounds, in Global Atmospheric-Biospheric Chemistry: The First IGAC Scientific Conference, R.G. Prinn, ed., OIIOLO Conference Series Books, Plenum Publishing, N.Y., p. 223-247. 
Rau, G. H., J. E. Penner, H. E. Eddleman, J. K. Hobson, and J. J. Walton, 1994, A model of dust/micronutrient delivery to the ocean. Transactions, American Geophy. Union 75(44): 377

Taylor, K. E., and J. E. Penner, 1994, Response of the climate system to atmospheric aerosols and greenhouse gases, Nature, 369, 734-737.

Teller, E., L. Wood, R. Hyde, M. Ishikawa, A. Ledebuhr, C. Leith, J. Nuckolls and G. Canavan, 1998: Long range weather predictions enabled by probing of the atmosphere at high space time resolution. LLNL Report UCRL-JC-131601.

Walton, J. J., M. C. MacCracken and S. J. Ghan, 1988: A global-scale Lagrangian trace species model of transport, transformation, and removal process. J. Geophys. Res., 93, 83398354. 